\title{
Coupled IMPACT aerosol and NCAR CAM3 model: Evaluation of predicted aerosol number and size distribution
}

\author{
Minghuai Wang, ${ }^{1}$ Joyce E. Penner, ${ }^{1}$ and Xiaohong Liu ${ }^{2}$ \\ Received 20 May 2008; revised 4 September 2008; accepted 9 January 2009; published 21 March 2009.
}

[1] Simulated aerosol fields from a coupled aerosol/atmospheric circulation model that includes prediction of both sulfate aerosol size and number are evaluated. Sensitivity tests are used to evaluate uncertainties due to the inclusion of primary emitted particulate sulfate as a means of representing nucleation of particles in subgrid-scale plumes, the use of two boundary layer aerosol nucleation mechanisms, and a three-mode sulfate aerosol representation. Simulated annual and global aerosol budgets are comparable to other model studies with the exception of carbonaceous aerosols and fine mode dust, where smaller mass concentrations are simulated. The model underestimates the accumulation mode aerosol number in the marine boundary layer over middle and low latitudes, which is consistent with an underestimate of fine mode sea salt mass in these locations.

Primary emitted particulate sulfate contributes significantly to aerosol number at sites located in the boundary layer over Europe, but the absence of constraints on the number of such particles from either observations or fine-resolution models makes this treatment undesirable. Boundary layer nucleation mechanisms improve the comparison of simulated aerosol number concentrations with observations in the marine boundary layer, suggesting that a treatment of boundary layer nucleation is needed in global aerosol models, although more studies are needed to quantify how different nucleation mechanisms and condensable gases other than sulfuric acid affect aerosol number. The three-mode representation of sulfate aerosol simulates the observed increase in accumulation mode number concentration with altitude in the upper troposphere and improves the simulated Aitken mode aerosol number concentration there. This indicates the importance of a separate representation of freshly nucleated particles when nucleation is an important source of particle number concentrations.

Citation: Wang, M., J. E. Penner, and X. Liu (2009), Coupled IMPACT aerosol and NCAR CAM3 model: Evaluation of predicted aerosol number and size distribution, J. Geophys. Res., 114, D06302, doi:10.1029/2008JD010459.

\section{Introduction}

[2] Atmospheric aerosols are an important component of the global climate system. Aerosol particles can directly scatter or absorb solar radiation and, therefore, change both the amount of solar radiation absorbed by the earth system as well as its distribution. Absorbing aerosols, such as soot and/or dust particles, act to heat the atmosphere and can therefore also change cloud cover, an impact called the semidirect effect. Aerosol particles also modify cloud properties by acting as cloud condensation nuclei (CCN). This effect is termed the indirect effect and is made up of the so-called "first indirect effect," the effect of aerosol particles on cloud droplet size and cloud albedo [Twomey, 1977]; and the "second indirect effect," the response of the cloud morphology to changes in the precipitation efficiency

\footnotetext{
${ }^{1}$ Department of Atmospheric, Oceanic and Space Sciences, University of Michigan, Ann Arbor, Michigan, USA.

${ }^{2}$ Pacific Northwest National Laboratory, Richland, Washington, USA.

Copyright 2009 by the American Geophysical Union. 0148-0227/09/2008JD010459
}

[Albrecht, 1989]. Additionally, aerosol particles that are deposited on snow and ice can change the surface albedo [Hansen and Nazarenko, 2004]. Aerosol particles also deliver nutrients such as iron to the ocean's surface, and thereby alter its biogeochemistry. Furthermore, Sherwood [2002] suggested that biomass burning aerosols may affect the transport of the water vapor into the stratosphere.

[3] Dynamical feedbacks from aerosol effects that rely on knowing the aerosol size and number introduce uncertainties in predicted cloud fields. Ackerman et al. [2004] showed that increased cloud droplet number concentrations caused by an increase in atmospheric aerosol number concentrations can enhance the entrainment of overlying dry air into stratocumulus clouds in the marine boundary layer, while Guo et al. [2007] showed that when the large-scale subsidence is strong, the growth of the cloud top is suppressed and the entrainment drying makes no significant difference. Andreae et al. [2004] showed that the delay in the onset of precipitation, which can be caused by smaller cloud droplets from enhanced aerosol number concentrations, leads to an invigoration of and a restructuring of clouds. Ramanathan et al. [2005] and Rotstayn et al. [2007] 
showed that the change in temperature gradients created by anthropogenic aerosols in the Indian Ocean may change the monsoon precipitation in south Asia and Australia. Zhang et al. [2007] showed that enhanced storm track activities in the Pacific Ocean may be related to the increase in anthropogenic aerosol number concentration.

[4] A fully coupled climate-aerosol model is required to evaluate these rather complicated climate effects. Here we coupled the IMPACT aerosol model [Rotman et al., 2004; Liu et al., 2005] to the NCAR CAM3 atmospheric circulation model [Collins et al., 2006a] (see appendix A for a description of the coupling method). We describe results from the version of IMPACT that uses a sulfate aerosol microphysics module [Liu et al., 2005] and the standard version of the NCAR CAM3 model. We evaluate the aerosol fields from the coupled model and investigate some uncertainties associated with the simulation of the aerosol number concentration and its size distribution.

[5] Subgrid-scale nucleation and aerosol growth near strong sources of sulfur emissions are usually represented as preexisting primary sulfate particles in global aerosol models [Adams and Seinfeld, 2002]. Therefore, Liu et al. [2005] assumed that $2 \%$ of the emitted anthropogenic sulfur formed sulfate particles prior to mixing within a grid box. Particles also formed as a result of nucleation events in the upper troposphere associated with binary homogeneous nucleation. Boundary layer nucleation events have been postulated to occur as a result of a number of mechanisms [Yu and Turco, 2000; Korhonen et al., 1999; O'Dowd et al., 2002; Zhang et al., 2004; Kulmala et al., 2006]. Here, we add the boundary layer nucleation mechanisms from Kulmala et al. [2006] and Sihto et al. [2006] to the IMPACT model to explore the effect of additional nucleation events on the predicted aerosol size and number concentration. In addition, we explore the impact of different choices for the fraction of sulfate emitted as primary particles. Finally, we investigate the size and number concentration of aerosols associated with using three modes to represent sulfate aerosol instead of the two-mode representation described by Liu et al. [2005].

[6] The coupled model and emission data are described in section 2. Sensitivity tests using different representations for nucleation and primary emissions of sulfate aerosols as well as the number of sulfate modes included in the microphysics module are described in section 3. Model results from our base case are presented in section 4 (global budget and spatial distributions), section 5 (comparison with observed mass fields) and section 6 (comparison with observed aerosol size and number), respectively. Results from the sensitivity tests are shown in section 7 . Finally, a summary is presented in section 8 .

\section{Model Description}

[7] The coupled IMPACT-CAM model used in this study consists of two components: the Lawrence Livermore National Laboratory (LLNL) IMPACT aerosol model, and the NCAR CAM3 atmospheric circulation model. The two components of the coupled system are run concurrently using the multiple processors multiple data (MPMD) mode to exchange aerosol fields and meteorological fields at each advection time step of the IMPACT model. We used 26 vertical levels and a horizontal resolution of $2 \times 2.5$ for both CAM3 and IMPACT. The time step for CAM3 was $30 \mathrm{~min}$, and that for advection in IMPACT was $1 \mathrm{~h}$. The time step for aerosol microphysics in IMPACT is dynamically adjustable and can be shorter than one second during a strong nucleation event [Liu et al., 2005; Herzog et al., 2004]. In this section, we describe both model components and the emission data used in this study.

\subsection{LLNL IMPACT Aerosol Model}

[8] The aerosol model component is based on the LLNL IMPACT model [Rotman et al., 2004; Penner et al., 1998]. In these studies, the IMPACT model was driven by archived meteorological fields from either a general circulation model or assimilated data. In our coupled model system, we replaced these offline meteorological fields with fields generated from the coupled atmospheric general circulation model (NCAR CAM3). Thus, the temperature, pressure, wind speeds, humidity, cloud fraction, cloud water, precipitation, convective mass flux, detrainment rate, and boundary layer height from CAM3 were made available at each time step of the IMPACT model.

[9] The LLNL IMPACT model [Rotman et al., 2004; Penner et al., 1998] was developed using massively parallel computer architecture and was extended by Liu and Penner [2002] to treat the mass of sulfate aerosol as a prognostic variable. It was further extended by Liu et al. [2005] to treat the microphysics of sulfate aerosol and the interactions between sulfate and nonsulfate aerosols based on the aerosol module developed by Herzog et al. [2004]. The model uses the flux form semi-Lagrangian (FFSL) advection algorithm of Lin and Rood [1996]. Cumulus transport was described in detail by Penner et al. [1998], and vertical diffusion is based on an implicit scheme from Walton et al. [1988].

[10] The LLNL IMPACT model simulates the microphysics of sulfate aerosol (nucleation, condensation, coagulation) and its interactions with primary emitted nonsulfate aerosols: organic matter (OM), black carbon (BC), dust and sea salt, using a modal representation of sulfate aerosol microphysics with an arbitrary number of modes [Herzog et al., 2004; Liu et al., 2005]. Both mass and number for pure sulfate aerosol are predicted. Here two modes are used for the base case: the nucleation/Aitken mode with particle radius less than $0.05 \mu \mathrm{m}$ and the accumulation mode with particle radius larger than $0.05 \mu \mathrm{m}$. Mineral dust and sea salt are predicted in four bins with radii varying from 0.05 to $0.63 \mu \mathrm{m}, 0.63-1.26 \mu \mathrm{m}, 1.26-2.5 \mu \mathrm{m}$, and $2.5-10 \mu \mathrm{m}$. The size distribution within each size bin follows a predefined, fixed distribution with the size distribution of dust represented by a superposition of three lognormal distributions and that of sea salt represented by a superposition of two lognormal distributions (see Table 1 and Liu et al. [2005]). This representation results in slight discontinuities in the number concentrations at the edges of the different size bins. Carbonaceous aerosol (OM and BC) is currently represented by a single submicron size bin with separate distributions assumed for biomass burning $\mathrm{OM} / \mathrm{BC}$ and natural $\mathrm{OM}$ and for fossil fuel $\mathrm{OM} / \mathrm{BC}$. Both of these are represented by a superposition of three lognormal distributions (Table 1).

[11] Sulfuric acid gas $\left(\mathrm{H}_{2} \mathrm{SO}_{4}(\mathrm{~g})\right)$, which is produced from gas phase chemistry, can nucleate to form new sulfate 
Table 1. Size Distribution Parameters for Nonsulfate Aerosols ${ }^{\mathrm{a}}$

\begin{tabular}{lccc}
\hline \multicolumn{1}{c}{ Aerosol Component } & $\mathrm{Ni}^{\mathrm{b}}$ & $\mathrm{Ri}(\mu \mathrm{m})$ & Sigma \\
\hline Fossil fuel OM/BC & 0.428571 & 0.005 & 1.5 \\
& 0.571428 & 0.08 & 1.7 \\
Biomass OM/BC and natural OM & $1.0 \mathrm{E}-6$ & 2.5 & 1.65 \\
& 0.9987 & 0.0774 & 1.402 \\
& $1.306 \mathrm{E}-3$ & 0.3360 & 1.383 \\
Sea salt & $2.830 \mathrm{E}-3$ & 0.9577 & 1.425 \\
& 0.965 & 0.035 & 1.92 \\
Dust & 0.035 & 0.41 & 1.70 \\
& 0.854240 & 0.05 & 1.65 \\
& 0.145687 & 0.27 & 2.67 \\
& $7.3 \mathrm{E}-5$ & 4.0 & 2.40 \\
\hline
\end{tabular}

${ }^{\mathrm{a}} \mathrm{See}$ Table 1 of Liu et al. [2005]. For each aerosol component, values for three lognormal modes are given.

${ }^{\mathrm{b}} \mathrm{Ni}$ is the fraction of the total particle number in a given size range and is dimensionless.

particles in the nucleation/Aitken mode or condense onto the preexisting sulfate and nonsulfate aerosol particles. In the base case, only binary homogeneous nucleation of $\mathrm{H}_{2} \mathrm{SO}_{4}-\mathrm{H}_{2} \mathrm{O}$ following the parameterization of Vehkamäki et al. [2002] is considered. Sulfate particles can coagulate with each other or with nonsulfate particles. The volume mean radius of each mode (pure sulfate aerosol) and each bin (nonsulfate aerosols) is used to calculate particle diffusion coefficients and coagulation kernels [Herzog et al., 2004]. The size distribution for nonsulfate aerosols is fixed and is used to calculate the rates of condensation and coagulation. A separate prognostic variable is used to track the amount of sulfate that condenses or coagulates with the nonsulfate aerosols. The hydrophilic and hydrophobic properties of nonsulfate aerosols are determined by the amount of sulfate coating that is produced through coagulation and condensation of pure sulfate as well as any aqueous phase formation on the nonsulfate particles [Liu et al., 2005]. Carbonaceous or mineral dust aerosol particles were assumed to be hygroscopic when there is a coating of more than 10 layers of sulfate molecules [Liu et al., 2005]. The sulfate produced from aqueous phase reactions is assumed to be equally distributed among the hygroscopic aerosol particles that are larger than $0.05 \mu \mathrm{m}$ in radius.

[12] Dry deposition is calculated using the module developed by Wang et al. [1998], which employs a resistance in series approach to calculate the dry deposition velocity from the aerodynamic resistance and surface resistance [Wesely et al., 1985]. Gravitational settling is taken into account for aerosol species. Wet deposition is calculated using the scavenging module developed by Mari et al. [2000] and Liu et al. [2001] which includes scavenging in convective updrafts and first-order rainout and washout in precipitating columns. The horizontal fractional area of each grid box experiencing precipitation is based on the work by Giorgi and Chameides [1986] assuming a cloud liquid water content of $1.5 \mathrm{~g} \mathrm{~m}^{-3}$ for stratiform cloud and $2.0 \mathrm{~g} \mathrm{~m}^{-3}$ for convective cloud.

[13] Scavenging efficiencies for the accumulation mode sulfate and sea salt are assumed to be 1.0 and the scavenging efficiency of nucleaiton/Aitken mode sulfate is calculated from the Brownian coagulation coefficient [Liu et al., 2005]. The scavenging efficiencies of $\mathrm{BC}, \mathrm{OM}$ and mineral dust depend on the amount of sulfate coating and the size of these aerosols [Liu et al., 2005], but we set the upper and lower limits for scavenging efficiencies in liquid clouds to the scavenging efficiencies for soluble and insoluble species, respectively, from Stier et al. [2005], which are based on the measurements of Henning et al. [2004]. The upper (lower) limits are $0.80(0.30), 0.85(0.40)$, and $0.99(0.6)$ for $\mathrm{BC} / \mathrm{OM}$, fine mode dust $(0.06-0.625 \mu \mathrm{m})$, and coarse mode dust $(0.625-10 \mu \mathrm{m})$, respectively. For cirrus clouds, the scavenging efficiencies are set to be 0.1 for all aerosol species [Feichter et al., 2004], but are subject to large uncertainties. Variations in this efficiency have a significant impact on upper tropospheric aerosol burdens [Hendricks et al., 2004]. For mixed phase clouds, the cloud water or ice-weighted mean scavenging efficiencies from liquid clouds and cirrus clouds are used.

\subsection{NCAR CAM3}

[14] The NCAR Community Atmospheric Model (CAM3) is a part of the Community Climate System Model (CCSM3) [Collins et al., 2006a, 2006b]. We employed CAM3 here in its stand-alone version. The model may be run using one of three dynamical cores with either an Eulerian spectral, semiLagrangian, or finite volume advection scheme. Here the finite volume dynamical core is used. In CAM3, the physics and the finite volume dynamical core are coupled in a time splitting approximation [Williamson, 2002]. Cloud liquid and cloud ice are prognostic variables in CAM3 [Boville et al., 2006], which replaced the diagnostic scheme in NCAR CCM3. Since cloud liquid is separated from cloud ice, it is possible to treat the differences in radiative properties and sedimentation properties between liquid and ice clouds. A prescribed aerosol concentration from an off-line calculation of a chemical transport model constrained by an assimilation of satellite retrievals was used to calculate the aerosol optical properties [Collins et al., 2001; Rasch et al., 2001]. Cloud droplet number concentrations were prescribed in the precipitation process and in calculating the radiative properties of cloud.

[15] In the coupled CAM-IMPACT aerosol model, the prescribed aerosol concentration from CAM3 was replaced with concentrations calculated in the IMPACT aerosol model, however, in this study, the simulated aerosol fields had no effect on the radiation fields or the predicted meteorology because we wished to focus on evaluating the aerosol fields in the coupled model.

\subsection{Emission Data}

[16] The emissions of anthropogenic sulfur were developed based on an updated and extended version of the emission data of Smith et al. [2001] [see Smith et al., 2004]. In our base case, $98 \%$ of anthropogenic sulfur is emitted as gas phase $\mathrm{SO}_{2}$. The remaining $2 \%$ of anthropogenic sulfur is assumed to be emitted as sulfate particles. $85 \%$ of the mass is emitted in the accumulation mode with a mode diameter of $70 \mathrm{~nm}$ and a geometric standard deviation of 2.0 . The remaining $15 \%$ of the mass is emitted in the nucleation/Aitken mode with a mode diameter of $10 \mathrm{~nm}$ and a geometric standard deviation of 1.6 [Whitby, 1978].

[17] Volcanic $\mathrm{SO}_{2}$ emissions are a 25 -year average of sporadic and continuously emitting volcanoes based on the work by Andres and Kasgnoc [1998]. Marine DMS fluxes are the average of the high and low estimates from Kettle and Andreae [2000], who used the ocean DMS field 
compiled by Kettle et al. [1999] and flux formulations based on the works by Liss and Merlivat [1986] and Wanninkhof [1992]. The natural OM fluxes were derived by assuming that $9 \%$ of the terpene emissions developed by Guenther et al. [1995] were rapidly converted to OM [Penner et al., 2001]. Emissions of fossil fuel and biofuel carbonaceous aerosol were from the year 2000 emissions of Ito and Penner [2005] with some adjustments. In particular, we compared the simulated surface concentrations from IMPACT using the fossil fuel emissions in 2000 with surface observations and derived a scaling factor of 2.3 over East Europe and a scaling factor of 1.45 over Asia. Fossil fuel BC emissions are highly uncertain [Bond et al., 2004; Novakov et al., 2003; Ito and Penner, 2005]. The fossil fuel inventory we use is an update to the year 2000 from that developed by Bond et al. [2004] and is about a factor of 2 lower than inventories that are thought to give smaller absorption in the atmosphere than that deduced from the analysis of Sun photometer data [Sato et al., 2003]. We assumed that both fossil fuel and biofuel aerosol are emitted into the surface layer. The year 2000 open biomass burning emissions were developed using the inverse method described by Zhang et al. [2005] together with an a priori estimate of the emissions for the year 2000 based on scaling the bottom up aerosol emission inventory estimate of Ito and Penner [2005] with the ratio of the $\mathrm{CO}$ emissions from the inverse study of Arellano et al. [2004] and the bottom up study of Ito and Penner [2005]. The open biomass emissions were emitted uniformly into the boundary layer.

[18] Sea salt emissions are calculated online in the coupled model using the method defined by Gong et al. [1997] based on the $10 \mathrm{~m}$ wind speeds from CAM3, and sea salt particles are injected into the lowest model layer. Dust emissions were not calculated based on the CAM3 model wind speeds, but used emission fluxes provided by P. Ginoux (private communication, 2004) at a $6 \mathrm{~h}$ interval. These emission fluxes were developed using the method described by Ginoux et al. [2001] based on the $10 \mathrm{~m}$ wind speed and soil wetness calculated by the GFDL GCM nudged with the NCEP meteorological fields. The emission flux is similar to that described by Ginoux et al. [2001] with the formula for the threshold wind velocity defined by Ginoux et al. [2004]. These prescribed dust fluxes were used because the use of the Ginoux et al. [2001] emission parameterization with the CAM3 wind speeds did not capture the right seasonal variation of dust concentrations near the Sahara desert. Dust is uniformly injected into the boundary layer.

\section{Sensitivity Tests}

[19] There are large uncertainties in simulated aerosol particle number concentrations and size in global model studies [Spracklen et al., 2005a]. We used five additional simulations to study the sensitivity of aerosol number and size to the use of primary emitted sulfate particles to represent nucleation in subgrid-scale plumes, the inclusion of boundary layer nucleation mechanisms, and the use of a three-mode representation of sulfate aerosol. The descriptions of these five runs are presented here, and comparisons with the base case as well as with observations are presented in section 7 .

\subsection{Primary Emission of Sulfate Particles to Represent Subgrid-Scale Nucleation}

[20] In the base case, $2 \%$ of anthropogenic sulfur is assumed to be emitted as primary sulfate particles. Most global model studies that predict both aerosol mass and number have included some fraction of sulfate emissions as primary emitted sulfate to represent nucleation in subgridscale plumes [Liu et al., 2005; Easter et al., 2004; Stier et al., 2005; Adams and Seinfeld, 2002; Spracklen et al., 2005a, 2007; Pierce and Adams, 2006; Pierce et al., 2007]. The size distribution and total amount of the primary emitted particulate sulfate should account for all microphysical processes that occur within subgrid-scale plumes (nucleation, condensational growth and coagulation) [Adams and Seinfeld, 2003] as well as any sulfate particles emitted directly from the source. In the model of Adams and Seinfeld [2002], the primary emitted particulate sulfate is also used as a surrogate for other nonsulfate primary particles.

[21] Observations provide little constraint on how much sulfur should be emitted as primary particles or what size to assume in a global model. Observed mass conversion rates from gas-phase $\mathrm{SO}_{2}$ to particulate sulfate in power plant plumes range from near 0 to $6 \% \mathrm{~h}^{-1}$ in clear conditions [Hewitt, 2001] and most of the $\mathrm{H}_{2} \mathrm{SO}_{4}$ that is formed undergoes condensation rather than nucleation. The mass conversion rate also strongly depends on sunlight exposure.

[22] The absence of constraints from observations leads to large uncertainties with respect to the treatment of the amount of the sulfur and the size distribution of particles emitted as particulate sulfate in global model studies. Some models used the size distribution from Whitby [1978] (two modes: $0.01 \mu \mathrm{m}$ and $0.07 \mu \mathrm{m}$ in diameter) for anthropogenic particulate sulfate emissions but different amounts are assumed ( $2 \%$ of anthropogenic sulfur in the works by Liu et al. [2005] and Easter et al. [2004]; 3\% in the works by Adams and Seinfeld [2002], Pierce and Adams [2006], Pierce et al. [2007], and Spracklen et al. [2007]). Stier et al. [2005, 2006] used larger sizes for ship, industrial and power plant emissions (two modes: $0.15 \mu \mathrm{m}$ and $1.5 \mu \mathrm{m}$ in diameter) and smaller sizes for other sources (two modes: $0.06 \mu \mathrm{m}$ and $0.15 \mu \mathrm{m}$ in diameter), and assumed that $2.5 \%$ of anthropogenic sulfur is emitted as particles. Lauer et al. [2005] did not assume any primary emitted particle sulfate, but this was partly compensated for by the large number concentrations of primary fossil fuel BC particles which were very small in their model $(75 \%$ of the fossil fuel BC mass had a mode diameter of $0.02 \mu \mathrm{m})$.

[23] Although primary emitted sulfate particles have little impact on the simulated sulfate aerosol mass, they can have a large impact on the simulated sulfate aerosol number [Adams and Seinfeld, 2002, 2003; Spracklen et al., 2005a]. Adams and Seinfeld [2002] used a model that only included sulfate and showed that the inclusion of $3 \%$ of the sulfur emissions as primary emitted particulate sulfate almost doubled the predicted number concentration of $\mathrm{CCN}$ in the planetary boundary layer and improved the comparison between the model and the observations compared to no primary emissions. Spracklen et al. [2005a] used a model that only included sulfate and sea salt and confirmed the large increase in the aerosol number concentration when 3\% of the sulfur emissions were treated as primary emitted 
sulfate particles. Stier et al. [2006] on the other hand, used a size distribution for primary emitted sulfate aerosols that was more aged than that used by Spracklen et al. [2005a] and Adams and Seinfeld [2002]. They showed that anthropogenic sulfate increases the global mean number burden of the soluble nucleation, Aitken and accumulation modes by $8 \%, 20 \%$, and $27 \%$, respectively. They did not specifically analyze the increase in the number concentration associated with the primary emission of sulfate particles. The specific impact of primary sulfate particles on number concentrations is likely a function of the assumed size distribution and the degree of aging. Here, our use of the Whitby size distribution is guided by the fact that it represents an average continental size distribution which would account for aging during subgrid-scale processes, but we cannot rule out that either less or more aging of the distribution within the grid box in which they are emitted might be appropriate.

[24] In order to examine the sensitivity of the simulated aerosol size distribution to the assumed primary emitted particulate sulfate fraction, we examined a case in which no sulfur is emitted as primary particles and all sulfur is emitted as gas phase $\mathrm{SO}_{2}$ : "0\%SO2." In contrast to the studies by Adams and Seinfeld [2002, 2003] and Spracklen et al. [2005a], our model study includes all major primary aerosol particle types: organic carbon, black carbon, dust and sea salt.

\subsection{Boundary Layer Nucleation}

[25] In the base case, only binary homogeneous nucleation [Vehkamäki et al., 2002] is included. Nucleation by this mechanism occurs most frequently in the upper troposphere and over polar regions, where favorable conditions (low temperature and low preexisting particle surface area) occur [Lucas and Akimoto, 2006]. However, a variety of observations have shown that nucleation events are common in the planetary boundary layer [Kulmala et al., 2004; Koponen et al., 2003; Vehkamäki et al., 2004; Dal Maso et al., 2005; Laaksonen et al., 2005; O'Dowd et al., 1999]. Several nucleation mechanisms, including ion-mediated nucleation [Yu and Turco, 2000], ternary homogeneous nucleation involving ammonia, sulfate, and water [Korhonen et al., 1999], nucleation involving iodine species [O'Dowd et al., 2002] and nucleation involving organics [Zhang et al., 2004] have been suggested as important in the boundary layer, but no agreement has been reached about the relative importance of different nucleation mechanisms.

[26] Sihto et al. [2006] fit the observed time rate of change of particles in the 3 to $6 \mathrm{~nm}$ range at Hyytiälä, Finland, with either a linear or a quadratic function of the observed sulfuric acid gas concentration. The quadratic empirical fit is appropriate for a kinetic nucleation mechanism, in which two molecules containing sulfuric acid collide to form a stable cluster [McMurry and Friedlander, 1979]. The linear fit is appropriate for an activation nucleation mechanism [Kulmala et al., 2006] in which a cluster containing a single sulfuric acid molecule together with other molecules is activated by heterogeneous nucleation or heterogeneous chemical reactions. Spracklen et al. [2006] applied the linear empirical formula from Kulmala et al. [2006] to relate the nucleation rate in the boundary layer to the sulfuric acid concentration in their global aerosol model, and demonstrated that this mechanism could be important to determining the regional and global aerosol number concentration.

[27] We implemented both the linear and quadratic empirical formulas in the global model to examine their impacts on the aerosol number concentration. Following Spracklen et al. [2006], we first calculate the nucleation rate of $1 \mathrm{~nm}$ particles from Kulmala et al. [2006] and Sihto et al. [2006] as

$$
j_{1 n m}=A\left[\mathrm{H}_{2} \mathrm{SO}_{4}\right]
$$

or

$$
j_{1 n m}=K\left[\mathrm{H}_{2} \mathrm{SO}_{4}\right]^{2},
$$

where $A\left(1.0^{-6} \mathrm{~s}^{-1}\right)$ and $K\left(1.0^{-12} \mathrm{~cm}^{3} \mathrm{~s}^{-1}\right)$ are rate constants chosen from the median values derived in case studies [Sihto et al., 2006]. Then we used the formula from Kerminen and Kulmala [2002] to calculate the rate of formation of $3 \mathrm{~nm}$ particles:

$$
j_{3 \mathrm{~nm}}=j_{1 \mathrm{~nm}} \exp [-0.66 \gamma \mathrm{CS} / \mathrm{GR}]
$$

where CS is the reduced condensation sink $\left(\mathrm{m}^{-2}\right)$, GR is the growth rate $\left(\mathrm{nm} \mathrm{h}^{-1}\right)$, and $\gamma$ is a proportionality factor $\left(\mathrm{m}^{2} \mathrm{~nm} \mathrm{~h} \mathrm{~h}^{-1}\right)$. The reduced condensation sink (CS) is calculated by summing over all aerosol modes and/or bins $j$ :

$$
\mathrm{CS}=\sum_{j} \beta_{j} r_{j} N_{j}
$$

where $\beta_{j}$ is the transitional correction factor for the condensational mass flux, $N_{j}$ is the number concentration in the size class $j$, and $r_{j}$ is the volume-mean particle radius. The growth rate (GR) is calculated as by Kerminen and Kulmala [2002] by summing over all condensable gases $i$ :

$$
\mathrm{GR}=\frac{3.0 \times 10^{-9}}{\rho} \sum c_{i} M_{i} C_{i}
$$

where $c_{i}$ is the mean molecular speed of the condensing vapor $\left(\mathrm{m} \mathrm{s}^{-1}\right), M_{i}$ is the molecular weight $\left(\mathrm{g} \mathrm{mol}^{-1}\right), C_{i}$ is the gas phase concentration of condensing vapor (molecules $\mathrm{cm}^{-3}$ ), $\rho$ is the density of the nuclei $\left(\mathrm{kg} \mathrm{m}^{-3}\right)$. In this study, the only condensing vapor is sulfuric acid gas. The proportionality factor $\gamma$ is the semiempirical formula derived by Kerminen and Kulmala [2002]:

$$
\gamma=0.23\left(\frac{d_{\text {mean }}}{150}\right)^{0.048}\left(\frac{\rho_{\text {nuc }}}{1000}\right)^{-0.33}\left(\frac{T}{293}\right)^{-0.75}
$$

Here $d_{\text {mean }}$ is the number mean diameter of the preexisting particle population $(\mathrm{nm}), \rho_{\text {nuc }}$ is the density of the nuclei $\left(\mathrm{kg} \mathrm{m}^{-3}\right)$, and $\mathrm{T}$ is the ambient temperature $(\mathrm{K})$. In this study we assume $\gamma=0.23 \mathrm{~m}^{2} \mathrm{~nm} \mathrm{~h}^{-1}$ as an approximation.

[28] Three additional simulations are added to investigate how these boundary layer nucleation mechanisms affect the simulated aerosol size and number. In the case " $2 \% \mathrm{SO} 2+\mathrm{Act}$," the boundary layer nucleation mechanism in equation (1) (the Activation mechanism) is added to the base case. Spracklen et al. [2005b] showed that binary homogeneous nucleation has little effect on simulated 
Table 2. Description of Cases

\begin{tabular}{|c|c|c|c|c|c|}
\hline Case & $\begin{array}{c}\text { Within } \\
\mathrm{BL}^{\mathrm{a}}\end{array}$ & $\begin{array}{l}\text { Within } \\
\text { FT }^{\mathrm{b}}\end{array}$ & Primary Sulfate & $\begin{array}{l}\text { Number of Modes } \\
\text { for Pure Sulfate }\end{array}$ & $\begin{array}{c}\text { Integration } \\
\text { Time (years) }\end{array}$ \\
\hline Base-5years & $\mathrm{BHN}^{\mathrm{c}}$ & $\mathrm{BHN}$ & $2 \% \mathrm{SO} 2^{\mathrm{f}}$ & 2 & 5 \\
\hline Base-1year & $\mathrm{BHN}$ & $\mathrm{BHN}$ & $2 \% \mathrm{SO} 2$ & 2 & 1 \\
\hline $0 \% \mathrm{SO} 2$ & $\mathrm{BHN}$ & $\mathrm{BHN}$ & $0 \% \mathrm{SO} 2^{\mathrm{g}}$ & 2 & 1 \\
\hline $0 \% \mathrm{SO} 2+\mathrm{Act}$ & $\mathrm{BL}_{1 s t^{\mathrm{d}}}$ & $\mathrm{BHN}$ & $0 \% \mathrm{SO} 2$ & 2 & 1 \\
\hline $0 \% \mathrm{SO} 2+\mathrm{Kin}$ & BL2nd ${ }^{\mathrm{e}}$ & $\mathrm{BHN}$ & $0 \% \mathrm{SO} 2$ & 2 & 1 \\
\hline $2 \% \mathrm{SO} 2+\mathrm{Act}$ & BL1st & $\mathrm{BHN}$ & $2 \% \mathrm{SO} 2$ & 2 & 1 \\
\hline Three-mode & $\mathrm{BHN}$ & $\mathrm{BHN}$ & $2 \% \mathrm{SO} 2$ & 3 & 1 \\
\hline NOBHN & $\mathrm{BHN}$ & No FT nucleation & $2 \% \mathrm{SO} 2$ & 2 & 1 \\
\hline
\end{tabular}

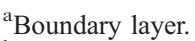

${ }^{\mathrm{b}}$ Free troposphere.

${ }^{\mathrm{c}}$ Binary homogeneous nucleation (scheme of Vehkamäki et al. [2002]).

${ }^{\mathrm{d}}$ Boundary layer nucleation using equation (1).

${ }^{\mathrm{e}}$ Boundary layer nucleation using equation (2).

${ }^{\mathrm{f}}$ Two percent of anthropogenic $\mathrm{SO}_{2}$ emissions are input as primary sulfate.

${ }^{\mathrm{g}}$ Zero percent of anthropogenic $\mathrm{SO}_{2}$ emissions are input as primary sulfate.

marine boundary layer aerosol number concentrations, so we have replaced the binary homogeneous nucleation mechanism with the empirical boundary layer nucleation scheme in the boundary layer and do not allow any competition between binary nucleation and the empirical boundary layer nucleation mechanisms. This approximation may miss some areas (such as polar regions in the winter) where binary homogeneous nucleation may dominate the empirical boundary layer nucleation scheme used here, but these areas are relatively small. In the case $0 \% \mathrm{SO} 2+$ Act, the empirical boundary layer nucleation in equation (1) is added to the case $0 \% \mathrm{SO} 2$ replacing the binary homogeneous nucleation mechanism in the boundary layer. In the case " $0 \% \mathrm{SO} 2+\mathrm{Kin}$ " (the kinetic mechanism), equation (2) replaces the binary homogeneous nucleation rate in the boundary layer instead of using equation (1).

\subsection{Three-Mode Representation for Sulfate Aerosol}

[29] In our base case, two modes are used to represent pure sulfate aerosol: a nucleation/Aitken mode (radius < $0.05 \mu \mathrm{m})$ and the accumulation mode (radius $>0.05 \mu \mathrm{m}$ ) which is similar to the study of Lauer et al. [2005]. While our two-mode representation is able to capture some of the variability of the aerosol size distribution [Liu et al., 2005], a three-mode or four-mode representation would be more realistic and, therefore, expected to perform better compared with observations. For example, the four-mode version of our aerosol microphysics module was shown to be in better agreement with a sectional model than the two-mode version in box model intercomparisons [Herzog et al., 2004]. Lauer et al. [2005] also suggested that a three-mode representation of the aerosol size distribution with an additional mode representing nucleation sizes (radius $<5 \mathrm{~nm}$ ) may be able to better simulate an aged Aitken mode. Therefore, in the "three-mode" case, we used the three-mode version of our aerosol microphysics module in the IMPACT aerosol model with an additional mode at nucleation sizes (radius $<5 \mathrm{~nm}$ ). Aerosol particles from nucleation are put into the nucleation mode and the primary emitted sulfate particles are put into the Aitken mode $(5 \mathrm{~nm}<$ radius $<50 \mathrm{~nm})$ and the accumulation mode (radius $>50 \mathrm{~nm}$ ).

[30] Table 2 lists all sensitivity tests along with the base case. In addition to the above cases, the case "NOBHN" was included. This is the same as the base case except that binary homogeneous nucleation is turned off above the boundary layer. This case is examined to study the extent to which binary homogeneous nucleation above the boundary layer affects the simulated mass profile in the upper troposphere in section 5.2.

[31] All simulations used climatological sea surface temperatures. In the base case the coupled model was integrated for 5 years after an initial spin-up time of 4 months and monthly average data were used in the analysis. In the sensitivity tests, the model was only integrated for 1 year after an initial spin-up of 4 months in order to save computation cost. Since the aerosol fields are not allowed to change heating rates or droplet number concentrations in the climate model, the aerosol fields do not affect the simulated meteorological fields. Therefore, the meteorological fields are the same for all the first year simulations, which allows us to make comparisons of different cases from only 1 year of simulation.

\section{Model Results}

\subsection{Annual and Global Budgets}

[32] The global budgets of the simulated aerosols and their precursor species are shown in Tables 3-6. Also listed are the average, median, and standard deviation of all available models from the model intercomparison study in the Aerosol Model Intercomparison Initiative (AeroCom, see Textor et al. [2006, Table 10]). More than a dozen models were included in the AeroCom intercomparison study.

[33] The model predicts that $78.6 \%$ of the total sulfate mass is pure sulfate aerosol $(5.9 \%$ in the nucleation/Aitken mode and $72.6 \%$ in the accumulation mode) with the remaining sulfate mass $(21.4 \%)$ coated on nonsulfate aerosols (16\% on carbonaceous aerosol, $3.6 \%$ on dust and $1.8 \%$ on sea salt). The model predicts a smaller sulfate fraction in the nucleation/Aitken mode (5.9\% versus $9.7 \%)$ than in the work by Liu et al. [2005] in part because there is a smaller contribution of gas-phase $\mathrm{SO}_{2}$ oxidation to the sulfate source (30\% versus $34 \%$ of Liu et al. [2005]). The total source of sulfate is $60.03 \mathrm{Tg} \mathrm{a}^{-1}$, similar to the mean of the AeroCom models [Textor et al., 2006]. The model has a larger burden of sulfate aerosol, $0.84 \mathrm{Tg} \mathrm{S}$, compared to $0.60 \mathrm{Tg} \mathrm{S}$ in the AeroCom models, which is due to smaller wet and dry removal rate coefficients in our model. 
Table 3. Global Budget for Sulfate Aerosol

\begin{tabular}{|c|c|c|c|}
\hline & \multirow[b]{2}{*}{ This Study } & \multicolumn{2}{|c|}{ AeroCom } \\
\hline & & Mean $^{\mathrm{a}}$ & $\mathrm{SD}^{\mathrm{b}}$ \\
\hline Sources $\left(\mathrm{Tg} \mathrm{S} \mathrm{a}^{-1}\right)$ & 60.03 & 59.67 & 22 \\
\hline Emission & 1.23 & & \\
\hline Gas-phase $\mathrm{SO}_{2}$ oxidation & 18.01 & & \\
\hline Aqueous-phase $\mathrm{SO}_{2}$ oxidation & 40.79 & & \\
\hline Burden (Tg S) & 0.84 & 0.66 & 25 \\
\hline $\mathrm{H}_{2} \mathrm{SO}_{4}(\mathrm{~g})(\%)$ & 0.03 & & \\
\hline $\begin{array}{l}\text { Nuclei and accumulation } \\
\text { mode sulfate }(\%)\end{array}$ & $5.93,72.64$ & & \\
\hline $\begin{array}{l}\text { On carbonaceous } \\
\text { aerosols }(\%)\end{array}$ & 15.98 & & \\
\hline On dust bins $1-4(\%)$ & $2.96,0.44,0.18,0.0054$ & & \\
\hline On sea salt bins $1-4(\%)$ & $1.69,0.11,0.04,0.0003$ & & \\
\hline Above $5 \mathrm{~km}(\%)$ & 39.90 & 32.23 & 36 \\
\hline In polar ${ }^{\mathrm{c}}(\%)$ & 1.30 & 5.91 & 55 \\
\hline Lifetime (days) & 5.08 & 4.12 & 18 \\
\hline $\begin{array}{l}\text { Rate coefficient } \\
\text { for removal }\left(\mathrm{d}^{-1}\right)\end{array}$ & 0.20 & 0.25 & 18 \\
\hline Wet & 0.18 & 0.22 & 22 \\
\hline Dry & 0.01 & 0.03 & 55 \\
\hline Wet $(\%)$ & 93.41 & 88.50 & 8 \\
\hline
\end{tabular}

${ }^{\mathrm{a}}$ The mean value from available models in AeroCom [see Textor et al., 2006, Table 10].

${ }^{\mathrm{b}}$ The standard deviation normalized by the all models average in the percentage in AeroCom [see Textor et al., 2006, Table 10].

${ }^{\mathrm{c}}$ South of $80^{\circ} \mathrm{S}$ and north of $80^{\circ} \mathrm{N}$.

[34] $39.90 \%$ of the sulfate mass is located above $5 \mathrm{~km}$, which is similar to the mean of the AeroCom models $(32.23 \%)$. But the model predicts much less sulfate in polar regions (south of $80^{\circ} \mathrm{S}$ and north of $80^{\circ} \mathrm{N}$ ) compared to that in the AeroCom models: only $1.30 \%$ compared to $5.91 \%$ for AeroCom. This is also true for the other aerosol species (see below). This may point to differences in the wet removal mechanism as well as to differences in the efficiency of transport to the poles between our model and the other models that participated in AeroCom.

[35] Table 4 shows the budget for carbonaceous aerosols. The OM burden is $0.99 \mathrm{Tg}$, which is about two thirds that of the mean of the AeroCom models. The burden of $\mathrm{BC}$ is $0.13 \mathrm{Tg}$, which is about half of that in AeroCom. The smaller burdens (and shorter lifetimes) in our model are mainly due to the larger removal rate coefficients from wet scavenging. The hygroscopic properties of carbonaceous aerosols in our model are based on the amount of sulfate coated on these initially hydrophobic aerosols. As pointed out by Liu et al. [2005], most carbonaceous aerosols in our model are internally mixed with sulfate and generally hygroscopic except near the source regions, which makes the wet removal rate of carbonaceous aerosols larger than that in many other models. Liu et al. [2005] showed that the global mean aging time for carbonaceous aerosols using our treatment is about 1.8 days which is smaller than the aging time of 2-4 days typically used in models that do not account for the physical processes that lead to the coating of hydrophobic aerosols by sulfate. The rate coefficient for wet removal of carbonaceous aerosols is about $0.19 \mathrm{~d}^{-1}$ in the model, compared with $0.13 \mathrm{~d}^{-1}$ for the mean of the AeroCom models. In addition, the emissions of carbonaceous aerosols in our model are smaller than the mean of the emissions in the AeroCom models, which also contributes to the smaller burden. About $14 \%$ of the carbonaceous aerosol burden is above $5 \mathrm{~km}$ in our model, compared with about $21 \%$ in AeroCom. This is consistent with the larger rate coefficient for wet removal in our model. The mass fractions of $\mathrm{OM}$ and $\mathrm{BC}$ at the poles are $0.29 \%$ and $0.38 \%$, respectively, which is much smaller than the corresponding fractions $(3.27 \%$ for $\mathrm{OM}$ and $4.18 \%$ for $\mathrm{BC}$ ) in AeroCom. The differences at the poles are associated with the larger rate coefficient for wet removal of carbonaceous aerosols in the model, but are probably also due to transport differences.

[36] The total burden of mineral dust (Table 5) is $23.14 \mathrm{Tg}$, which is slightly larger than that from the mean of the AeroCom models $(19.20 \mathrm{Tg})$. The mass fraction of finemode mineral dust (diameter $<1 \mu \mathrm{m}$ ) is $3.76 \%$ in our model compared with $20.80 \%$ for the mean of the AeroCom models. The smaller fine-mode mass fraction in our model partly results from the larger rate coefficient for wet removal. Wet scavenging is the dominant removal mechanism for finemode mineral dust particles but is less important relative to settling and dry deposition for coarse-mode particles. Therefore, a larger wet removal rate will lead to a smaller finemode mass fraction. The larger wet removal rate is caused by the coating of dust particles by sulfate. Sulfate coated on mineral dust increases its hygroscopicity and increases the rate coefficient for wet removal, which is $0.12 \mathrm{~d}^{-1}$ and contributes $41.31 \%$ to the total removal rate coefficient for dust in the model. The wet removal rate coefficient in the AeroCom models is $0.08 \mathrm{~d}^{-1}$, or $33 \%$ of the total removal rate coefficient for dust. The size range of the emitted particles in our model can also cause a smaller fine-mode mass fraction. As shown by Textor et al. [2006], the PNNL model used the same Ginoux et al. [2001] total emission flux as that in our model, but they assumed that dust particles are

Table 4. Global Budget for $\mathrm{OM}$ and $\mathrm{BC}$

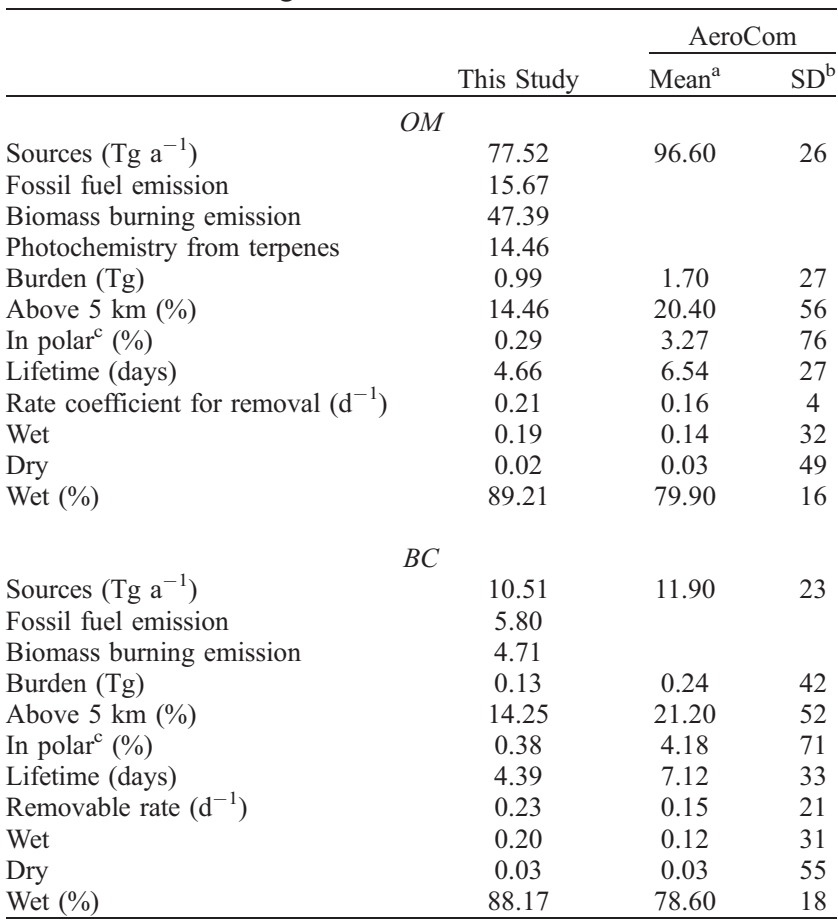

${ }^{\mathrm{a}}$ The mean value from available models in AeroCom [see Textor et al., 2006, Table 10].

${ }^{\mathrm{b}}$ The standard deviation normalized by the all models average in the percentage in AeroCom [see Textor et al., 2006, Table 10].

${ }^{\mathrm{c}}$ South of $80^{\circ} \mathrm{S}$ and north of $80^{\circ} \mathrm{N}$. 
Table 5. Global Budget for Dust

\begin{tabular}{|c|c|c|c|c|c|c|c|c|}
\hline & \multicolumn{5}{|c|}{ This Study } & \multicolumn{3}{|c|}{ AeroCom Total } \\
\hline & $0.05-0.63$ & $0.63-1.25$ & $1.25-2.50$ & $2.50-10.0$ & Total & Mean $^{\mathrm{a}}$ & Median $^{\mathrm{b}}$ & $\mathrm{SD}^{\mathrm{c}}$ \\
\hline Emission $\left(\mathrm{Tg} \mathrm{a}^{-1}\right)$ & 76.57 & 291.54 & 662.59 & 1325.20 & 2355.90 & 1840.00 & 1640.00 & 49 \\
\hline Burden $(\mathrm{Tg})$ & 1.60 & 5.99 & 10.92 & 4.62 & 23.14 & 19.20 & 20.50 & 40 \\
\hline Fine mass ${ }^{\mathrm{d}}(\%)$ & - & - & - & - & 3.76 & 20.80 & 10.80 & 114 \\
\hline Above $5 \mathrm{~km}(\%)$ & 11.12 & 10.71 & 9.28 & 4.04 & 8.73 & 14.10 & 14.10 & 51 \\
\hline In $\operatorname{polar}^{\mathrm{e}}(\%)$ & 0.30 & 0.29 & 0.24 & 0.05 & 0.22 & 1.54 & 1.00 & 102 \\
\hline Lifetime (days) & 7.65 & 7.51 & 6.02 & 1.27 & 3.59 & 4.14 & 4.04 & 43 \\
\hline Rate coefficient for removal rate $\left(\mathrm{d}^{-1}\right)$ & 0.13 & 0.13 & 0.17 & 0.79 & 0.28 & 0.31 & 0.25 & 62 \\
\hline Wet & 0.11 & 0.11 & 0.12 & 0.11 & 0.12 & 0.08 & 0.09 & 42 \\
\hline Dry & 0.02 & 0.02 & 0.05 & 0.68 & 0.16 & 0.23 & 0.16 & 84 \\
\hline Wet $(\%)$ & 87.65 & 86.01 & 71.00 & 13.97 & 41.31 & 33.00 & 31.70 & 54 \\
\hline
\end{tabular}

${ }^{\mathrm{a}}$ The mean value from available models in AeroCom [see Textor et al., 2006, Table 10].

${ }^{\mathrm{b}}$ The median value from available models in AeroCom [see Textor et al., 2006, Table 10].

${ }^{\mathrm{c}}$ The standard deviation normalized by the all models average in the percentage in AeroCom [see Textor et al., 2006, Table 10].

${ }^{\mathrm{d}}$ Particles with size less than $0.5 \mu \mathrm{m}$ in radius.

${ }^{\mathrm{e}} \mathrm{S}$ outh of $80^{\circ} \mathrm{S}$ and north of $80^{\circ} \mathrm{N}$.

emitted at only two sizes: 0.31 and $2.81 \mu \mathrm{m}$ in diameter, resulting in a much higher fine-mode mass fraction (34\%). The mass fraction for dust above $5 \mathrm{~km}$ is $8.73 \%$ compared to a mean of $14.10 \%$ in AeroCom. The mass fraction at the poles is $0.22 \%$, which is only about one seventh that of the value in AeroCom (1.54\%).

[37] The total burden for sea salt aerosol (Table 6) is $5.10 \mathrm{Tg}$, which is smaller than the mean in the AeroCom models $(7.52 \mathrm{Tg})$. The mass fraction of sea salt aerosol in the fine mode is $4.79 \%$ compared to $14.60 \%$ in the AeroCom models. The larger mass fraction in AeroCom mainly results from the large mass fraction of fine-mode aerosols in the GISS model which is about $70 \%$. The lifetime of sea salt aerosols is 0.71 day, which is $50 \%$ larger than the mean of the AeroCom models (0.48 day). The longer lifetime in our model is from the smaller rate coefficient for dry removal. The total rate coefficient for wet removal is almost the same as that for dry removal in our model, but in the AeroCom models the dry removal rate coefficient is several times that of the wet removal rate coefficient. This may partly result from the smaller mass fraction $(9.2 \%)$ in the supercoarse mode (radius $>2.5 \mu \mathrm{m}$ ) in our model. The mass fraction for sea salt above $5 \mathrm{~km}$ is $2.54 \%$ compared to $8.65 \%$ in the AeroCom models and the mass fraction at the poles is $0.86 \%$ compared to $3.32 \%$ in the AeroCom models.

\subsection{Global and Vertical Distributions}

[38] Figures 1 and 2show the vertically integrated annual mean mass concentrations and zonal averaged annual mean mass concentrations for sulfate, $\mathrm{OM}, \mathrm{BC}$, dust and sea salt aerosols. The dominant contributions to the burden and concentrations of total sulfate come from anthropogenic sources which are mainly located in the industrial regions in the Northern Hemisphere (NH). As a secondary aerosol, the sulfate concentrations extend further north than the primary particles (OM, BC, dust and sea salt). Carbonaceous aerosols show strong contributions from both biomass burning emissions (e.g., central Africa, Central and South America, and Australia) and fossil fuel emissions (e.g., China, India, Turkey, and eastern Europe). The vertical transport of carbonaceous aerosols is efficient, in part because of the uniform injection of biomass burning carbonaceous aerosols in the boundary layer and in part because they are smaller than dust and sea salt aerosols and do not experience as much gravitational settling. They also show strong transport toward the poles in the middle troposphere, which results in higher concentration in the middle troposphere than in the lower

Table 6. Global Budget for Sea Salt

\begin{tabular}{|c|c|c|c|c|c|c|c|c|}
\hline & \multicolumn{5}{|c|}{ This Study } & \multicolumn{3}{|c|}{ AeroCom Total } \\
\hline & $0.05-0.63$ & $0.63-1.25$ & $1.25-2.50$ & $2.50-10.0$ & Total & Mean $^{\mathrm{a}}$ & Median $^{\mathrm{b}}$ & $\mathrm{SD}^{\mathrm{c}}$ \\
\hline Emission $\left(\mathrm{Tg} \mathrm{a}^{-1}\right)$ & 114.18 & 437.71 & 947.62 & 1097.90 & 2597.41 & 166000.00 & 6280.00 & 199 \\
\hline Burden $(\mathrm{Tg})$ & 0.43 & 1.59 & 2.62 & 0.47 & 5.10 & 7.52 & 6.37 & 54 \\
\hline Fine mass ${ }^{\mathrm{d}}(\%)$ & - & - & - & - & 4.79 & 14.60 & 8.72 & 118 \\
\hline Above $5 \mathrm{~km}(\%)$ & 3.45 & 3.15 & 2.39 & 0.49 & 2.54 & 8.65 & 6.94 & 92 \\
\hline In polar ${ }^{\mathrm{e}}(\%)$ & 1.26 & 1.13 & 0.78 & 0.07 & 0.86 & 3.32 & 1.88 & 140 \\
\hline Lifetime (days) & 1.37 & 1.32 & 1.01 & 0.16 & 0.71 & 0.48 & 0.41 & 58 \\
\hline Removal rate coefficient $\left(\mathrm{d}^{-1}\right)$ & 0.73 & 0.76 & 0.99 & 6.35 & 1.39 & 5.07 & 2.50 & 188 \\
\hline Wet & 0.65 & 0.66 & 0.70 & 1.09 & 0.72 & 0.79 & 0.68 & 77 \\
\hline Dry & 0.08 & 0.10 & 0.29 & 5.26 & 0.67 & 4.28 & 1.40 & 219 \\
\hline Wet $(\%)$ & 89.16 & 87.27 & 71.02 & 17.20 & 51.80 & 30.50 & 30.30 & 65 \\
\hline
\end{tabular}

${ }^{\mathrm{a}}$ The mean value from available models in AeroCom [see Textor et al., 2006, Table 10].

${ }^{\mathrm{b}}$ The median value from available models in AeroCom [see Textor et al., 2006, Table 10].

${ }^{\mathrm{c}}$ The standard deviation normalized by the all models average in the percentage in AeroCom [see Textor et al., 2006, Table 10].

${ }^{\mathrm{d}}$ Particles with size less than $0.5 \mu \mathrm{m}$ in radius.

${ }^{\mathrm{e}}$ South of $80^{\circ} \mathrm{S}$ and north of $80^{\circ} \mathrm{N}$. 

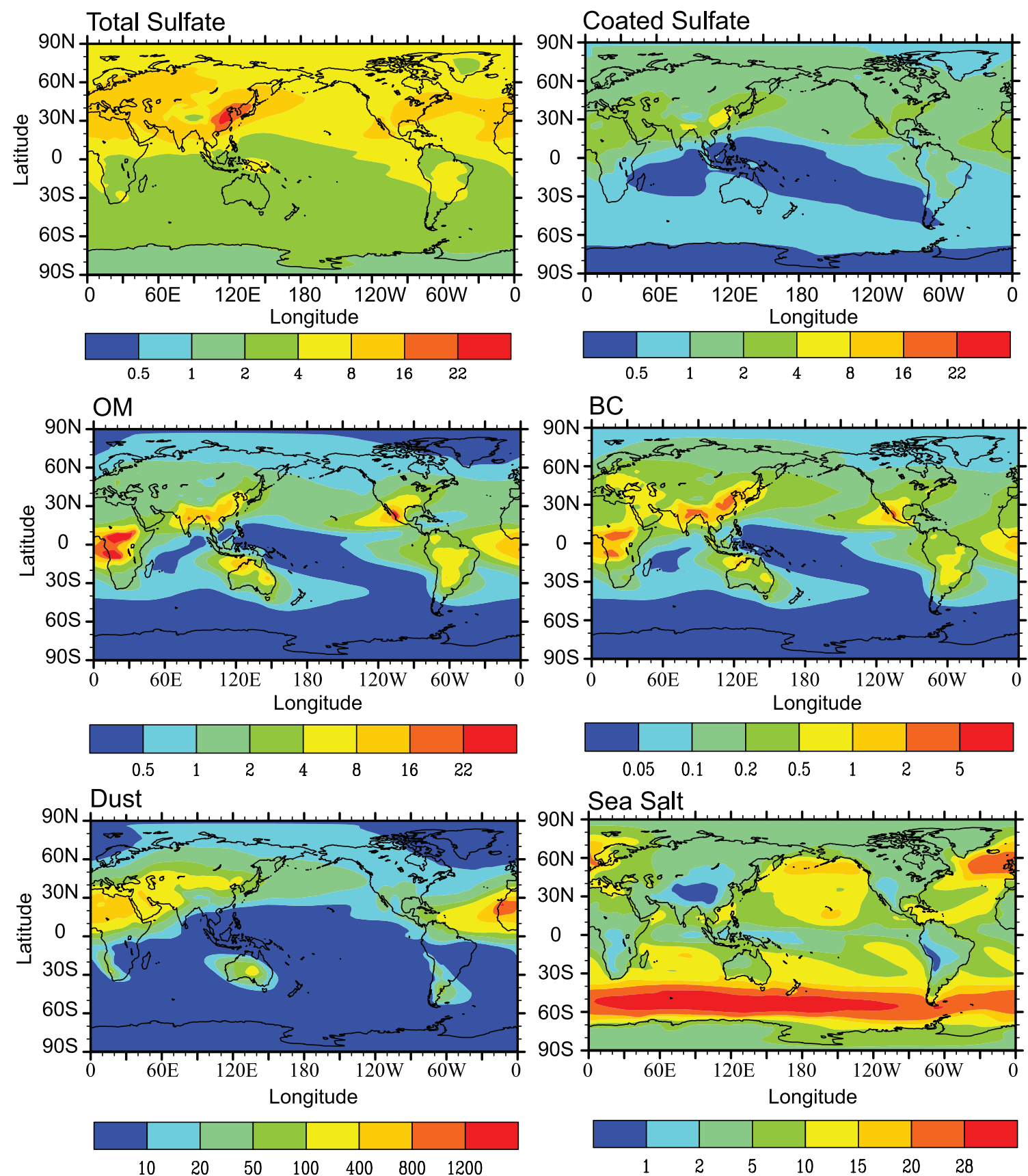

Figure 1. Vertically integrated annual mean concentrations $\left(\mathrm{mg} \mathrm{m}^{-2}\right)$ of total sulfate, sulfate associated with nonsulfate aerosols, OM, BC, dust, and sea salt predicted by the model.

troposphere over polar regions. Dust aerosol shows a distinct maximum extending from sources in the African Sahara toward the Atlantic Ocean and Central America, and a second maximum extending from the middle of Asia toward the North Pacific. Dust also has strong vertical transport. Sea salt aerosol shows large concentrations over the storm tracks in the middle latitudes of both hemispheres where surface wind speeds are large. Its concentration decays rapidly with altitude, in part because of the large settling velocity of these aerosols as well as their effective wet removal. Sulfate aerosol coated on nonsulfate aerosols depends on the concentrations of both sulfuric acid gas and nonsulfate aerosols. It is not surprising that the amount of sulfate aerosol coated on nonsulfate aerosols is large over east Asia, India, North Africa, the eastern United States, and the $60^{\circ} \mathrm{S}$ latitude belt, where the concentrations of both nonsulfate aerosols and sulfuric acid gas concentrations are large.

[39] Figure 3 shows the model predicted zonal mean number concentrations of pure sulfate aerosol in the nucleation/ Aitken and accumulation modes in January and July. There is a distinct maximum in the number concentration of the nucleation/Aitken mode in the tropical upper troposphere in both January and July. This maximum results from strong nucleation events in the upper troposphere, due to the favorable conditions there (very low temperature and low preexisting aerosol surface area [see Liu and Penner, 

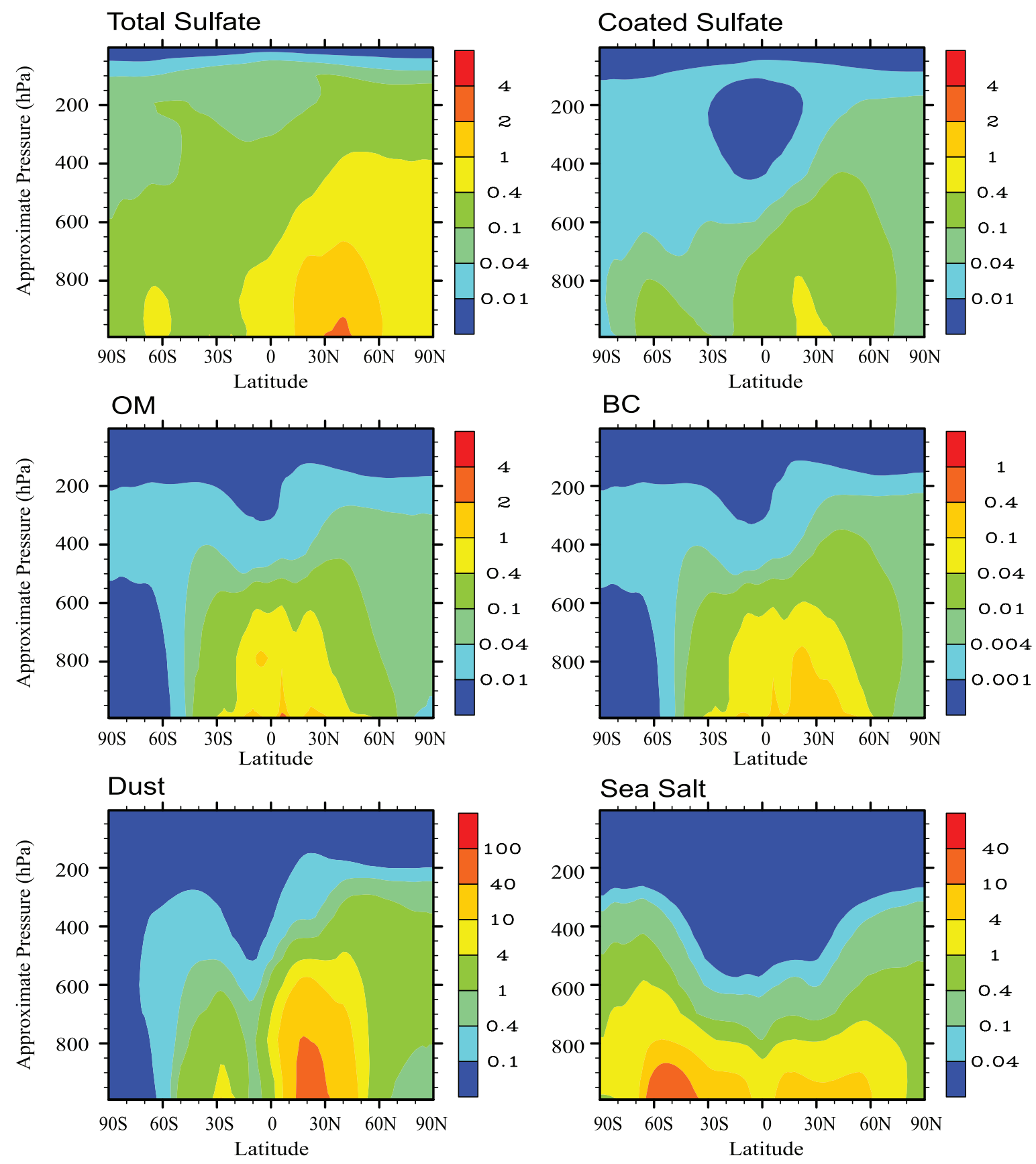

Figure 2. Annual averaged zonal mean concentration $\left(\mu \mathrm{g} \mathrm{m}^{-3}\right)$ of total sulfate, sulfate associated with nonsulfate aerosols, OM, BC, dust, and sea salt predicted by the model. CAM3 used a hybrid vertical coordinate and the pressure at the $k$ th model level is given by $p(k)=A(k) p_{0}+B(k) p_{s}$, where $p_{s}$ is surface pressure, $p_{0}$ is a specified constant pressure $(1000 \mathrm{hPa})$, and $A$ and $B$ are coefficients. Data are plotted as a function of this hybrid vertical coordinate times 1000 and labeled "Approximate Pressure."

2002]). Another maximum can be seen at NH middle latitudes in the region close to the surface, which is due to the direct emission of primary sulfate from anthropogenic sources. The depletion of aerosol particles in the nucleation/ Aitken mode in the lower troposphere of the Southern Hemisphere (SH) near $60^{\circ} \mathrm{S}$ comes from the scavenging of $\mathrm{H}_{2} \mathrm{SO}_{4}$ gas and the coagulation of nucleation/Aitken mode particles with sea salt particles which have large concentrations there (Figures 1 and 2). Large concentrations in the accumulation mode in the $\mathrm{NH}$ lower troposphere come from the direct primary emissions of anthropogenic sulfate particles, and from the growth of particles in the nucleation/ Aitken mode.

\section{Comparison With Observations: Aerosol Mass 5.1. Surface Observations}

[40] Figure 4 shows the simulated monthly average sulfate concentrations at 9 selected sites. At $\mathrm{SH}$ high latitudes (Mawson, Antarctica), the model reproduces the 

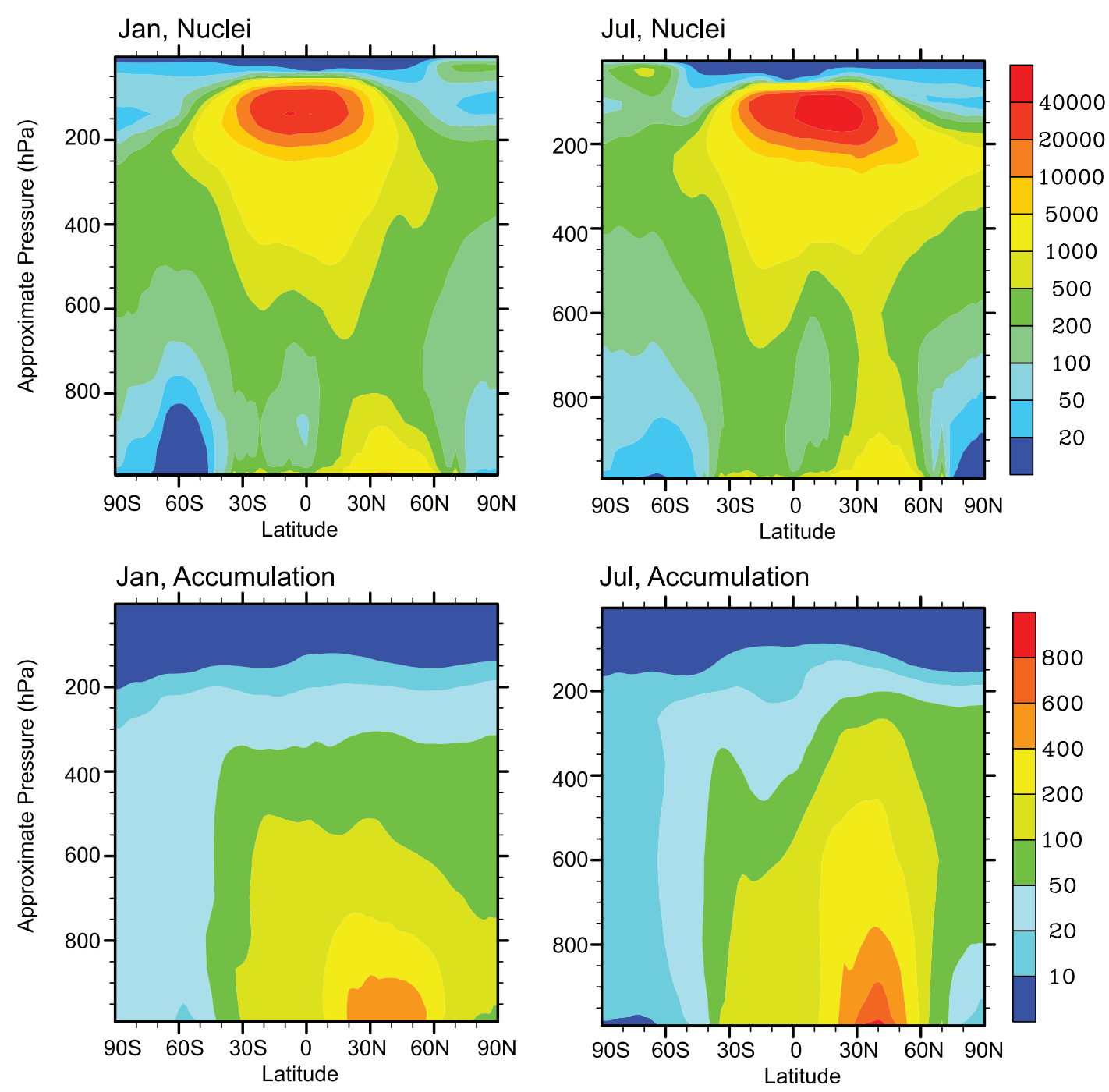

Figure 3. Model predicted zonal mean number concentration (number $\mathrm{cm}^{-3}$ ) of pure sulfate aerosol in the (top) nuclei and (bottom) accumulation mode in (right) January and (left) July. Approximate pressure is defined in Figure 2 caption.

observed seasonal cycle, but it overestimates the sulfate concentration in summer, which may be due to the high DMS emissions used in the model [see also Liu et al., 2005]. The observed sulfate concentrations are reproduced well at Chatham Island, New Zealand. At Cape Point, South Africa, the model overestimates sulfate concentrations in spring, but reproduces observations well in other months. At Reunion Island, the model underestimates sulfate concentrations in the fall and winter. At Ragged Point, Barbados, the model reproduces the seasonal cycle with a peak in the summer. At Bermuda, the model underestimates sulfate concentrations in spring and summer, which may be caused by a bias in the westward transport in the CAM model, since concentrations at Bermuda are primarily associated with the transport of sulfate and precursors from North America [Savoie et al., 2002]. Hurrell et al. [2006] showed that summertime NH tropical easterlies in CAM3 are too strong (by $\sim 4 \mathrm{~m} \mathrm{~s}^{-1}$ ) and extend too far poleward, which may lead to the bias in the westward transport in the subtropics over the eastern United States. At Midway Island, in the Pacific Ocean, the model reproduces sulfate concentrations well. At the two high-latitude sites (Mace Head, Ireland; Heimaey, Iceland), the model reproduces the seasonal cycle reasonably well. The peak value in the summer is from the transport of pollution from Europe.

[41] Figure 5 shows the simulated monthly average concentrations of $\mathrm{BC}$ at selected sites. At high-latitude sites (South Pole; Halley, Antarctica; Barrow, Alaska; Albert, Canada), the model largely underestimates the BC concentrations. This underestimation is consistent with the smaller mass fractions in the polar regions compared to other models that was presented in section 4 and can be due to the larger wet scavenging efficiency of $\mathrm{BC}$ in the model together with possible stronger precipitation or weaker poleward transport. At Jungfraujoch, Switzerland, the model reproduces the observations well. At Amsterdam Island, the model underestimates the $\mathrm{BC}$ concentration. At Mace Head, Ireland, the model also underestimates the $\mathrm{BC}$ concentration except in the summer. At Mauna Loa, Hawaii, which is located in the lower free troposphere, the simulated $\mathrm{BC}$ concentration is reasonable in winter, but is overestimated in summer. The global distribution shows that this overestimation in summer 


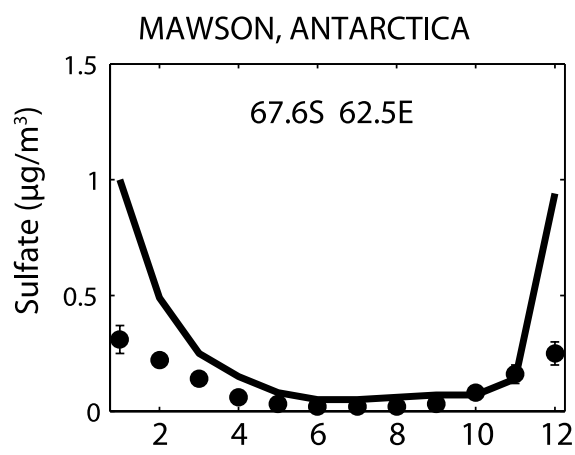

CHATHAM ISL., NEW ZEALAND
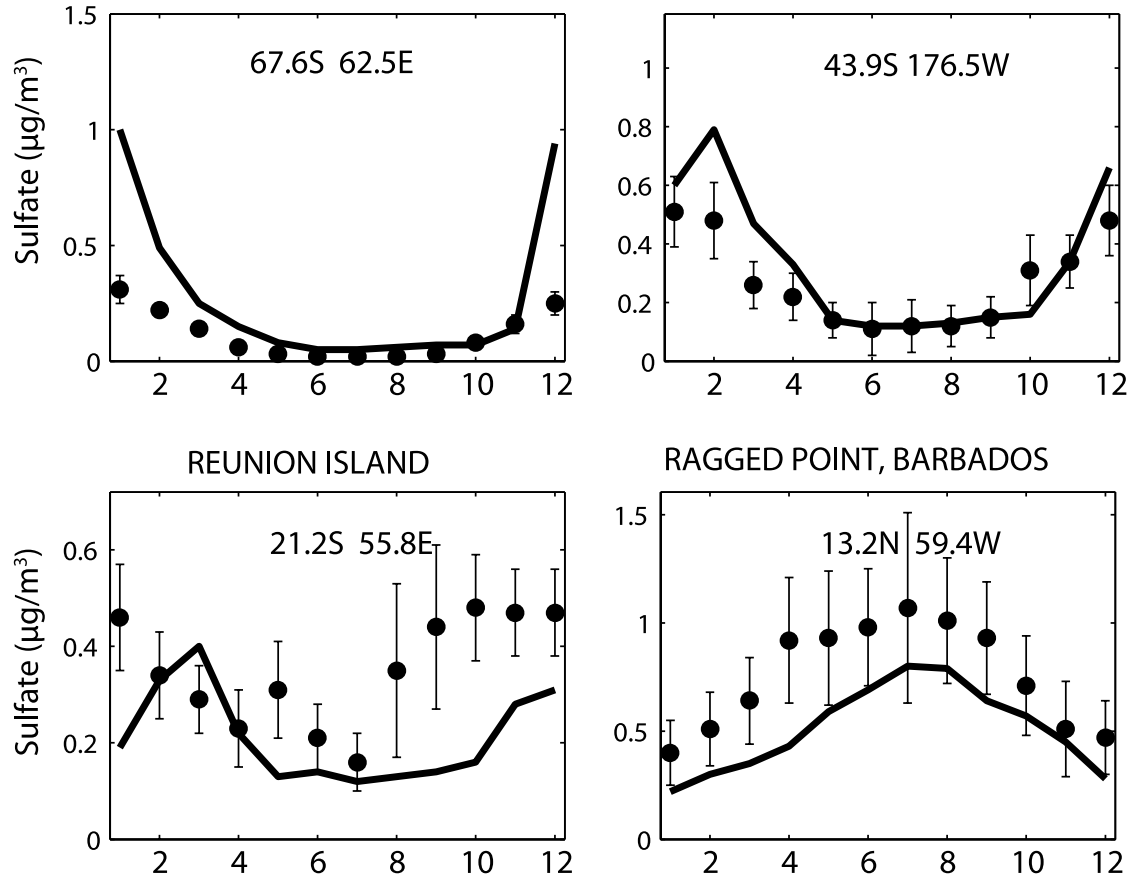

BERMUDA

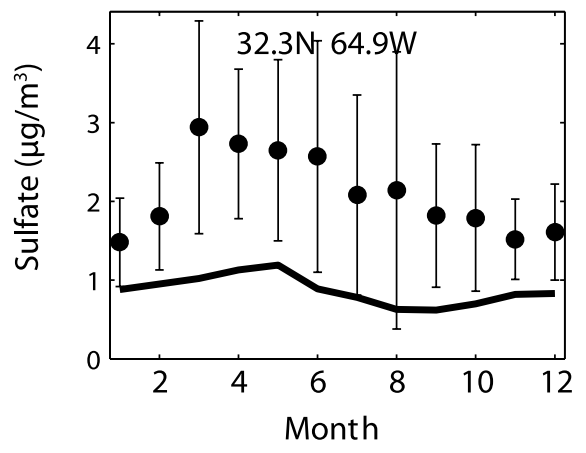

\section{RAGGED POINT, BARBADOS}

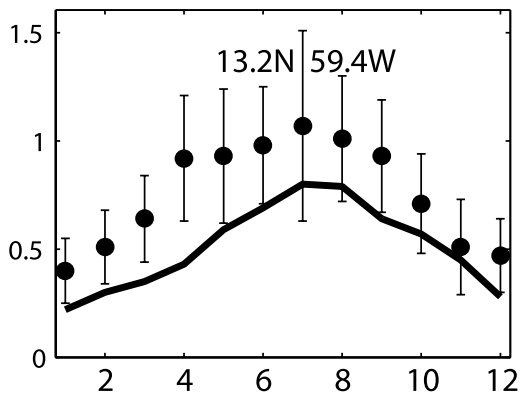

MACE HEAD, IRELAND

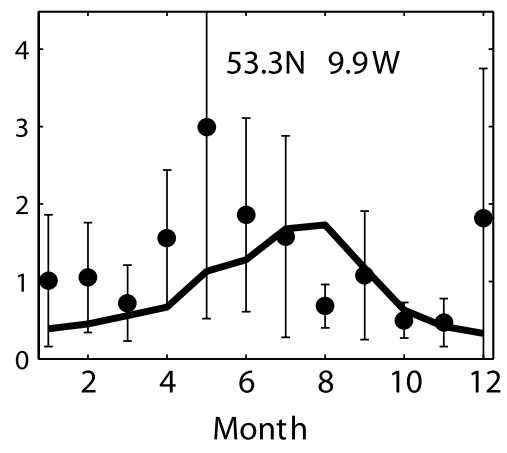

CAPE POINT, S. AFRICA

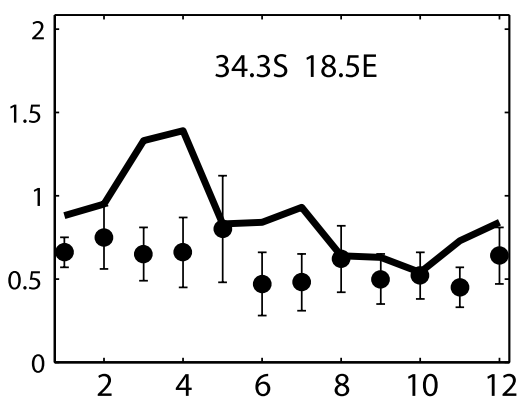

MIDWAY ISLAND

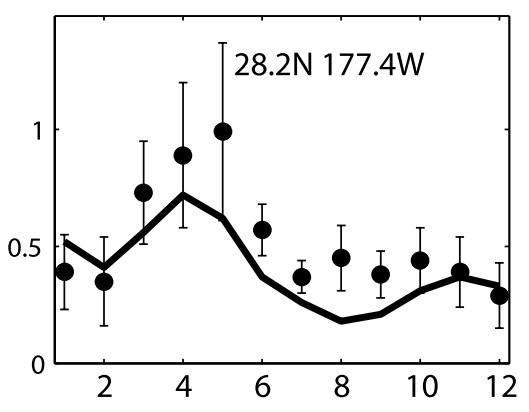

HEIMAEY, ICELAND

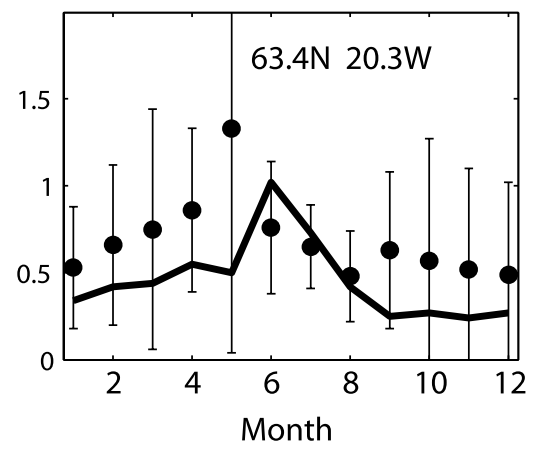

Figure 4. Monthly average sulfate concentration at selected sites that are part of an ocean network operated by a group at the University of Miami [Prospero et al., 1989; Arimoto et al., 1996; Savoie et al., 1989, 1993]. Model results are in solid lines, and observed data are in dots with one standard deviation.

comes from the very strong biomass burning emissions in Central America. The overestimation may also come from the tropical easterly winds which are too strong (by $\sim 4 \mathrm{~m} \mathrm{~s}^{-1}$ ) in CAM3 [Hurrell et al., 2006].

[42] Figure 6 shows a scatterplot of the annual average simulated and observed OC and BC for 3 years (from March 1996 to February 1999) from 48 sites in the Interagency Monitoring of Protected Visual Environments (IMPROVE) network [Malm et al., 2000]. The simulated concentrations at most sites are within a factor of 2 of the observed concentrations. However, the model generally underestimates the concentrations of both $\mathrm{BC}$ and $\mathrm{OC}$, a feature which also appears in other models [e.g., Easter et al., 2004; Chung and Seinfeld, 2002].

[43] Figures $7 \mathrm{a}-7 \mathrm{~h}$ show the monthly average sea salt concentrations at eight selected sites. The model represents the NH sites well compared with observations. At high latitudes (Mace Head, Ireland and Heimaey, Iceland), the model captures the observed seasonal variations with a maximum in winter and a minimum in summer. But the model underestimates the maximum sea salt concentrations in winter at Heimaey, Iceland and therefore underestimates the seasonal variation. At the midlatitude sites, Cheju and Bermuda, the model reproduces the seasonal variation of the observations, but it underestimates the magnitude of sea salt concentrations. In the SH, at Cape Point, South Africa, the model reproduces the observed sea salt concentrations reasonably well, but it overestimates the sea salt concentrations at Invercargill, New Zealand. As shown below, this overestimation is mainly caused by coarse sea salt particles. At Mawson, Antarctica, the model also overestimates the concentration, especially during the Southern Hemisphere winter.

[44] Although the coarse mode accounts for most of the sea salt mass, sea salt in the fine mode has the most important contribution to the number of $\mathrm{CCN}$ and to the light scattering by the aerosol. Figure $7 \mathrm{i}$ compares the simulated monthly average sea salt concentration in the fine 
(a) SOUTH POLE

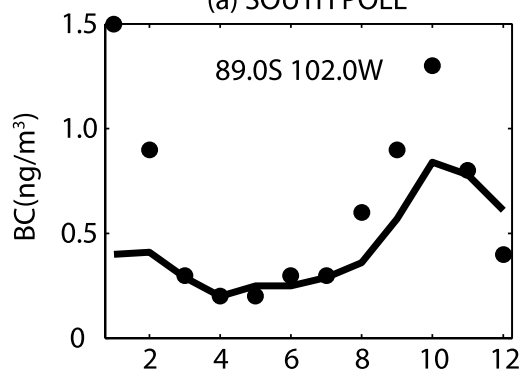

(d) MAUNA LOA, HAWAI

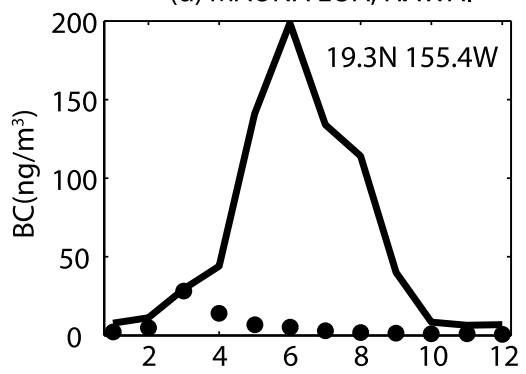

(g) BARROW, ALASKA

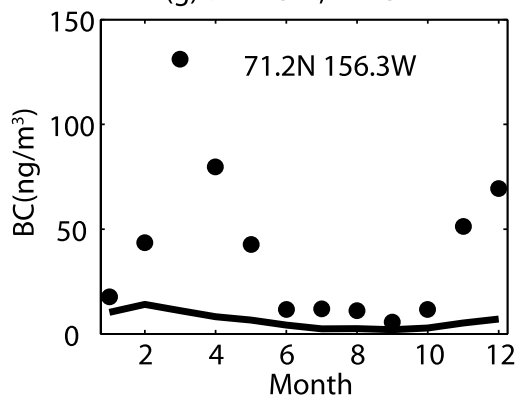

(b) HALLEY, ANTARCTICA

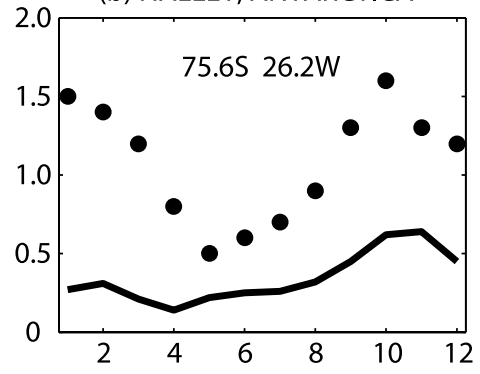

(e) JUNGFRAUJOCH, SWITZERLAND

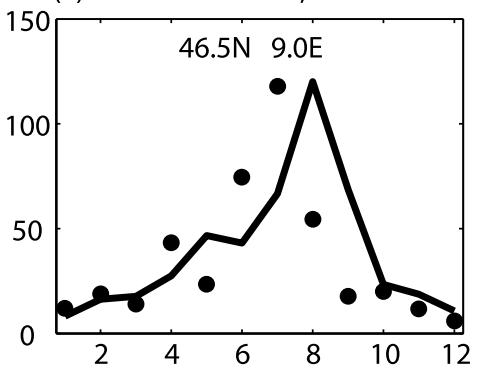

(h) ALBERT, CANADA

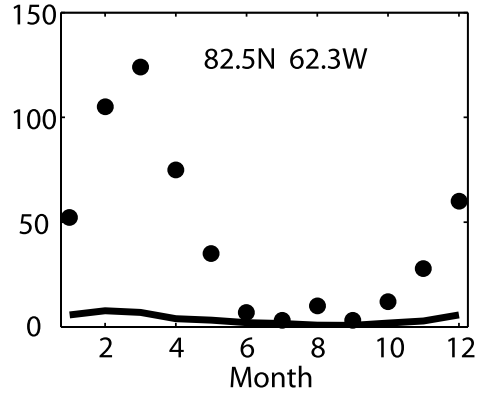

(c) AMSTERDAM ISLAND

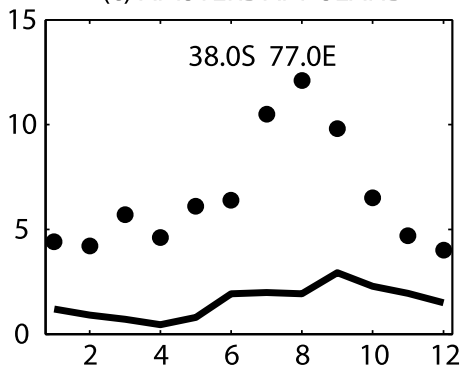

(f) MACE HEAD, IRELAND

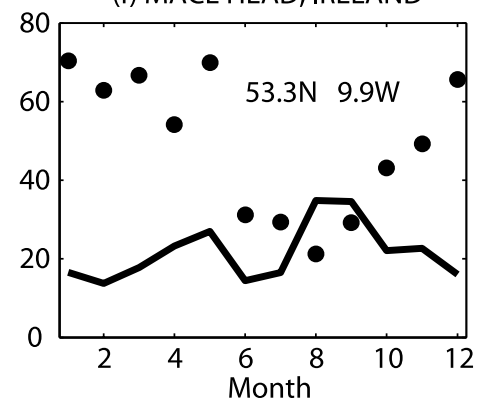

Figure 5. BC concentration at various sites [Liu et al., 2005]: (a) Amundsen-Scott, South Pole [Bodhaine, 1995], (b) Halley, Antarctica [Wolff and Cachier, 1998], (c) Amsterdam Island, France [Wolff and Cachier, 1998], (d) Mauna Loa, Hawaii (3.4 km above sea level) [Bodhaine, 1995], (e) Jungfraujoch, Switzerland (3.5 km above sea level) [Nyeki et al., 1998], (f) Mace Head, Ireland [Cooke et al., 1997], (g) Barrow, Alaska [Bodhaine, 1995], (h) Alert, Canada [Hopper et al., 1994]. Model results are in solid lines, and observed data are in dots.

mode (with diameter $<1.5 \mu \mathrm{m}$ ) with observations at Mace Head, Ireland [Yoon et al., 2007]. The model reproduces the observed seasonal variation well, with a maximum in winter and a minimum in summer. But the model overestimates the magnitude of the fine mode sea salt aerosol, especially in summer, where the model predicts values that are two or three times larger than the observations.

[45] Table 7 compares the simulated and observed fine and coarse mode sea salt mass concentrations at several locations. In the $\mathrm{SH}$ middle to high latitudes, the model is in good agreement with observations for the fine mode (RIST 93 South, RIST 94 South, and ACE-1). In tropical regions, the model underestimates observed fine mode sea salt concentrations by a factor 2 or 3 (RIST93 Tropical, RIST 94 Tropical, and MAGE 92), but it is within one standard deviation of the observations. It also underestimates the fine mode sea salt concentrations in the NH middle latitudes, but to a lesser extent. In the $\mathrm{SH}$ middle latitudes, the model also underestimates the observed fine mode sea salt concentrations (Cape Grim JJA, Cape Grim DJF). The model overestimates the coarse mode sea salt concentrations in the $\mathrm{SH}$ middle to high latitudes, consistent with its overestimation of the total sea salt concentrations (Figure 7).

[46] Figure 8 compares the simulated and observed total monthly averaged dust concentrations at nine selected sites. At Mawson, Antarctica, the model reproduces the concentrations during winter months, but it underestimates dust concentrations during the summer, which was also true for BC concentrations. At Cape Grim, which is located southeast of the dust source in Australia, the model is not able to simulate the seasonal cycle. The largest dust concentrations in the model occur during the winter, whereas the observations have a minimum concentration at that time. At New Caledonia, downwind of the dust source in Australia, the modeled seasonal cycle is reasonable, although the concentration in September is still overestimated. At Cape Point, South Africa, which is located at the southern most tip of the African dust source, the model simulates the seasonal cycle reasonably well, but it overestimates dust concentrations. At Tenerife, which is close to the Saharan dust source, the model 

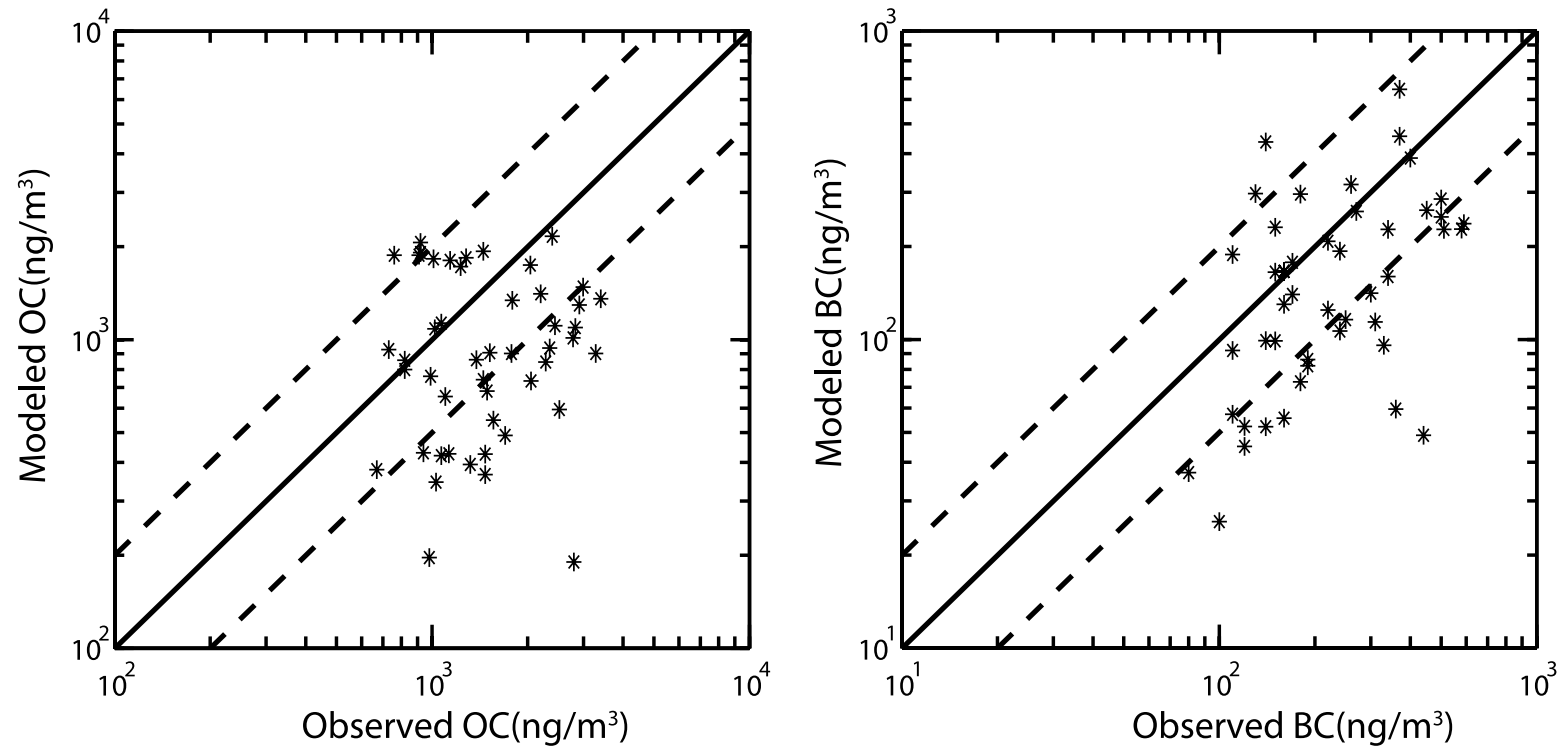

Figure 6. Annual average simulated $\mathrm{OC}$ and $\mathrm{BC}$ concentrations versus observations from the IMPROVE network. The solid lines are 1:1, and the dashed lines are 2:1 or 1:2.

(a) MAWSON, ANTARCTICA

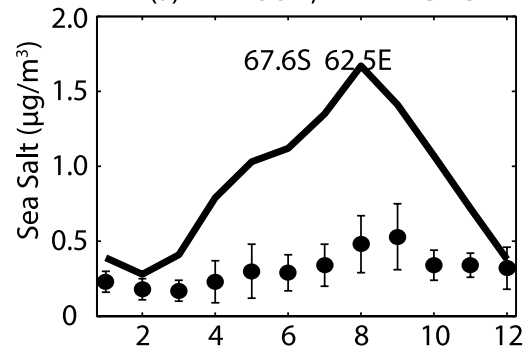

(d) OAHU, HAWAII

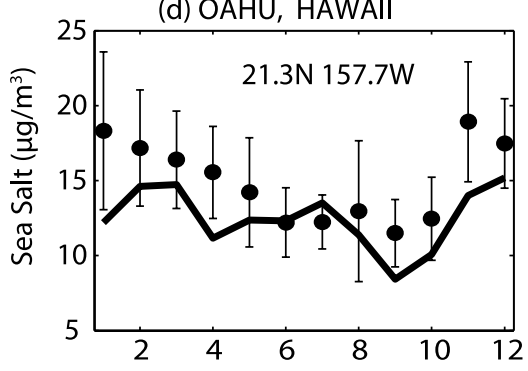

(g) MACE HEAD, IRELAND

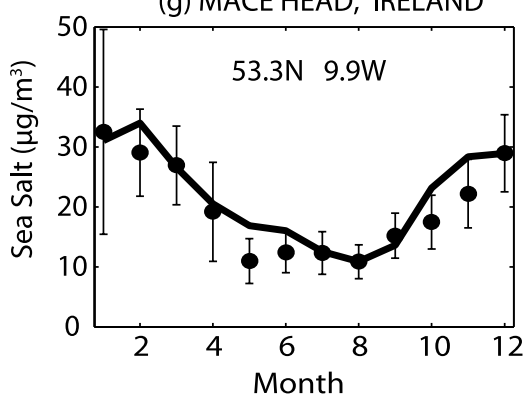

(b) INVERCARGILL, NEW ZEALAND

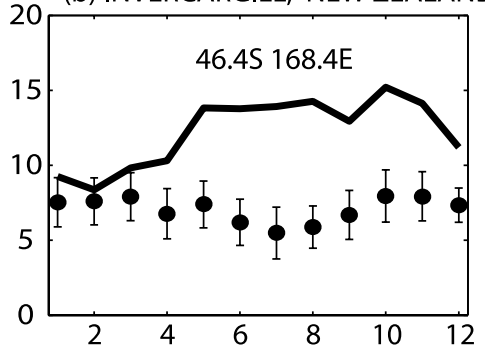

(e) BERMUDA
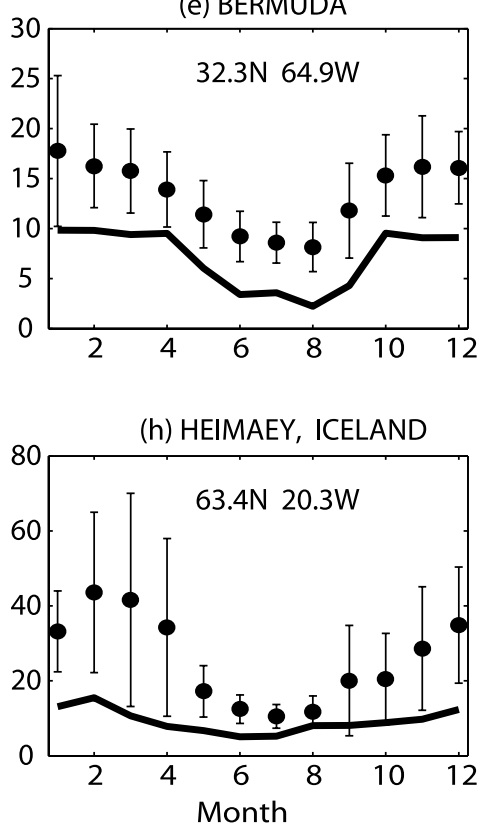

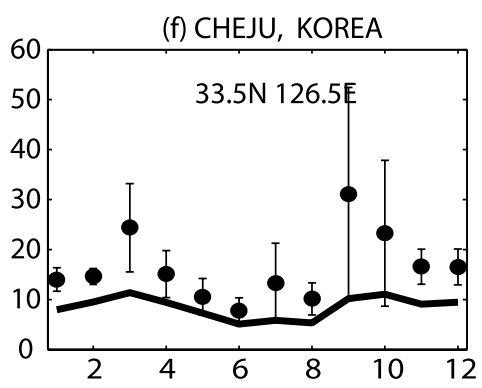

(i) Fine particles MACE HEAD

(c) CAPE POINT, SOUTH AFRICA

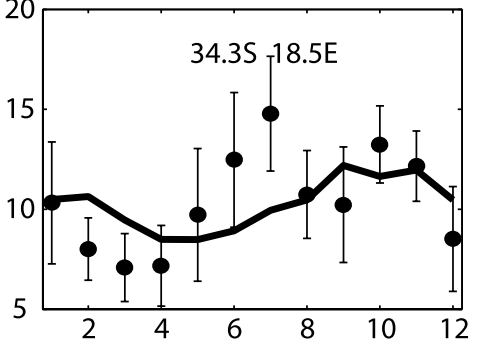

(f) CHEJU, KOREA

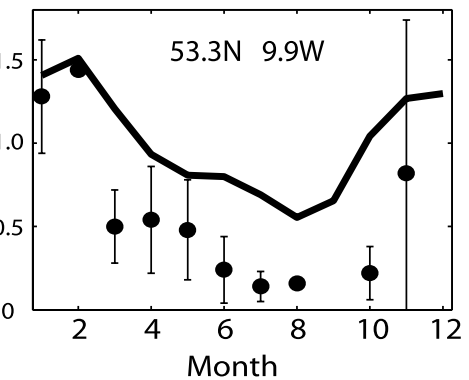

Figure 7. $(\mathrm{a}-\mathrm{h})$ Monthly average total sea salt concentrations at selected sites that are part of an ocean network operated by a group at the University of Miami [Prospero et al., 1989; Arimoto et al., 1996; Savoie et al., 1989, 1993]; (i) monthly fine sea salt particles $(\mathrm{d}<1.5 \mu \mathrm{m})$ at Mace Head, Ireland [Yoon et al., 2007]. Model results are in solid lines, and observed data are in dots with one standard deviation. 
Table 7. Simulated and Observed Fine and Coarse Mode Sea Salt Aerosols ${ }^{\mathrm{a}}$

\begin{tabular}{|c|c|c|c|c|c|c|}
\hline & \multirow[b]{2}{*}{ Location } & \multirow[b]{2}{*}{ Time } & \multicolumn{2}{|c|}{$\begin{array}{l}\text { Fine Particles } \\
(\mathrm{d}<1.4 \mu \mathrm{m})^{\mathrm{b}}\end{array}$} & \multicolumn{2}{|c|}{$\begin{array}{l}\text { Coarse Particles } \\
(\mathrm{d}>1.4 \mu \mathrm{m})^{\mathrm{b}}\end{array}$} \\
\hline & & & Model & Observations & Model & Observations \\
\hline \multirow[t]{3}{*}{ RITS $1993^{c}$} & $70^{\circ} \mathrm{S}-40^{\circ} \mathrm{S}, 80^{\circ} \mathrm{W}-140^{\circ} \mathrm{W}$ & Mar-May & 0.83 & $0.84 \pm 0.64$ & 19.49 & $4.8 \pm 2.3$ \\
\hline & $20^{\circ} \mathrm{S}-20^{\circ} \mathrm{N}, 140^{\circ} \mathrm{W}$ & Mar-May & 0.23 & $0.56 \pm 0.50$ & 7.11 & $7.4 \pm 3.8$ \\
\hline & $30^{\circ} \mathrm{N}-54^{\circ} \mathrm{N}, 140^{\circ} \mathrm{W}$ & Mar-May & 0.45 & $0.84 \pm 0.96$ & 11.74 & $7.3 \pm 4.6$ \\
\hline \multirow[t]{3}{*}{ RITS $1994^{\mathrm{c}}$} & $70^{\circ} \mathrm{S}-40^{\circ} \mathrm{S}, 80^{\circ} \mathrm{W}-140^{\circ} \mathrm{W}$ & Nov-Dec & 0.80 & $0.7 \pm 0.31$ & 16.96 & $5.0 \pm 2.0$ \\
\hline & $20^{\circ} \mathrm{S}-20^{\circ} \mathrm{N}, 140^{\circ} \mathrm{W}$ & Nov-Dec & 0.26 & $0.82 \pm 0.90$ & 8.31 & $8.8 \pm 2.6$ \\
\hline & $30^{\circ} \mathrm{N}-54^{\circ} \mathrm{N}, 140^{\circ} \mathrm{W}$ & Nov-Dec & 0.54 & $0.71 \pm 0.15$ & 15.40 & $5.3 \pm 2.5$ \\
\hline MAGE $1992^{c}$ & $12^{\circ} \mathrm{S}-20^{\circ} \mathrm{N}, 140^{\circ} \mathrm{W}$ & Feb-Mar & 0.28 & $0.75 \pm 0.55$ & 8.55 & $12.0 \pm 6.0$ \\
\hline PSI $1991^{\mathrm{c}}$ & $48^{\circ} \mathrm{N}, 127^{\circ} \mathrm{W}$ & Apr-May & 0.36 & $0.33 \pm 0.29$ & 9.85 & $3.3 \pm 2.3$ \\
\hline ACE-1 $1995^{\mathrm{c}}$ & $46^{\circ} \mathrm{S}, 110^{\circ} \mathrm{W}$ & Nov-Dec & 0.72 & $1 \pm 0.56$ & 20.09 & $9.3 \pm 5.4$ \\
\hline \multirow{2}{*}{ Cape Grim $1988-1990^{\mathrm{d}}$} & $41^{\circ} \mathrm{S}, 145^{\circ} \mathrm{E}$ & Jun-Aug & 0.43 & 1.4 & 13.14 & 17.5 \\
\hline & $41^{\circ} \mathrm{S}, 145^{\circ} \mathrm{E}$ & $\mathrm{Dec}-\mathrm{Feb}$ & 0.36 & 1.09 & 9.80 & 13.7 \\
\hline
\end{tabular}

${ }^{\mathrm{a}}$ Units of $\mu \mathrm{g} \mathrm{m}^{-3}$

${ }^{\mathrm{b}}$ Wet size at $70 \%$ relative humidity.

${ }^{\mathrm{c}}$ From Quinn and Coffman [1999].

${ }^{\mathrm{d}}$ From Andreae et al. [1999].

overestimates dust concentrations in the summer months (June-August) but simulates the observed concentrations well in other months. At downwind sites from the African dust source (Barbados and University of Miami), the model reproduces the seasonal cycle in the dust concentration: high concentrations in summer months, and lower concentrations in winter months. At sites downwind of the Asian dust source (Cheju, Korea, and Oahu, Hawaii), the model simulates the
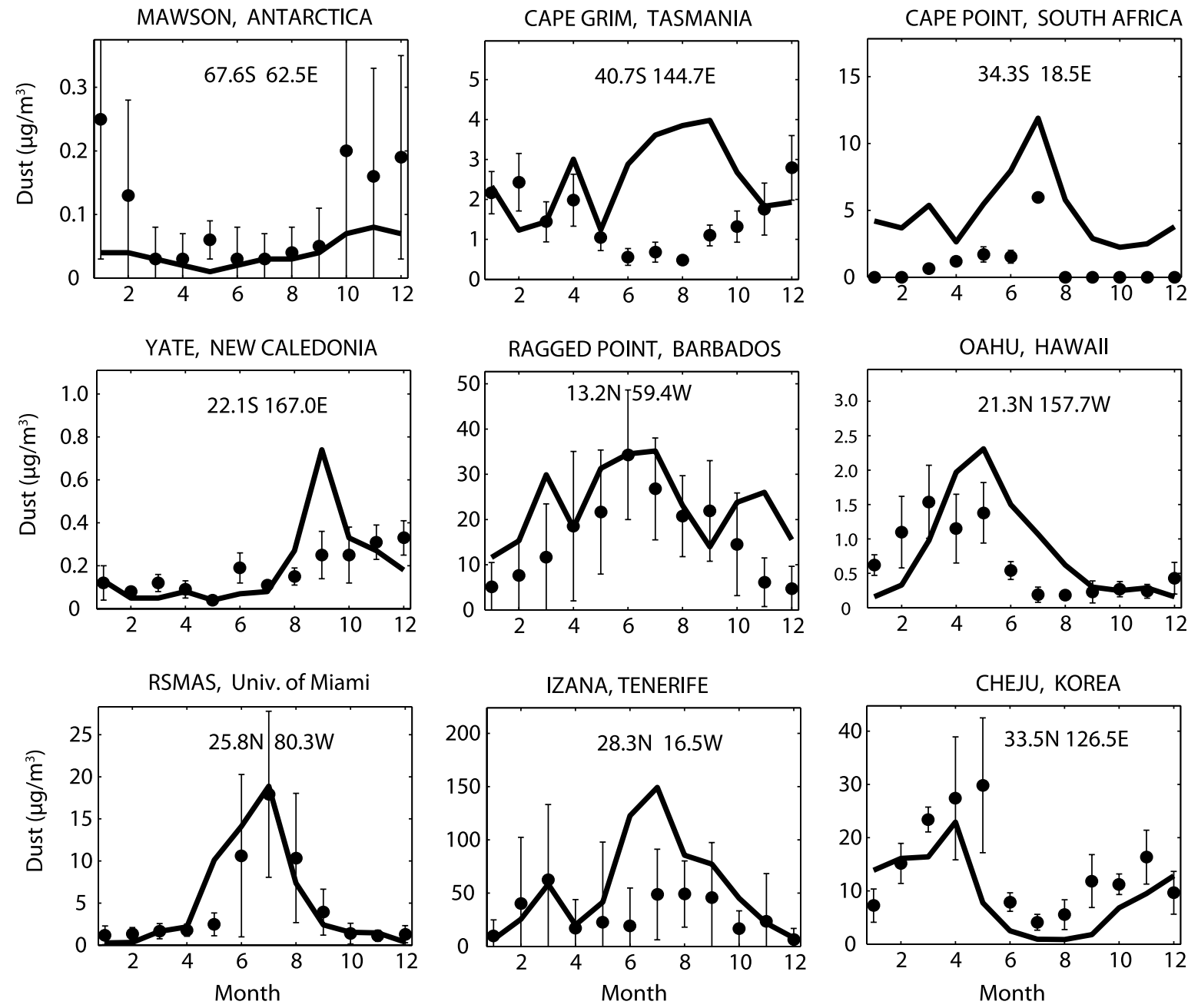

Figure 8. Monthly average dust concentration at selected sites that are part of an ocean network operated by a group at the University of Miami [Prospero et al., 1989; Arimoto et al., 1996; Savoie et al., 1989, 1993]. Model results are in solid lines, and observed data are in dots with one standard deviation. 
(a) Florida

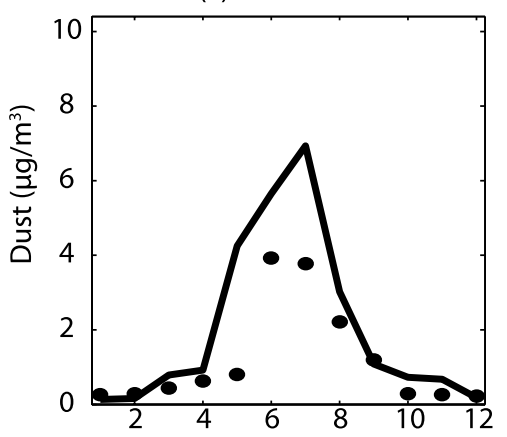

(d) Midwest

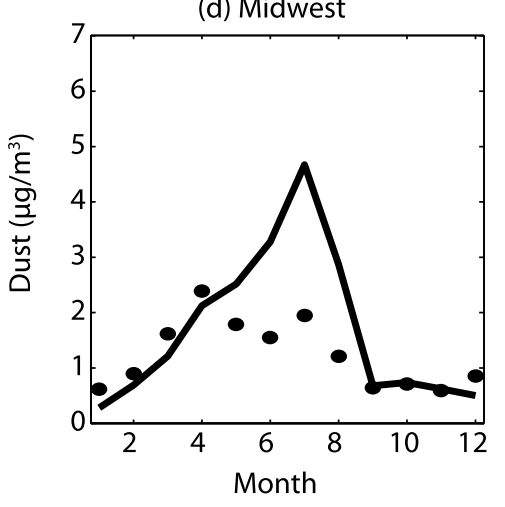

(b) Alaska

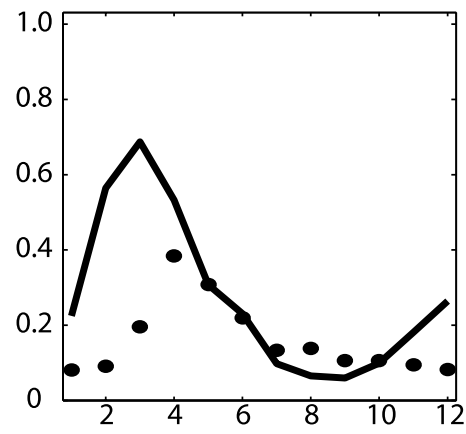

(e) West NA

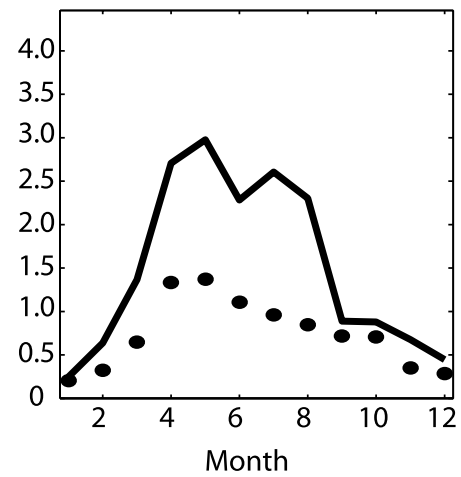

(c) Hawaii

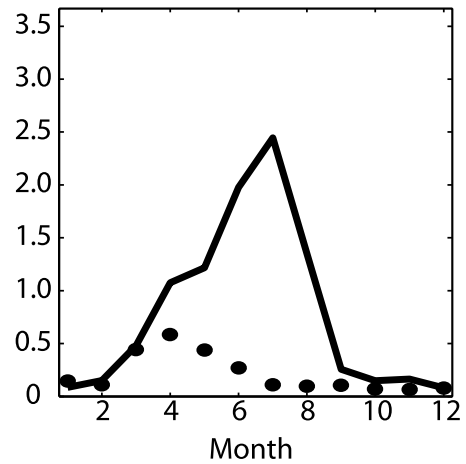

Figure 9. Monthly average fine mode dust concentration $(\mathrm{d}<2.5 \mu \mathrm{m})$ at the IMPROVE network stations listed in Table 8. (a) Florida $\left(80.68^{\circ} \mathrm{W}, 25.39^{\circ} \mathrm{N}\right.$, at surface); (b) Alaska $\left(148.97^{\circ} \mathrm{W}, 63.72^{\circ} \mathrm{N}\right.$, $658 \mathrm{~m})$; (c) Hawaii $\left(156-155^{\circ} \mathrm{W}, 19.5^{\circ} \mathrm{N}, 1258-3439 \mathrm{~m}\right)$; (d) midwest North America $\left(105-100^{\circ} \mathrm{W}\right.$, $\left.28-44^{\circ} \mathrm{N}, 736-1672 \mathrm{~m}\right)$; and (e) western North America $\left(120-105^{\circ} \mathrm{W}, 28-44^{\circ} \mathrm{N}, 1000-3000 \mathrm{~m}\right)$.

observed maximum in the spring. At Cheju, it reproduces the observed dust concentrations in winter, but underestimates somewhat the dust concentrations in other months. At Oahu, it overestimates the observed dust concentrations from May to August.

[47] Figure 9 shows the monthly average dust concentrations in the fine mode (with radius $<1.25 \mu \mathrm{m}$ ) compared to observations in five regions of the United States (as defined in Table 8) from the IMPROVE network. Overall, the model captures the seasonal variation of observed dust concentrations, but there are some months in which the model overestimates the fine dust concentration. In Florida, the model reproduces the peak concentration in summer, which is associated with the African dust source. In Alaska, the model overestimates the dust concentrations in winter and spring. In Hawaii, the model simulates well the observed concentrations in winter, but overestimates the concentrations in summer. Moreover, the peak concentration occurs in summer rather than in spring as observed. As noted previously, the easterlies in the CAM3 model are too far north and too strong [Hurrell et al., 2006], and this causes a maximum in the concentrations of dust in summer in Hawaii from sources in Africa and North America. In the midwestern United States and in western North America, the observations have their peak concentrations in spring, which may indicate the influence of the Asian dust source. Our model produces a peak concentration in the summer in the midwest and in April in western North America. The overestimation in the model is consistent with that found by Cakmur et al. [2006]. They suggested that the optimal fraction of fine particles (radius $<$ $1 \mu \mathrm{m})$ that fits observations best is lower than current model estimates.

\subsection{Vertical Profiles}

[48] Figure 10 compares vertical profiles of the total aerosol and $\mathrm{BC}$ mixing ratios over Houston, Texas, from observations [Schwarz et al., 2006] with monthly averaged data from the model in November. The observations took place on 10 November and 12 November 2004. A Single Particle Soot Photometer (SP2) was used to measure aerosol particles in the size range from 0.15 to $0.7 \mu \mathrm{m}$ volume equivalent diameter. Schwarz et al. [2006] scaled the raw observations of $\mathrm{BC}$ mass by a factor of 1.7. The factor of 1.7 is determined by comparing the normalized integral of the average size distribution measured by the SP2 with the normalized integral of the average size distribution from several other airborne campaigns, to determine the aerosol mass for the entire size spectrum. Both the BC mass mixing ratio and the total aerosol mass mixing ratio from the observations decrease strongly with altitude from the surface to the lower troposphere. The mixing ratios reach a minimum in the middle troposphere and increase slightly with altitude from the middle troposphere to the lower stratosphere.

[49] The model simulates a near constant mixing ratio for $\mathrm{BC}$ and total aerosol from the surface to $700 \mathrm{hPa}$ and a maximum in the $\mathrm{BC}$ mixing ratio from 700 to $800 \mathrm{hPa}$ which is not seen in the observations. Vertical profiles of the simulated individual aerosol components indicate that the 
Table 8. IMPROVE Sites Used in Figure 9

\begin{tabular}{|c|c|c|c|c|}
\hline Location $^{\mathrm{a}}$ & ID & Longitude & Latitude & Elevation $(\mathrm{m})$ \\
\hline \multicolumn{5}{|c|}{ Figure 9a, Florida } \\
\hline Everglades NP & Ever1 & $80.68 \mathrm{~W}$ & $25.39 \mathrm{~N}$ & 1 \\
\hline \multicolumn{5}{|c|}{ Figure 9b, Alaska } \\
\hline Denali NP & Dena1 & $148.97 \mathrm{~W}$ & $63.72 \mathrm{~N}$ & 650 \\
\hline \multicolumn{5}{|c|}{ Figure $9 c$, Hawaii } \\
\hline Hawaii Volcanoes NP & Havo1 & $155.26 \mathrm{~W}$ & $19.43 \mathrm{~N}$ & 1258 \\
\hline Mauna Loa Observatory 1 & Malo1 & $155.58 \mathrm{~W}$ & $19.54 \mathrm{~N}$ & 3439 \\
\hline Mauna Loa Observatory 2 & Malo2 & $155.58 \mathrm{~W}$ & $19.54 \mathrm{~N}$ & 3439 \\
\hline \multicolumn{5}{|c|}{ Figure 9d, Midwest } \\
\hline Badlands NP & badl1 & $101.9 \mathrm{~W}$ & $43.7 \mathrm{~N}$ & 736 \\
\hline Big Bend NP & bibe1 & $103.2 \mathrm{~W}$ & $29.3 \mathrm{~N}$ & 1066 \\
\hline Guadalupe Mountains NP & gumo1 & $104.8 \mathrm{~W}$ & $31.8 \mathrm{~N}$ & 1672 \\
\hline \multicolumn{5}{|c|}{ Figure 9e, Western North America } \\
\hline Bandelier NM & band1 & $106.3 \mathrm{~W}$ & $35.8 \mathrm{~N}$ & 1988 \\
\hline Bliss SP & blis 1 & $120.1 \mathrm{~W}$ & $39.0 \mathrm{~N}$ & 2130 \\
\hline Bryce Canyon NP & brcal & $112.2 \mathrm{~W}$ & $37.6 \mathrm{~N}$ & 2481 \\
\hline Bridger Wilderness & brid1 & $109.8 \mathrm{~W}$ & $43.0 \mathrm{~N}$ & 2626 \\
\hline Canyonlands NP & cany1 & $109.8 \mathrm{~W}$ & $38.5 \mathrm{~N}$ & 1798 \\
\hline Chiricahua NM & chir1 & $109.4 \mathrm{~W}$ & $32.0 \mathrm{~N}$ & 1554 \\
\hline Gila Cliff Dwellings NP & gicl1 & $108.2 \mathrm{~W}$ & $33.2 \mathrm{~N}$ & 1775 \\
\hline Great Basin NP & grba1 & $114.2 \mathrm{~W}$ & $39.0 \mathrm{~N}$ & 2065 \\
\hline Great Sand Dunes NM & grsa1 & $105.5 \mathrm{~W}$ & $37.7 \mathrm{~N}$ & 2499 \\
\hline Jarbidge Wilderness & jarb 1 & $115.4 \mathrm{~W}$ & $41.9 \mathrm{~N}$ & 1869 \\
\hline Lone Peak Wilderness & lope1 & $111.7 \mathrm{~W}$ & $40.4 \mathrm{~N}$ & 1768 \\
\hline Mesa Verde NP & meve1 & $108.5 \mathrm{~W}$ & $37.2 \mathrm{~N}$ & 2172 \\
\hline Mount Zirkel Wilderness & mozil & $106.7 \mathrm{~W}$ & $40.5 \mathrm{~N}$ & 3243 \\
\hline Petrified Forest NP & pefol 1 & $109.8 \mathrm{~W}$ & $35.1 \mathrm{~N}$ & 1766 \\
\hline Rocky Mountain NP & romo1 & $105.6 \mathrm{~W}$ & $40.3 \mathrm{~N}$ & 2760 \\
\hline San Gorgonio NP & sagol & $116.9 \mathrm{~W}$ & $34.2 \mathrm{~N}$ & 1726 \\
\hline Sequoia NP & sequ1 & $118.8 \mathrm{~W}$ & $36.5 \mathrm{~N}$ & 519 \\
\hline Tonto NM & tont1 & $111.1 \mathrm{~W}$ & $33.7 \mathrm{~N}$ & 775 \\
\hline Weminuche Wilderness & wemil & $107.8 \mathrm{~W}$ & $37.7 \mathrm{~N}$ & 2750 \\
\hline Yellowstone NP & yell2 & $110.4 \mathrm{~W}$ & $44.6 \mathrm{~N}$ & 2425 \\
\hline Yosemite NP & yose1 & $119.7 \mathrm{~W}$ & $37.7 \mathrm{~N}$ & 1603 \\
\hline
\end{tabular}

${ }^{\mathrm{a}} \mathrm{NP}$, National Park; NM, National Monument; SP, State Park.

mixing ratio of aerosol species from fossil fuel emissions decrease with altitude from the surface to lower free troposphere, while the mixing ratio of biomass burning aerosols and dust increase with altitude from the surface to about $700 \mathrm{hPa}$ and reach a maximum near $700 \mathrm{hPa}$ (not shown). The maximum in the mixing ratio of dust and biomass aerosols at $700 \mathrm{hPa}$ is associated with their uniform injection in the boundary layer and their long-range transport in the lower free troposphere. Biomass burning explains the maximum mixing ratio of $\mathrm{BC}$ from 700 to $800 \mathrm{hPa}$. Compensating effects from the decrease with altitude of fossil fuel aerosols, and the increase with altitude of dust produces a near constant mixing ratio for total aerosol.

[50] While the model predicts a reasonable magnitude for the total aerosol and $\mathrm{BC}$ mixing ratios near the surface and in the upper troposphere, it overestimates the mixing ratio in the lower and middle free troposphere. This may be caused by either vertical transport that is too strong, assumed injection heights for biomass burning and dust aerosols that are too high, or wet deposition that is too weak in the model. However, it may also be due to the fact that there are only 2 days of observational data which may not be representative.

[51] Figure 10 also shows simulated profiles from two another cases. One is from the three-mode case, and the other is from the base case with binary homogeneous nucleation switched off above the boundary layer (NOBHN). The differences between the mass mixing ratio profiles from these two cases and those from the base case are minor, despite the fact that the simulated aerosol number concentrations for these two cases differ significantly from those in the base case. For example, the NOBHN case has far smaller aerosol number concentrations in the upper troposphere than those in the base case due to the absence of nucleation, and the size of aerosol particles is much larger as a result of coating of preexisting aerosols by sulfate. This suggests that different treatments in aerosol microphysics as described here and the effects of microphysics on scavenging have only a small effect on the vertical profile of either the total aerosol mass or the black carbon mass.

\section{Comparison With Observations: Aerosol Number and Size Distribution}

\subsection{Aerosol Size Distribution}

[52] Figure 11 shows the aerosol size distribution in the marine boundary layer from the model and observations [Heintzenberg et al., 2000]. The observational data were compiled and aggregated onto a $15^{\circ} \times 15^{\circ}$ grid. We sampled the model over the same regions as those of the observations (see appendix B for a description of the derivation of the simulated size distribution and number concentration from the mode and bin structure in the model). Generally, the model simulates a bimodal distribution for aerosols over the marine boundary layer, with an Aitken mode with a geometric diameter of $20 \mathrm{~nm}$ and an accumulation mode with a diameter of $150 \mathrm{~nm}$. The observed size distribution is also bimodal, but the model underestimates both the accumulation mode radius and mode number at all latitudes except 45$60^{\circ} \mathrm{N}$, where it slightly overestimates the aerosol number (by about $50 \%$ ). The largest underestimate of accumulation mode aerosol number (a factor of 2 to 3 ) occurs over SH middle latitudes and tropical regions $\left(45^{\circ} \mathrm{S}-15^{\circ} \mathrm{N}\right)$. The underestimate of the accumulation mode aerosol number is consistent with the underestimate of the total sea salt aerosol mass at Cheju and Bermuda (Figure 7). This underestimation may not be due to the use of the two-mode aerosol representation, since it also occurs in the model results of Pierce and Adams [2006] and Pierce et al. [2007] and, to a lesser extent, in the results of Spracklen et al. [2007]. They both used a sectional representation for aerosol size distributions (30 bins in the work by Pierce and Adams [2006] and Pierce et al. [2007]; 20 bins in the work by Spracklen et al. [2007]). As pointed out by Pierce and Adams [2006], there are large differences between different sea salt source functions. Nevertheless, none of the different source functions applied by Pierce and Adams [2006] leads to a significant improvement in their models' agreement with observations, possibly because of a bias in the wind speeds in the GISS model that they were using. The sea salt source function has also been implicated in possible disagreements between aerosol optical depth over the southern oceans and observations [e.g., Penner et al., 2002]. Further work is needed to improve the representation of sea salt in global models.

[53] The model also underestimates both the Aitken mode radius and number concentration in the marine boundary layer outside regions that are heavily influenced by conti- 

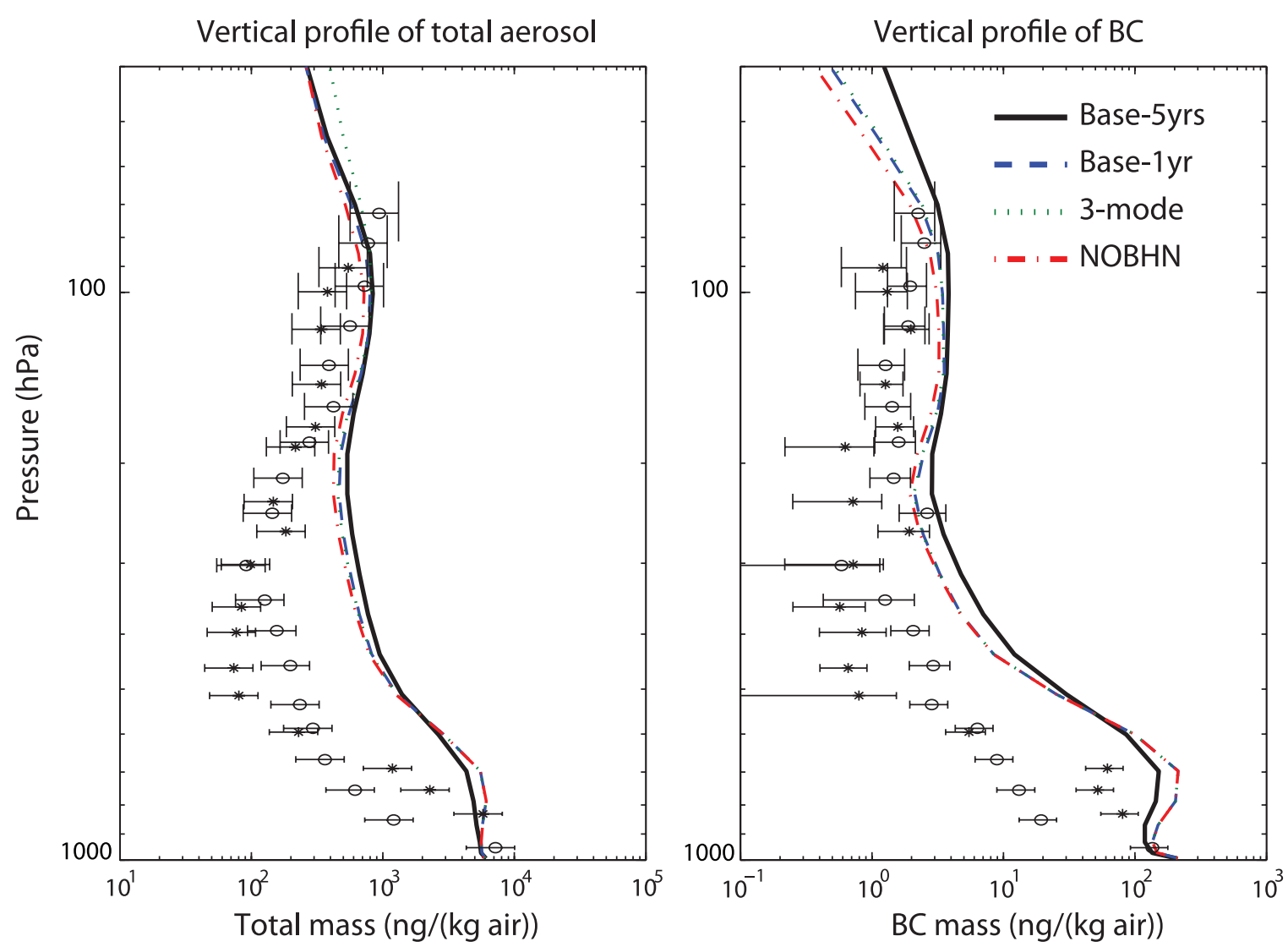

Figure 10. Vertical profiles of (left) total aerosol and (right) BC mass mixing ratios. Observations are from Schwarz et al. [2006] and took place on 10 November (stars) and 12 November (open circles), 2004, over Houston, Texas. The error bars represent the sample standard deviation. All simulation cases are defined in Table 2.

nental sources (e.g., $\left.75^{\circ} \mathrm{S}-15^{\circ} \mathrm{N}, 75^{\circ} \mathrm{N}-90^{\circ} \mathrm{N}\right)$. The absence of ultrafine sea salt particles (radius $<0.05 \mu \mathrm{m}$ ) in our source representation may contribute somewhat to the underestimation of the aerosol number in the Aitken mode in the model, especially at high latitudes. Pierce and Adams [2006] found better agreement at high latitudes $\left(45^{\circ} \mathrm{S}-75^{\circ} \mathrm{S}\right)$ when they used the Martensson et al. [2003] sea salt source function though other latitudes were not improved. In addition, the absence of a boundary layer nucleation scheme in the base case simulation (as well as its absence in the simulation of Pierce and Adams) may also bias results. Indeed, including a boundary layer nucleation mechanism improves the comparison of the model with observations over the tropics and over the SH middle latitudes (section 7.2).

[54] Over regions that are heavily affected by continental sources $\left(30^{\circ} \mathrm{N}-60^{\circ} \mathrm{N}\right)$, the base case model overestimates aerosol number concentrations and underestimates the mode radius in the Aitken mode, which may be associated with the assumed size distribution and number concentration of primary emitted sulfate particles. A larger emitted size and smaller fraction in the Aitken mode would provide a better agreement between the model and observations. The role of the primary emitted sulfate particles is further discussed in section 7.1.

[55] Figure 12 shows the aerosol size distribution from the model and observations at four sites in Europe in winter and summer in the continental boundary layer [Putaud et al., 2003]. Aspvreten is located in a region with background continental conditions $50 \mathrm{~km}$ from any large pollution source. Harwell and Hohenpeissenberg are located in a rural location 10 to $50 \mathrm{~km}$ from large pollution sources, and Ispra is a polluted site less than $10 \mathrm{~km}$ from a large pollution source. The observed number concentrations at Aspvreten are smaller and have larger sizes than those at the polluted site, Ispra. The aerosol at this background site represents a more aged aerosol than that at Ispra. There is also a narrower size spectrum and smaller number concentration in winter compared to summer which may come from additional nucleation events during summer, when the rate of production of sulfate is larger. At Aspvreten, the model is in better agreement with the observations in summer than it is in winter. In winter, the simulated Aitken mode size is too small. Apparently, the assumed fixed size distribution and fraction (2\%) of primary emitted sulfate particles in the base case is not able to represent the seasonal variations in subgrid-scale nucleation events which depend on the rate of production of sulfate gas and its variation with sunlight.

[56] Given the model's resolution (about $200 \mathrm{~km}$ ), it is not surprising that the simulation overestimates the aerosol number concentrations at Harwell because the grid box at this location includes the emissions from London. The Hohenpeissenberg site is located at an altitude of about $1 \mathrm{~km}$, and the model is in better agreement with the observed 

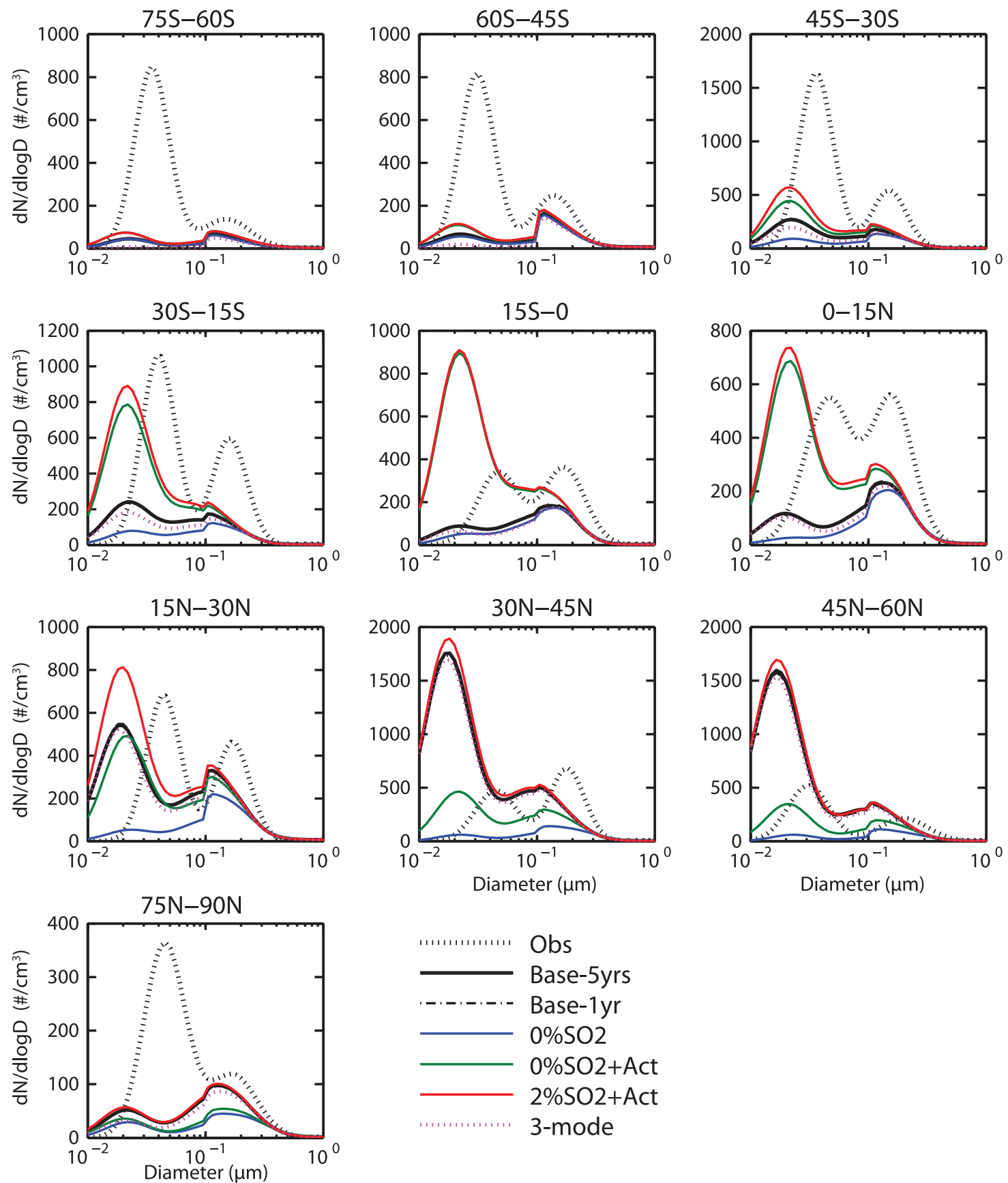

Figure 11. Aerosol size distribution in the marine boundary layer. Observations (Obs) are from Heintzenberg et al. [2000]. All simulated cases are defined in Table 2.

size distribution in summer than it is in winter. The model underestimates the total aerosol number concentration in winter.

[57] At Ispra, we would expect the model to give smaller aerosol number concentrations compared to the observations, since the grid near Ispra includes some rural regions. In both winter and summer, the model underestimates aerosol number concentrations in both the accumulation mode and the Aitken mode.

[58] Figures 13a-13d shows aerosol size distributions in the lower free troposphere from the model and observations at three sites (Jungfraujoch, $3580 \mathrm{~m}$ [Putaud et al., 2003]; Florida during the Crystal-Face experiment, 2-5 km [Fridlind et al., 2004]; and Tenerife, $2360 \mathrm{~m}$ [Raes et al., 1997]). The observations show a monomodal distribution at all sites. This has been argued to result from descending aerosol particles from the upper troposphere and the depletion of accumulation mode particles from the boundary layer by wet and dry deposition [Raes et al., 2000]. The model predicts a prominent Aitken mode together with a less prominent accumulation mode. The accumulation mode in the model is associated with both accumulation mode aerosols transported from the boundary layer (such as dust, which is especially prominent at the Tenerife site) and with coagulation and the condensational growth of aerosols. The observations at Jungfraujoch have a higher aerosol number concentration and a larger 

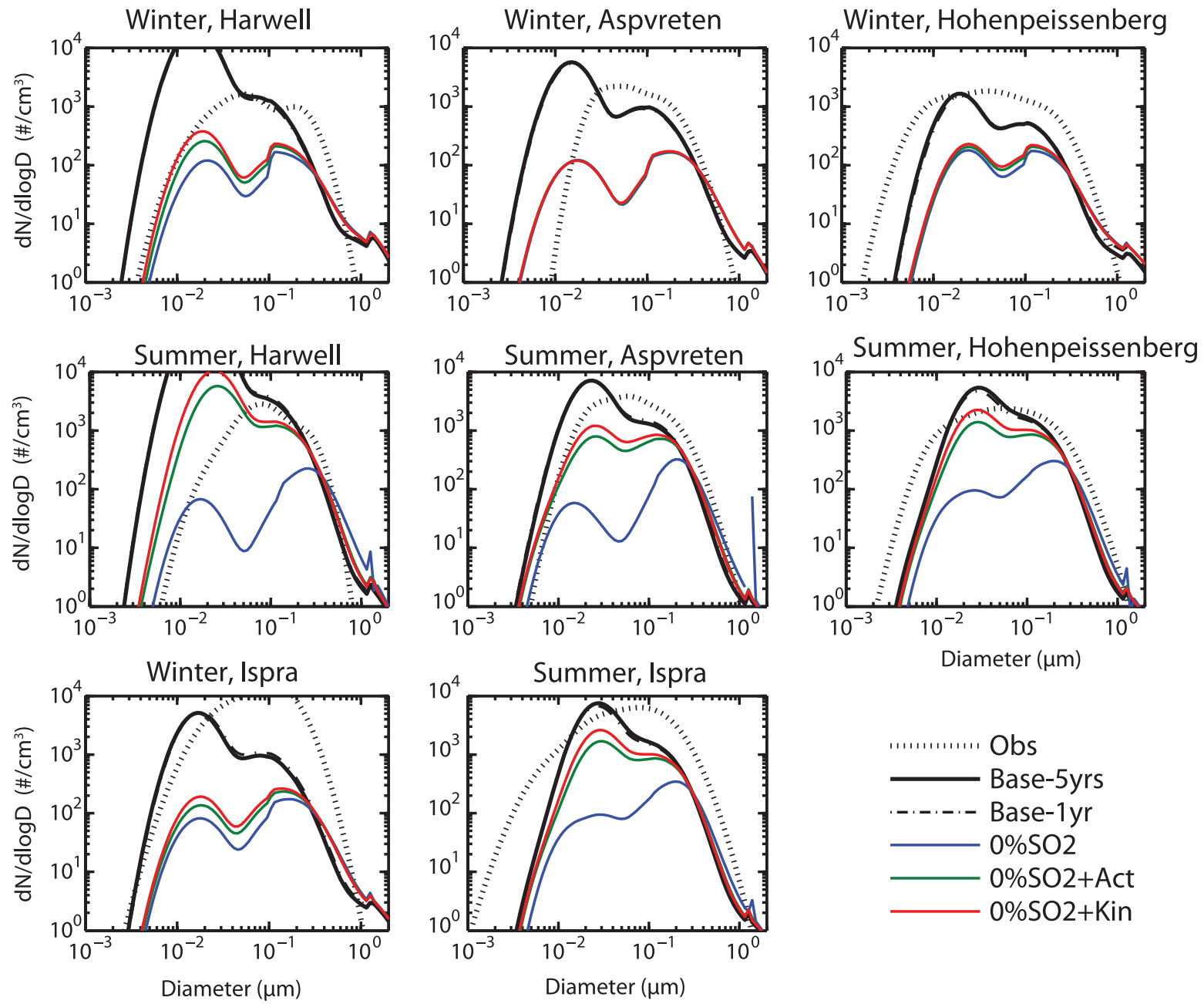

Figure 12. Aerosol size distribution over sites in Europe. Observations (Obs) are from Putaud et al. [2003]. All simulated cases are defined in Table 2.

mode radius in spring than in winter, which may result from the higher $\mathrm{H}_{2} \mathrm{SO}_{4}$ production rate in spring. The model simulates these features well. Over south Florida (CrystalFace), the model underestimates the aerosol number concentration at $2 \mathrm{~km}$. However, it should be noted that the observations only represent a single date.

[59] At both $5 \mathrm{~km}$ and $10 \mathrm{~km}$, the observed aerosol size distributions are monomodal with higher number concentrations at higher altitudes, indicating that nucleation may be playing a significant role in determining number concentrations. The model reproduces the number concentration of the mode near $0.02-0.03 \mu \mathrm{m}$ well in the upper troposphere. However, it overestimates the Aitken mode radius in the middle troposphere. The observed mode radius in the middle troposphere is similar to that in the upper troposphere. In the model, the mode radius increases as aerosol particles descend from the upper troposphere. There is a large discrepancy between modeled and observed accumulation mode number concentrations in the middle and upper troposphere.

\subsection{Vertical Profiles of Aerosol Number Concentrations}

[60] Figure 14 shows vertical profiles of ultrafine particles (diameter $>3 \mathrm{~nm}$ ) from the model and the observations of
Clarke and Kapustin [2002]. Clarke and Kapustin [2002] compiled field data taken over the Pacific Ocean over several decades, and separated them into three regions: the South Pacific $\left(70^{\circ} \mathrm{S}-20^{\circ} \mathrm{S}\right)$, tropical Pacific $\left(20^{\circ} \mathrm{S}-20^{\circ} \mathrm{N}\right)$, and North Pacific $\left(20^{\circ} \mathrm{N}-70^{\circ} \mathrm{N}\right)$. All profiles show an increase in the ultrafine particle number concentration with altitude, which is associated with nucleation events in the upper troposphere. The observations also show a larger aerosol number concentration in the upper troposphere over the tropics than over the South Pacific or the North Pacific. The model reproduces the increase in the aerosol number concentration with altitude. The model also predicts larger aerosol number concentrations in the upper troposphere over the tropics than over higher latitudes. However, the ultrafine aerosol number concentration in the model is larger than in the observations at the highest altitudes. As we show in section 7.3, the use of the three-mode aerosol representation decreases the simulated ultrafine particle number concentration. Over the South Pacific, the model underestimates the aerosol number concentration between the surface and $5 \mathrm{~km}$. The observational data over the South Pacific is mainly derived from ACE-1 observations, which may be biased toward strong convective regions with higher aerosol number concentrations [Clarke and Kapustin, 2002]. Over the 
$\begin{array}{lll}\text { a) Winter, Jungfraujoch }(3.6 \mathrm{~km}) & \text { b) Summer, Jungfraujoch }\end{array}$
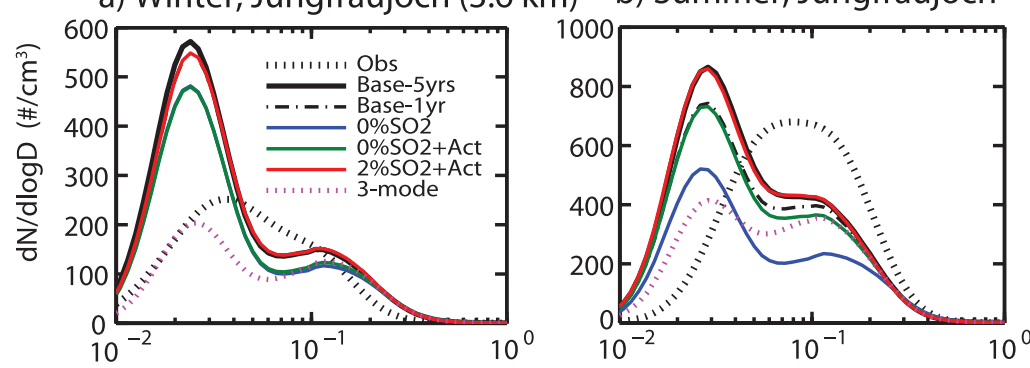

d) CRYSTAL-FACE (2 km)

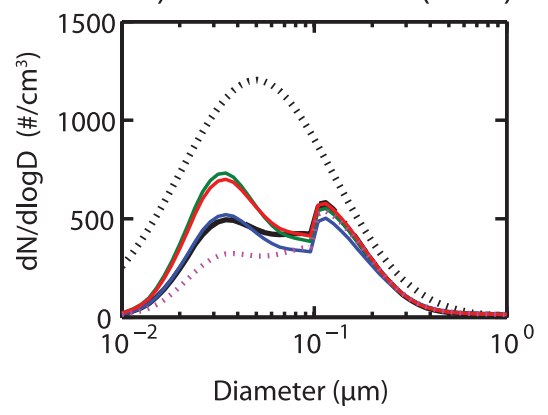

e) CRYSTAL-FACE $(5 \mathrm{~km})$

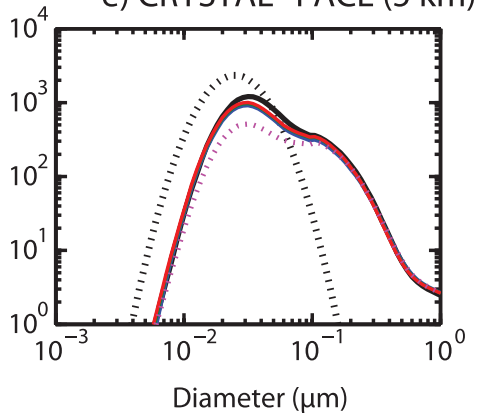

c) Tenerife $(2.36 \mathrm{~km})$

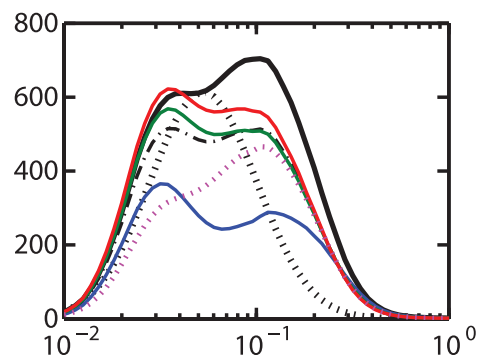

f) CRYSTAL-FACE (10 km)

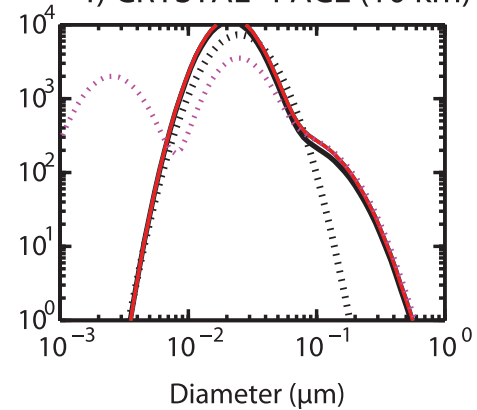

Figure 13. Aerosol size distribution in the free troposphere. Observations (Obs) are from Putaud et al. [2003] (Jungfraujoch), Raes et al. [2000] (Tenerife); and Fridlind et al. [2004] (Crystal-Face, Florida). All simulated cases are defined in Table 2.

tropics, the observational data are nearly constant with altitude in the boundary layer, but the model simulates a factor of 2 increase in the aerosol number concentration with altitude. As we show in section 6.2, the inclusion of a boundary nucleation mechanism can improve this comparison.

[61] Figure 15 shows vertical profiles of the aerosol number concentration in the Aitken mode (diameter $>14 \mathrm{~nm}$ ) and in the accumulation mode (diameter $>100 \mathrm{~nm}$ ) from both the model and observations at Punta Arenas, Chile and Prestwick, Scotland [Minikin et al., 2003]. The observed aerosol number concentrations in the Aitken mode are nearly constant with altitude in the free troposphere at both locations. Model results increase with altitude in the free troposphere and decrease with altitude in the boundary layer near Scotland. The model overestimates the Aitken mode number concentration at altitudes from $8 \mathrm{~km}$ to $12 \mathrm{~km}$, a feature that is improved in the three-mode representation (section 7.3).

[62] Observed accumulation mode aerosol number concentrations near Scotland decrease with altitude from surface to the lower free troposhere, are nearly constant with altitude in the middle troposphere, and increase slightly in the upper troposphere. The model reproduces this trend in the low and middle troposphere, though the decrease in the boundary layer is somewhat smaller than observed. However, the increase in the upper troposphere is not reproduced by the model. This feature too is improved with the three-mode representation (see section 7.3). The observed vertical profile of accumulation mode aerosol number concentration near Punte Arenas, is similar to that near Scotland. The model also reproduces near constant concentrations in the lower and middle troposphere, with a very small decrease in the concentration with height in the boundary layer. This very small decrease with height is the result of an increase in the sulfate aerosol number with height and a decrease in the sea salt aerosol number with height. The increase in accumulation mode aerosol number (by a factor of 2) from Punta Arenas to Scotland is reproduced by the model.

\section{Sensitivity of Aerosol Size and Number to Model Formulation}

[63] In this section, five additional 1 year simulations as described in section 3 are compared with the first year simulation of the base case and with observations to study how the simulated aerosol size and number vary with the assumed fraction of primary emitted sulfate particles, with the inclusion of a boundary layer nucleation mechanism, and with the use of a three-mode representation of aerosol size.

\subsection{Primary Emission of Sulfate Particles}

[64] The primary emitted sulfate particles in the model have a significant influence on the aerosol number in both the Aitken mode and the accumulation mode over the $\mathrm{SH}$ middle latitudes $\left(45^{\circ} \mathrm{S}-15^{\circ} \mathrm{S}\right)$ and over the $\mathrm{NH}$ middle to high latitudes $\left(15^{\circ} \mathrm{N}-90^{\circ} \mathrm{N}\right)$ in the marine boundary layer (Figure 11) and over the continental boundary layer in Europe (Figure 12), where the influence of continental sources is large. While the inclusion of the primary emitted sulfate particles improves the comparison with observations at most latitudes, it overestimates the Aitken aerosol number concentration in $\mathrm{NH}$ middle latitudes $\left(30^{\circ} \mathrm{N}-60^{\circ} \mathrm{N}\right)$.

[65] Including primary emitted sulfate improves the agreement of the model with observations in the lower free troposphere at Junfraujoch in spring and at Tenerife, but has almost no effect in the middle and upper free troposphere (Figure 13). The influence of primary particles transported 


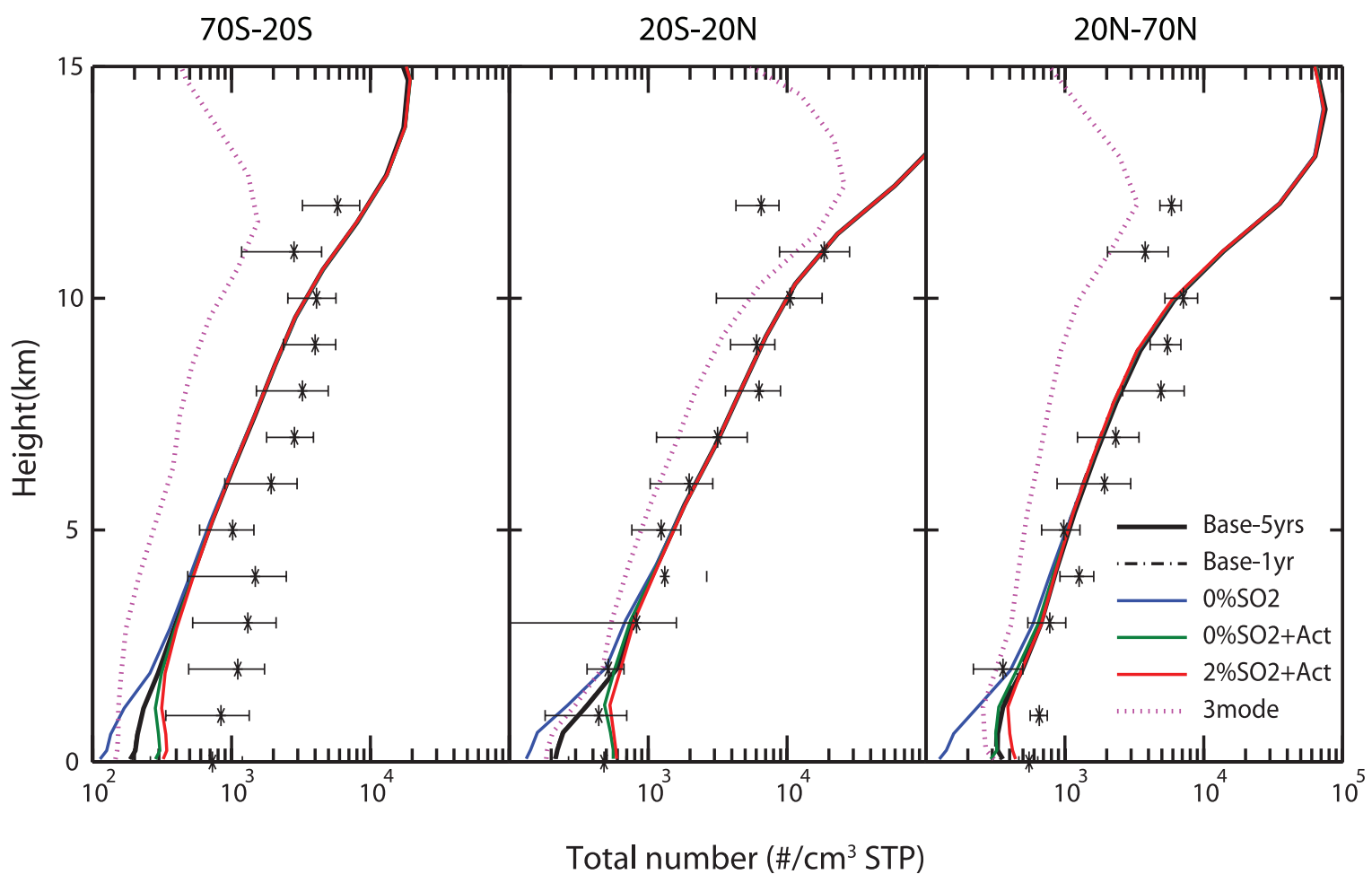

Figure 14. Vertical profiles of the number concentration of ultrafine particles (diameter $>3 \mathrm{~nm}$ ) averaged for latitude bands (left) $70^{\circ} \mathrm{S}-20^{\circ} \mathrm{S}$, (middle) $20^{\circ} \mathrm{S}-20^{\circ} \mathrm{N}$, and (right) $20^{\circ} \mathrm{N}-70^{\circ} \mathrm{N}$ over the Pacific Ocean. Observations (star) are from Clarke and Kapustin [2002], and the error bars represent 50\% of the standard deviation. Model results are annual means over the same grid squares as the observations $\left(175^{\circ}-270^{\circ} \mathrm{E}\right.$ for the tropics, $200^{\circ}-240^{\circ} \mathrm{E}$ for the $\mathrm{NH}$ and $135^{\circ}-180^{\circ} \mathrm{E}$ for the $\left.\mathrm{SH}\right)$. All simulated cases are defined in Table 2.

from surface sources decreases with altitude while the influence from homogeneous binary aerosol nucleation increases.

[66] The vertical profiles of aerosol number concentrations (Figures 14 and 15) demonstrate the importance of primary sulfate particles in the boundary layer and in the lower free troposphere. Without primary sulfate particles (or a boundary layer nucleation scheme), the model is not able to simulate the decrease in the aerosol number concentration with altitude in the boundary layer over Scotland in the NH.

[67] Since the contribution of the assumed primary emitted sulfate particles to the aerosol particle number concentration is large, and since there is a poor understanding of the amount of subgrid-scale nucleation which should be represented in the form of primary emitted sulfate particles, the development of a more rigorous method of representing these processes is needed. The treatment of these processes in a global aerosol model still constitutes one of the largest uncertainties in the modeling of aerosol size distributions in a global model [Adams and Seinfeld, 2003].

\subsection{Boundary Layer Nucleation}

[68] In the marine boundary layer, including the activation mechanism (equation (1)) for boundary layer nucleation increases the simulated aerosol number and improves the comparison with observations over the tropics and over the SH middle latitudes $\left(45^{\circ} \mathrm{S}-15^{\circ} \mathrm{N}\right.$, in Figure 11). Over these regions, the concentration of sulfuric acid gas is high and the concentration of primary particles are low, both of which favor new particle formation. In tropical regions, the aerosol number in the Aitken mode can be of order 10 times that simulated without boundary layer nucleation, and the aerosol number in the accumulation mode can increase by $50 \%$. Boundary layer nucleation also improves the comparison with the observed vertical profile of ultrafine particles in the tropical and southern Pacific (Figure 14). Without boundary layer nucleation, the model is unable to simulate the nearly constant number concentration with altitude in the boundary layer in the tropical and southern Pacific.

[69] Over the marine boundary layer in regions that are influenced by pollution such as the $\mathrm{NH}$ middle latitudes (e.g., $15^{\circ} \mathrm{N}-60^{\circ} \mathrm{N}$ in Figure $11,20^{\circ} \mathrm{N}-70^{\circ} \mathrm{N}$ in Figure 14), and over continental sites influenced by pollution (e.g., Scotland in Figure 15 and continental Europe sites (not shown)), the effect of including the activation mechanism for boundary layer nucleation largely depends on whether or not primary emitted sulfate particles are included. The comparison of the base case (with $2 \%$ of the anthropogenic sulfur emitted as particulate sulfate) with the $2 \% \mathrm{SO} 2+$ Act case shows that including the boundary layer nucleation mechanism has almost no effect on the simulated aerosol number and size. In these regions, the inclusion of primary emitted sulfate particles produce a high preexisting surface area, which depletes the sulfuric acid gas concentration, and slows or inhibits boundary layer nucleation. In contrast, when there are no primary emitted sulfate particles (compare $0 \% \mathrm{SO} 2$ with $0 \% \mathrm{SO} 2+\mathrm{Act}$ ), boundary layer nucleation 
Diameter $>14 \mathrm{~nm}$, in Chile

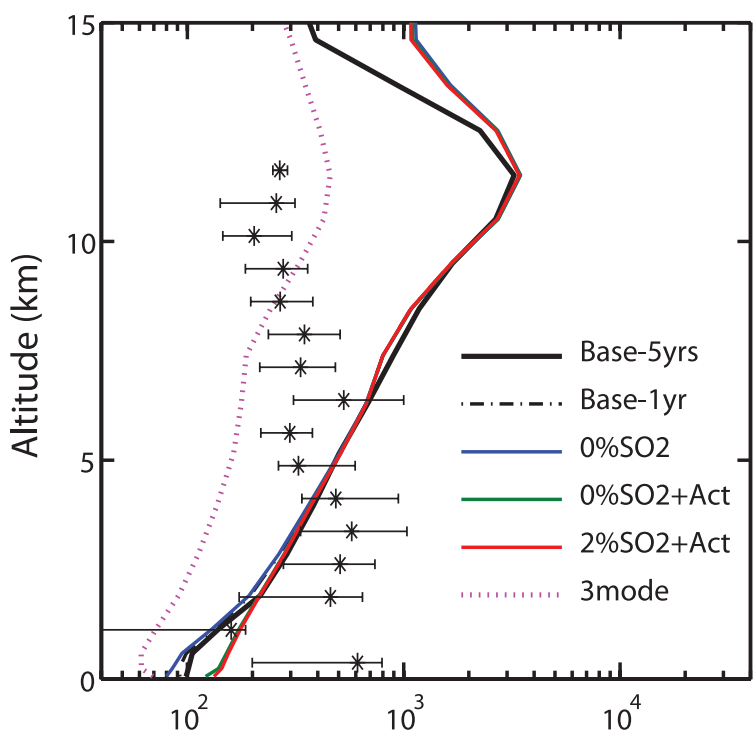

Diameter > $14 \mathrm{~nm}$, in Scotland

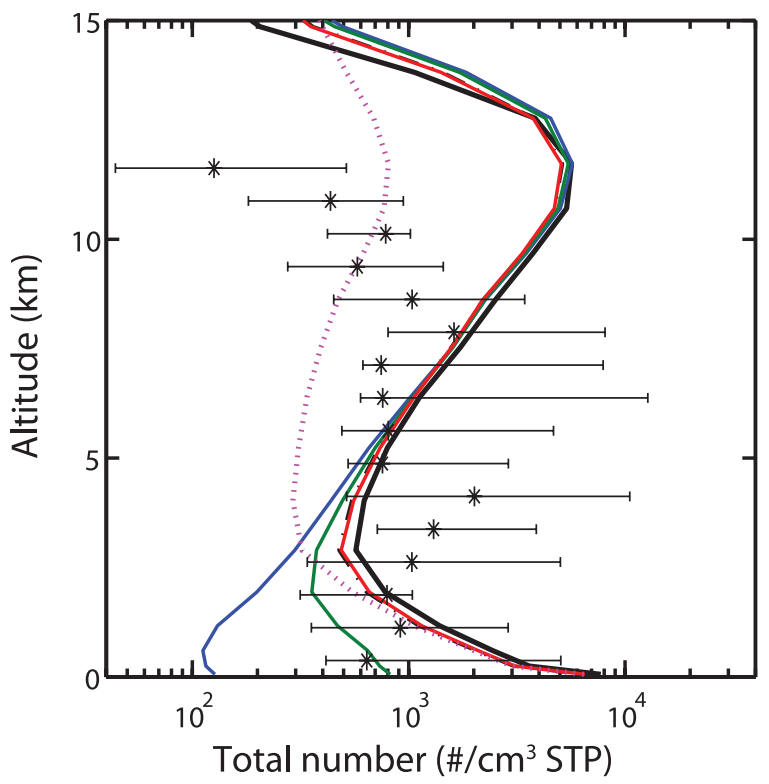

Diameter $>100 \mathrm{~nm}$, in Chile

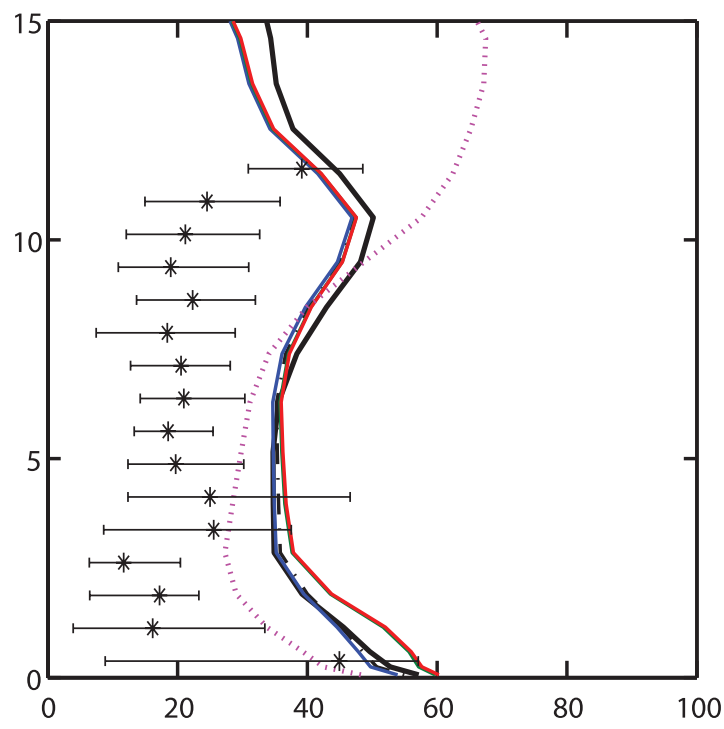

Diameter $>100 \mathrm{~nm}$, in Scotland

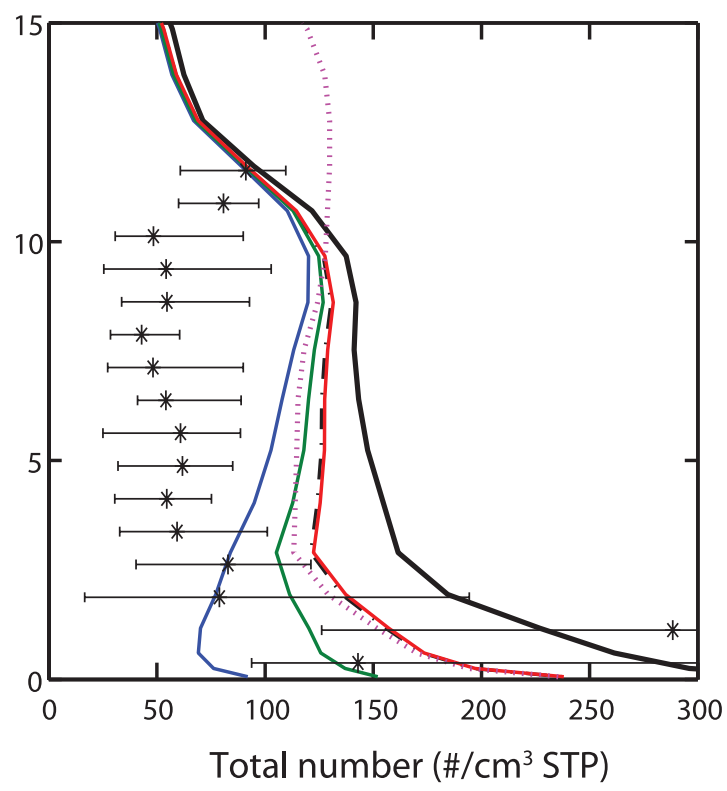

Figure 15. Vertical profiles of the number concentration of (left) Aitken mode particles (diameter $>14 \mathrm{~nm}$ ) and (right) accumulation mode particles (diameter $>100 \mathrm{~nm}$ ) (top) over Punta Arenas, Chile, in March/April and (bottom) over Prestwick, Scotland, in September/October. Observations are from Minikin et al. [2003]: median (star), 25 and 75 percentiles (left end and right end of error bars). Model results are averaged over $60^{\circ}-50^{\circ} \mathrm{S}, 70^{\circ}-85^{\circ} \mathrm{W}$ for Chile, and over $50^{\circ}-60^{\circ} \mathrm{N}, 10^{\circ} \mathrm{W}-5^{\circ} \mathrm{E}$ for Scotland. All simulated cases are defined in Table 2.

increases the aerosol number concentration significantly in the boundary layer of the remote $\mathrm{NH}\left(\right.$ e.g., $15^{\circ} \mathrm{N}-60^{\circ} \mathrm{N}$ in Figure $11 ; 20^{\circ} \mathrm{N}-70^{\circ} \mathrm{N}$ in Figure 14 , and Scotland in Figure 15). This is also true for polluted continental sites during spring (Figure 12). However, during winter, boundary layer nucleation has little effect (Figure 12) because the sulfuric acid gas production rate is low at these continental sites.

[70] Over regions either with a very low sulfuric acid concentration $\left(75^{\circ}-60^{\circ} \mathrm{S}\right.$ and $75^{\circ}-90^{\circ} \mathrm{N}$ in Figure 11) or with a very large amount of primary particles $\left(60^{\circ}-45^{\circ} \mathrm{S}\right.$ in
Figure 11 and Chile in Figure 15, from sea salt aerosol), the boundary layer nucleation mechanism has little effect on the simulated aerosol number concentration, which does not depend on the primary sulfate particles. The boundary layer nucleation has a small effect on the simulated aerosol number and size in the lower free troposphere, and has almost no effect in the middle and upper troposphere.

[71] Figure 12 compares the effects from the kinetic boundary layer nucleation mechanism (which is second order in the $\mathrm{H}_{2} \mathrm{SO}_{4}$ concentration, $0 \% \mathrm{SO} 2+\mathrm{Kin}$ ) and the activation boundary layer nucleation mechanism (which is 
first order in the $\mathrm{H}_{2} \mathrm{SO}_{4}$ concentration, $0 \% \mathrm{SO} 2+\mathrm{Act}$ ). Both mechanisms produce similar aerosol number concentrations, with only slightly higher concentrations in the Aitken mode from the kinetic nucleation mechanism.

[72] Although the empirical boundary layer nucleation mechanism used in this study was derived from long-term observations at Hyytiälä, there are large differences between the nucleation rates observed at other sites. Riipinen et al. [2007] showed that the rate constant derived from a site in Heidelberg is about 1 order of magnitude larger than that derived from Hyytiälä. Yu and Turco [2008] showed that an ion-mediated nucleation model can explain three of the nucleation events from Hyytiälä that were reported by Riipinen et al. [2007], but they did not examine cases from Heidelberg. The extent to which different mechanisms contribute at different sites, is not known. Different nucleation rates or different mechanisms may result in different contributions of boundary layer nucleation to the simulated aerosol size and number.

[73] The contribution of gases other than sulfate to the growth of nucleation size particles is also unknown. In the results shown above, the only condensing vapor was sulfuric acid gas. However, observational data has shown that other species may also contribute to the growth of nanoparticles [e.g., Stolzenburg et al., 2005]. In particular, a number of theoretical [Kerminen et al., 2000; Zhang and Wexler, 2002] and experimental [e.g., Allan et al., 2006; Smith et al., 2008] studies support the notion that organic species play a crucial role in the growth of nanoparticles. For example, Smith et al. [2008] showed that the condensation of sulfuric acid gas could have accounted for only about $10 \%$ of the growth that was observed in their measurements and that oxygenated organics and nitrogen-containing organics can play a dominate role in the growth of nanoparticles. Including the contribution of condensational growth of organic compounds in the model will increase the growth rate of nanoparticles, which will lead to an increase in the number of larger particles (e.g., $\mathrm{CCN}$ ) and may also improve the comparison with observations.

\subsection{Three-Mode Representation for Sulfate Aerosol}

[74] The three-mode version of the sulfate aerosol model is significantly different than the two-mode version in the upper troposphere where aerosol nucleation is the dominant source of particles. The three-mode version produces a distinct nucleation mode with a mode diameter of $2.5 \mathrm{~nm}$, which is not present in the two-mode version. This nucleation mode in the upper troposphere is also evident in the model study of Stier et al. [2005], who also separated the nucleation mode from the Aitken mode. Although this nucleation mode is not seen in the measurements that we examined, the size cutoff of the instruments used to measure aerosols in the upper troposphere limits any observation of this mode. In addition, the three-mode version results in fewer aerosol particles in the Aitken mode (Crystal-Face, $10 \mathrm{~km}$ in Figures 13 and 15) because freshly nucleated particles are no longer put into this mode and also because coagulation of the nucleation mode particles has moved Aitken mode particles into the accumulation mode. This improves the comparison of Aitken mode concentrations with observations at altitudes from $8 \mathrm{~km}$ to $12 \mathrm{~km}$ (Figure 15). Finally, the threemode version produces higher aerosol number concentrations in the accumulation mode in the upper troposphere (Figure 15). In the upper troposphere in both hemispheres, the predicted accumulation mode aerosol number concentrations in the three-mode version are about $2-3$ times that in the two-mode version. This version of the model may somewhat overestimate the accumulation mode aerosol number concentration compared with observations (Figure 15). Nevertheless, this version of the model is expected to be more physically realistic at high altitudes [see also Weisenstein et al., 2007].

[75] In the middle and lower troposphere, the three-mode version produces fewer aerosol particles in both the Aitken and accumulation modes (Figure 15). The descent of aerosols from the upper troposphere is an important source of particles in the Aitken mode in the lower and middle troposphere [Clarke and Kapustin, 2002]. Since the three-mode version produces fewer aerosol particles in the Aitken mode in the upper troposphere, it is not surprising that it also results in fewer Aitken aerosol particles in the middle and lower troposphere. This makes the comparison of the model with observations worse, especially over the SH (in Chile), but the comparison in Chile is improved when boundary layer nucleation is included in the three-mode version (not shown). Including ultrafine sea salt emissions [Pierce and Adams, 2006] may also improve the comparison of the three-mode version with the observations in these parts of the troposphere. The accumulation mode aerosol particles in the threemode version in the middle and lower troposphere are also smaller in number than in the two-mode version, despite the fact that there are more accumulation mode particles in the upper troposphere. In the middle and lower troposphere, the growth of aerosol particles in the Aitken mode by condensation, coagulation and cloud processing may be a more important source of accumulation mode particles than the source from the descent of accumulation particles directly from the upper troposphere. Then, fewer Aitken mode aerosol particles in the middle and lower troposphere would lead to fewer accumulation mode particles.

[76] In the boundary layer, the three-mode version produces results that are similar to the two-mode version for the aerosol size distribution over the regions where primary particles have a large contribution to aerosol particle population, such as continental sites over Europe (Figure 12) and marine sites over tropical regions and over the midlatitudes of both hemispheres $\left(45^{\circ} \mathrm{S}-60^{\circ} \mathrm{N}\right.$, Figure 11). Over these regions, the aerosol size distribution is mainly determined by the primary emitted particles and since there are no primary emitted particles in the nucleation mode (radius < $0.005 \mu \mathrm{m}$ ), the additional nucleation mode in the three-mode version has little effect on the simulated aerosol size distribution. The difference between the three-mode and twomode versions in the boundary layer is slightly larger over regions far from pollution sources (e.g., $75^{\circ} \mathrm{S}-45^{\circ} \mathrm{S}, 75^{\circ} \mathrm{N}-$ $90^{\circ} \mathrm{N}$ in Figure 11). Over these regions, aerosol particles entrained from the free troposphere are important sources of Aitken particles, and since the Aitken mode number concentration in the free troposphere is in general lower in the three-mode version than in the two-mode version, the concentrations in the boundary layer are also smaller (Figure 15).

[77] The three-mode version and the two-mode version are also similar in the boundary layer when boundary layer 
nucleation is included in both versions (not shown). In our treatment, the aerosol particles that are generated from boundary layer nucleation are added to the size range with $r>3 \mathrm{~nm}$ due to growth by condensation (equation (3)) whereas the particles produced through binary homogeneous nucleation in the upper troposphere are assumed to have a critical size of around $1 \mathrm{~nm}$. The particles from boundary layer nucleation also have lower number concentrations in the nucleation mode than those formed in the upper troposphere from binary homogeneous nucleation. In addition, the concentration of primary particles is much larger in the boundary layer than it is in the upper troposphere, which decreases the role of aerosol nucleation in the simulated aerosol size distribution in the boundary layer and thus decreases the differences between the two-mode and three-mode versions of the model.

[78] The three-mode version reproduces the observed trend in the change of the accumulation mode number with altitude (Figure 15). In both hemispheres, observations show that the accumulation mode number concentration first decreases in the boundary layer and lower free troposphere, then remains constant, and finally increases with altitude. The three-mode version captures these features well, while the two-mode version does not.

[79] Large-scale transport also plays a role in determining the difference between the three-mode version and twomode version. The separation of freshly nucleated particles from Aitken mode particles in the three-mode version has a large effect in the upper troposphere (i.e., Aitken mode particles decrease significantly and accumulation mode particles increase) because there is a strong source of freshly nucleated particles here. These effects are moved downward by large scale and affect the simulated aerosol size distribution in the middle troposphere.

[80] Our results show that it is important to separate the nucleation mode from the Aitken mode when a large number of freshly nucleated particles is produced with a very small size, as is the case for aerosol particles generated from binary homogeneous nucleation in the upper troposphere in our study. But a separate nucleation mode has only a small effect on the simulated aerosol size distribution when particle growth from condensation is also partially parameterized and particles are added into the model in a more aged size distribution with lower number concentrations (e.g., aerosol particles from the boundary layer nucleation scheme in this study). This parameterization of the growth of newly formed particles by condensation could also improve the number of Aitken particles without the introduction of an additional nucleation mode [e.g., Easter et al., 2004]. Easter et al. [2004] treated the nucleation of $\mathrm{H}_{2} \mathrm{SO}_{4}$ and water vapor using the nucleation and growth model of Harrington and Kreidenweis [1998], which calculates the formation of nanometer-sized particles during a nucleation burst and their subsequent growth to Aitken mode sizes (larger than $10 \mathrm{~nm}$ ). However, the method of Harrington and Kreidenweis [1998] cannot separate the parameterization of the subsequent growth of the newly formed particles from the parameterization of nucleation, which make it difficult to use other nucleation parameterizations [e.g., Vehkamäki et al., 2002]. The growth parameterization we used for aerosol particles generated from boundary layer nucleation (equation (3)) [Kerminen et al.,
2004; Kerminen and Kulmala, 2002] is independent of the parameterization of the nucleation rate of critical clusters. The application of this method in global models allows one to simulate the development of a more aged particle distribution from nucleation and condensation events even though the size resolution of the model is limited, although more studies may be needed to quantify the limitations of using this formula.

\section{Summary and Discussion}

[81] In this study, the IMPACT aerosol model was coupled to the NCAR CAM3 climate model. The version of IMPACT with aerosol microphysics was evaluated. Differences in the simulation of aerosol number and size from treating subgridscale nucleation events as primary emitted sulfate particles, the inclusion of boundary layer aerosol nucleation mechanisms and a three-mode aerosol representation are discussed.

[82] The annual and global budgets from the model are in the range of results from other models included in the AeroCom intercomparison. But the burden of $\mathrm{BC}$ is only about half of mean of the AeroCom models and the burden of OM is only about two thirds of the mean, which is mainly due to increased wet removal because of the treatment of sulfate coating on otherwise initially hydrophobic aerosols, such as $\mathrm{BC}, \mathrm{OM}$ and dust. This also partly explains the simulated smaller fine mode mass fraction for dust $(7.11 \%$ versus $20.80 \%$ in AeroCom). Our simulated mass fraction in polar regions is much less than that in AeroCom for all aerosol species, which may result from either differences in poleward transport or from differences in the treatment of wet removal processes.

[83] The comparison of the model with surface observations shows that the model simulates the observed concentrations and seasonal cycles reasonably well. Over Hawaii, the model overestimates $\mathrm{BC}$ and fine dust concentrations in summer, which can be partly explained by the bias in the tropical easterlies in CAM3. The model only simulates about one half or one third of the observed concentration of fine mode sea salt aerosol in the tropics, and it also underestimates the concentration in middle latitudes in both hemispheres. The model overestimates the concentration of fine mode dust aerosols over the United States.

[84] The model reproduces BC and total aerosol mixing ratios in the upper troposphere to lower stratosphere (Figure 10). But there is a maximum in the biomass burning aerosols and dust aerosols near $700 \mathrm{hPa}$ which results in a near constant mixing ratio of the total aerosol mass from the surface to $700 \mathrm{hPa}$ over Houston, Texas that is not present in the observations. Our sensitivity tests show that different treatments of the aerosol microphysics as described here and the effects of microphysics on scavenging have only a small effect on the vertical profile of either the total aerosol mass or the black carbon mass.

[85] In the marine boundary layer (Figure 11), the base case simulation overestimates the Aitken mode aerosol number concentrations in regions heavily influenced by pollution, but underestimates the Aitken mode in all other regions. The inclusion of the empirical boundary layer nucleation mechanisms improves the comparison with observations in the middle and low latitudes. At high latitudes, the comparison with observations may be improved by the 
inclusion of sea salt particles in the ultrafine size range [Pierce and Adams, 2006], which are neglected in the current model. The model also underestimates aerosol number concentrations in the accumulation mode in the marine boundary layer, especially at middle and low latitudes, which is consistent with the underestimation of fine mode sea salt particles in these regions.

[86] At sites located in the continental boundary layer in Europe (Figure 12), primary emitted sulfate particles contribute significantly to the aerosol number concentration in both the Aitken and accumulation modes since these sites are strongly influenced by anthropogenic emissions. When primary sulfate particles are included, boundary layer nucleation has little effect in polluted regions. Boundary layer nucleation improves the comparison to observations compared to the simulation without primary sulfate, but still underestimates the aerosol number concentration significantly, especially in winter, which may suggest that it is important to represent additional subgrid-scale particulate formation in global models.

[87] In the lower free troposphere, the model simulates a prominent Aitken mode and a less prominent accumulation mode, which are not seen in the observations. This may be caused by the wet removal mechanism, vertical transport, or particle nucleation in the upper troposphere. The model simulates a single mode distribution in the middle troposphere over Florida, as observed during the Crystal-Face experiment. Both primary emitted sulfate particles and boundary layer nucleation mechanisms have less impact on the aerosol number concentration in the free troposphere than in the boundary layer.

[88] The vertical profile of $\mathrm{CN}$ number is simulated well between the lower free troposphere and about $10 \mathrm{~km}$ in the base case (Figure 14), but is overestimated above $10 \mathrm{~km}$. The simulated $\mathrm{CN}$ number concentrations are significantly reduced in the three-mode representation. In the boundary layer, the $\mathrm{CN}$ number concentration in the Northern Hemisphere in the base case agrees with observations, but is underestimated in the Southern Hemisphere and in the tropics. This feature is improved when a boundary nucleation mechanism is included (Figure 14). The inclusion of a boundary layer nucleation mechanism also improves the simulation of the Aitken and accumulation mode particles in the boundary layer (Figure 15).

[89] The three-mode representation agrees with the observed increases in accumulation mode aerosol number with altitude in the upper troposphere, in contrast to the two-mode representation. The concentrations are 2 or 3 times those in the two-mode representation, and are somewhat overestimated in comparison to observations. The three-mode representation also decreases the Aitken mode number concentration.

[90] Our study suggests that simulated aerosol size and number concentrations are sensitive to the different assumptions used in the model. The large contribution of primary particulate sulfate to aerosol particle number concentration together with poor constraints on its treatment from either observations or fine-resolution models make this treatment undesirable until further constraints can be developed. More studies are needed to quantify the size and composition of directly emitted sulfate particles, newly formed particles in source plumes, and their growth on subgrid-scale time and spatial-scales. Boundary layer nucleation mechanisms are appealing, but the fact that the mechanism used in this study cannot yet capture all of the variations in the observed nucleation events prevent us from making further conclusions. More studies are needed to quantify how different nucleation mechanisms and how other condensable gases affect modeled Aitken and accumulation mode aerosol number. The results from the three-mode model show that it is important to separately represent freshly nucleated particles. This may also be achieved through a parameterization of nucleation together with the subsequent growth of the newly formed particles to larger size.

[91] Uncertainties in the simulated aerosol number and size distribution can have important implications for $\mathrm{CCN}$ concentrations, and aerosol indirect forcing, which is the focus of a separate study [Wang and Penner, 2009].

\section{Appendix A: Coupling of LLNL/University of Michigan IMPACT and NCAR CAM3}

[92] In this appendix, we explain the method used to couple the LLNL/University of Michigan IMPACT aerosol model and the NCAR CAM3 atmospheric circulation model.

[93] Coupling between an aerosol model and an atmospheric circulation model can be accomplished directly, by adding the equations that describe the transport and transformation of aerosols directly to the atmospheric component of a climate model [e.g., Lohmann et al., 2007], or by coupling a separate aerosol transport and transformation model to an atmospheric circulation and climate model [e.g., Easter et al., 2004; Chuang et al., 2002; Penner et al., 2003; Taylor and Penner, 1994]. Here we choose the second method and coupled the IMPACT aerosol model and the NCAR CAM3 atmospheric circulation model. In this strategy, water vapor, liquid and ice are transported by the CAM3 model, while aerosols are transported in the IMPACT model (the water associated with the aerosol is computed within the IMPACT model in steady state with the relative humidity from CAM). Both CAM and IMPACT use the finite volume numerical transport algorithm, so the large-scale transport in the two models is consistent. In addition, the instantaneous convective mass flux fields are passed to IMPACT at each time step to calculate the convective transport of aerosols, while the cloud and precipitation fields from CAM are used to calculate wet scavenging.

[94] This coupling strategy allows separate groups to update each component separately, and allows us to easily change aerosol model versions depending on the complexity that we wish to include. In addition, the same aerosol model can be run using off-line assimilated meteorological fields (as in the work by Liu et al. [2005]), facilitating the examination of the predicted aerosol fields for specific years. We currently have three configurations of the IMPACT aerosol model: a version that only predicts aerosol mass, but not aerosol number [e.g., Liu and Penner, 2002]; a version with an aerosol microphysical module, which includes nucleation of gas phase $\mathrm{H}_{2} \mathrm{SO}_{4}$, condensation, and coagulation among pure sulfate aerosols and between sulfate aerosols and other components [Liu et al., 2005]; and a version that includes the thermodynamics of the nitrate-ammonium-sulfuric aciddust-sea salt and water system [Feng and Penner, 2007]. We also have several versions of NCAR CAM model: the 
standard version of the NCAR CAM3 model [Collins et al., 2006a], a version with detailed ice microphysics [Liu et al., 2007], and, a version with both detailed liquid and ice microphysics M. Wang et al., manuscript in preparation, 2009).

[95] The method we chose to couple the two model components was determined by the unique features of each model component. The CAM3 and IMPACT models have different parallel schemes, and different domain decomposition methods. CAM3 uses a hybrid message passing MPI/OpenMP scheme, which is able to fully exploit the advantages of supercomputers with both shared and distributed memory. The model domain is decomposed nearly equally and distributed to each MPI processor which communicates with other MPI processors using MPI. Each individual MPI processor includes multiple threads which use OpenMP to speed calculation. The IMPACT model uses only MPI to parallelize the code. The master processor of IMPACT is used for all input and output, and to transfer data to and from all other processors (the so-called slave processors). The model domain is nearly equally decomposed in latitude/longitude blocks and distributed to the slave processors. These very different parallel schemes for the two components suggest that we need a coupler or a hub to facilitate communication between two model components. In addition, there is a massive amount of data that must be exchanged between the two model components (about 30 3-D variables needing about 80 Megabytes for each time step), which suggests that direct communication between the two model components through the master processor of IMPACT would save computer time.

[96] Thus we used the master processor of IMPACT as a "virtual" coupler, since, as we note above, the master processor of IMPACT was already used to control output and input for the IMPACT model and was not used for any additional model integration. This virtual coupler receives the meteorological data from CAM3 and sends them to the slave processors used by IMPACT. After each time step of the aerosol model, it receives the aerosol field from the slave processors, and sends them back to the individual processors used by the CAM3 model. The two model components of the coupled system run as separate executables in MPMD (Multiple Processors Multiple Data) mode, and communicate via MPI. The MPH (Multicomponent Handshaking) Library [He and Ding, 2005] is used to initialize the communication channels between the two model components and to map the processors to the model components. Because of the concurrent execution (i.e., operator splitting) of the two component models, there is a one time step lag between them.

[97] In this study, CAM3 and IMPACT use an identical global grid with 26 vertical levels and a $2^{\circ} \times 2.5^{\circ}$ horizontal resolution. The time step for CAM3 is $30 \mathrm{~min}$ and $1 \mathrm{~h}$ for IMPACT. Thus, at every other CAM3 time step, there is an exchange of data between CAM3 and IMPACT. Since the computational cost of IMPACT is high, the communication time between the two model components is only a small fraction of the total computational cost for the coupled model. By assigning the appropriate number of processors to each model component, we can minimize the idle time of each model component that results from waiting for the data from the other component. In doing this, the total computational cost of the coupled system is only slightly larger than the sum of the costs of each model component when they run in stand-alone versions. It takes about $1.5 \mathrm{~h}$ for a 1 month integration with three 32-thread nodes (2 MPI processors that each include16 threads are assigned to CAM3 and 64 MPI processors are assigned to IMPACT) on the Bluefire machine at NCAR, which is an IBM clustered Symmetric MultiProcessing (SMP) system based on the POWER6 ${ }^{\text {(ii }}$ processor.

\section{Appendix B: Simulated Aerosol Size Distribution and Number Concentration}

[98] In Figures 11-15, we compared our simulated aerosol size distribution and number concentration with a variety of observations. Here we describe how we derive the continuous simulated aerosol size distribution and the number concentration from the values in each of our size bins or modes. For each prognostic sulfate mode (3 lognormal modes in the simulation with 3 modes, and 2 lognormal modes in all other cases), the number median diameter can be derived from the predicted mass and number with the given geometric standard deviation. Then the size distribution of sulfate aerosol can be obtained from a superposition of all predicted sulfate modes. For nonsulfate aerosols, the assumed size distributions in Table 1 are used to calculate the number concentration of aerosols in each size bin (one bin for carbonaceous aerosols, 4 bins for both dust and sea salt aerosols). The size distribution of total aerosol is the sum of the size distribution of pure sulfate aerosol and nonsulfate aerosols. The simulated aerosol number concentrations in Figures 14 and 15 are derived by integrating the simulated size distribution over the appropriate size range of the observation. Since the smallest size for dust and sea salt is $0.1 \mu \mathrm{m}$ in diameter, there is a discontinuity in the simulated size distribution at around $0.1 \mu \mathrm{m}$ in diameter. Slight discontinuities can also occur at the edges of the 4 bins used to approximate the dust and sea salt size distributions.

[99] Acknowledgments. The authors acknowledge partial support from the National Science Foundation under grant ATM-0333016 and the support of NASA from grant NNG04GC01G. Pacific Northwest National Laboratory is operated for the DOE by Battelle Memorial Institute under contract DE-AC06-76RLO 1830.

\section{References}

Ackerman, A. S., M. P. Kirkpatrick, D. E. Stevens, and O. B. Toon (2004), The impact of humidity above stratiform clouds on indirect aerosol climate forcing, Nature, 432(7020), 1014-1017, doi:10.1038/nature03174.

Adams, P. J., and J. H. Seinfeld (2002), Predicting global aerosol size distributions in general circulation models, J. Geophys. Res., 107(D19), 4370, doi:10.1029/2001JD001010.

Adams, P. J., and J. H. Seinfeld (2003), Disproportionate impact of particulate emissions on global cloud condensation nuclei concentrations, Geophys. Res. Lett., 30(5), 1239, doi:10.1029/2002GL016303.

Albrecht, B. A. (1989), Aerosols, cloud microphysics, and fractional cloudiness, Science, 245(4923), 1227-1230, doi:10.1126/science.245.4923. 1227.

Allan, J. D., et al. (2006), Size and composition measurements of background aerosol and new particle growth in a Finnish forest during QUEST 2 using an Aerodyne aerosol mass spectrometer, Atmos. Chem. Phys., 6, 315-327.

Andreae, M. O., W. Elbert, Y. Cai, T. W. Andreae, and J. Gras (1999), Nonsea-salt sulfate, methanesulfonate, and nitrate aerosol concentrations and size distributions at Cape Grim, Tasmania, J. Geophys. Res., 104(D17), 21,695-21,706, doi:10.1029/1999JD900283. 
Andreae, M. O., D. Rosenfeld, P. Artaxo, A. A. Costa, G. P. Frank, K. M. Longo, and M. A. F. Silva-Dias (2004), Smoking rain clouds over the Amazon, Science, 303(5662), 1337-1342, doi:10.1126/science.1092779.

Andres, R. J., and A. D. Kasgnoc (1998), A time-averaged inventory of subaerial volcanic sulfur emissions, J. Geophys. Res., 103(D19), 25251-25,261, doi:10.1029/98JD02091.

Arellano, A. F., P. S. Kasibhatla, L. Giglio, G. R. van der Werf, and J. T. Randerson (2004), Top-down estimates of global CO sources using MOPITT measurements, Geophys. Res. Lett., 31, L01104, doi:10.1029/ 2003GL018609.

Arimoto, R., R. A. Duce, D. L. Savoie, J. M. Prospero, R. Talbot, J. D. Cullen, U. Tomza, N. F. Lewis, and B. J. Jay (1996), Relationships among aerosol constituents from Asia and the North Pacific during PEM-West A, J. Geophys. Res., 101(D1), 2011-2023, doi:10.1029/95JD01071.

Bodhaine, B. A. (1995), Aerosol absorption measurements at Barrow, Mauna Loa and the South Pole, J. Geophys. Res., 100(D5), 8967-8975, doi:10.1029/95JD00513.

Bond, T. C., D. G. Streets, K. F. Yarber, S. M. Nelson, J. H. Woo, and Z. Klimont (2004), A technology-based global inventory of black and organic carbon emissions from combustion, J. Geophys. Res., 109, D14203, doi:10.1029/2003JD003697.

Boville, B. A., P. J. Rasch, J. J. Hack, and J. R. McCaa (2006), Representation of clouds and precipitation processes in the Community Atmosphere Mode version 3 (CAM3), J. Clim., 19(11), 2184-2198, doi:10.1175/JCLI3749.1.

Cakmur, R. V., R. L. Miller, J. Perlwitz, I. V. Geogdzhayev, P. Ginoux, D. Koch, K. E. Kohfeld, I. Tegen, and C. S. Zender (2006), Constraining the magnitude of the global dust cycle by minimizing the difference between a model and observations, J. Geophys. Res., 111, D06207, doi:10.1029/2005JD005791.

Chuang, C. C., J. E. Penner, J. M. Prospero, K. E. Grant, G. H. Rau, and K. Kawamoto (2002), Cloud susceptibility and the first aerosol indirect forcing: Sensitivity to black carbon and aerosol concentrations, J. Geophys Res., 107(D21), 4564, doi:10.1029/2000JD000215.

Chung, S. H., and J. H. Seinfeld (2002), Global distribution and climate forcing of carbonaceous aerosols, J. Geophys. Res., 107(D19), 4407, doi:10.1029/2001JD001397.

Clarke, A. D., and V. N. Kapustin (2002), A Pacific aerosol survey. Part I: A decade of data on particle production, transport, evolution, and mixing in the troposphere, J. Atmos. Sci., 59(3), 363-382, doi:10.1175/15200469(2002)059<0363:APASPI >2.0.CO;2.

Collins, W. D., P. J. Rasch, B. E. Eaton, B. V. Khattatov, J. F. Lamarque, and C. S. Zender (2001), Simulating aerosols using a chemical transport model with assimilation of satellite aerosol retrievals: Methodology for INDOEX, J. Geophys. Res., 106(D7), 7313-7336, doi:10.1029/ 2000JD900507.

Collins, W. D., P. J. Rasch, B. A. Boville, J. J. Hack, J. R. McCaa, D. L. Williamson, B. P. Briegleb, C. M. Bitz, S. J. Lin, and M. H. Zhang (2006a), The formulation and atmospheric simulation of the Community Atmosphere Model version 3 (CAM3), J. Clim., 19(11), 2144-2161, doi:10.1175/JCLI3760.1.

Collins, W. D., et al. (2006b), The Community Climate System Model version 3 (CCSM3), J. Clim., 19(11), 2122-2143, doi:10.1175/JCLI3761.1.

Cooke, W. F., S. G. Jennings, and T. G. Spain (1997), Black carbon measurements at Mace Head, 1989-1996, J. Geophys. Res., 102(D21) 25,339-25,346, doi:10.1029/97JD01430.

Dal Maso, M., M. Kulmala, I. Riipinen, R. Wagner, T. Hussein, P. P. Aalto, and K. E. J. Lehtinen (2005), Formation and growth of fresh atmospheric aerosols: Eight years of aerosol size distribution data from SMEAR II, Hyytiala, Finland, Boreal Environ. Res., 10(5), 323-336.

Easter, R. C., S. J. Ghan, Y. Zhang, R. D. Saylor, E. G. Chapman, N. S. Laulainen, H. Abdul-Razzak, L. R. Leung, X. D. Bian, and R. A. Zaveri (2004), MIRAGE: Model description and evaluation of aerosols and trace gases, J. Geophys. Res., 109, D20210, doi:10.1029/2004JD004571.

Feichter, J., E. Roeckner, U. Lohmann, and B. Liepert (2004), Nonlinear aspects of the climate response to greenhouse gas and aerosol forcing, J. Clim., 17(12), 2384-2398, doi:10.1175/1520-0442(2004)017< 2384:NAOTCR $>2.0 . \mathrm{CO} ; 2$.

Feng, Y., and J. E. Penner (2007), Global modeling of nitrate and ammonium: Interaction of aerosols and tropospheric chemistry, J. Geophys. Res., 112, D01304, doi:10.1029/2005JD006404.

Fridlind, A. M., et al. (2004), Evidence for the predominance of midtropospheric aerosols as subtropical anvil cloud nuclei, Science, 304(5671), 718-722, doi:10.1126/science.1094947.

Ginoux, P., M. Chin, I. Tegen, J. M. Prospero, B. Holben, O. Dubovik, and S. J. Lin (2001), Sources and distributions of dust aerosols simulated with the GOCART model, J. Geophys. Res., 106(D17), 20,255-20,273, doi:10.1029/2000JD000053.

Ginoux, P., J. M. Prospero, O. Torres, and M. Chin (2004), Long-term simulation of global dust distribution with the GOCART model: Correlation with North Atlantic Oscillation, Environ. Model. Software, 19(2), 113-128, doi:10.1016/S1364-8152(03)00114-2.

Giorgi, F., and W. L. Chameides (1986), Rainout lifetimes of highly soluble aerosols and gases as inferred from simulations with a general-circulation model, J. Geophys. Res., 91(D13), 14,367-14,376, doi:10.1029/ JD091iD13p14367.

Gong, S. L., L. A. Barrie, and J. P. Blanchet (1997), Modeling sea-salt aerosols in the atmosphere: 1. Model development, J. Geophys. Res., 102(D3), 3805-3818, doi:10.1029/96JD02953.

Guenther, A., et al. (1995), A global model of natural volatile organic compound emissions, J. Geophys. Res., 100(D5), 8873-8892, doi:10.1029/94JD02950.

Guo, H., J. E. Penner, M. Herzog, and H. Pawlowska (2007), Examination of the aerosol indirect effect under contrasting environments during the ACE-2 experiment, Atmos. Chem. Phys., 7, 535-548.

Hansen, J., and L. Nazarenko (2004), Soot climate forcing via snow and ice albedos, Proc. Natl. Acad. Sci. U. S. A., 101(2), 423-428, doi:10.1073/ pnas. 2237157100

Harrington, D. Y., and S. M. Kreidenweis (1998), Simulations of sulfate aerosol dynamics: I. Model description, Atmos. Environ., 32(10), 1691-1700, doi:10.1016/S1352-2310(97)00452-4.

$\mathrm{He}$, Y., and C. Ding (2005), Coupling multi-component models with MPH on distributed memory computer architectures, Int. J. High Perform. Comput. Appl., 19(3), 329-340, doi:10.1177/1094342005056118.

Heintzenberg, J., D. C. Covert, and R. Van Dingenen (2000), Size distribution and chemical composition of marine aerosols: A compilation and review, Tellus, Ser. B, 52(4), 1104-1122, doi:10.1034/j.1600-0889. 2000.00136.x

Hendricks, J., B. Karcher, A. Dopelheuer, J. Feichter, U. Lohmann, and D. Baumgardner (2004), Simulating the global atmospheric black carbon cycle: A revisit to the contribution of aircraft emissions, Atmos. Chem. Phys., 4, 2521-2541.

Henning, S., S. Bojinski, K. Diehl, S. Ghan, S. Nyeki, E. Weingartner S. Wurzler, and U. Baltensperger (2004), Aerosol partitioning in natural mixed-phase clouds, Geophys. Res. Lett., 31, L06101, doi:10.1029/ 2003GL019025.

Herzog, M., D. K. Weisenstein, and J. E. Penner (2004), A dynamic aerosol module for global chemical transport models: Model description, J. Geophys. Res., 109, D18202, doi:10.1029/2003JD004405.

Hewitt, C. N. (2001), The atmospheric chemistry of sulphur and nitrogen in power station plumes, Atmos. Environ., 35(7), 1155-1170, doi:10.1016/ S1352-2310(00)00463-5

Hopper, J. F., D. E. J. Worthy, L. A. Barrie, and N. B. A. Trivett (1994), Atmospheric observations of aerosol black carbon, carbon-dioxide, and methane in the high Arctic, Atmos. Environ., 28(18), 3047-3054, doi:10.1016/1352-2310(94)90349-2.

Hurrell, J. W., J. J. Hack, A. S. Phillips, J. Caron, and J. Yin (2006), The dynamical simulation of the Community Atmosphere Model version 3 (CAM3), J. Clim., 19(11), 2162-2183, doi:10.1175/JCLI3762.1.

Ito, A., and J. E. Penner (2005), Historical emissions of carbonaceous aerosols from biomass and fossil fuel burning for the period $1870-2000$ Global Biogeochem. Cycles, 19, GB2028, doi:10.1029/2004GB002374.

Kerminen, V. M., and M. Kulmala (2002), Analytical formulae connecting the "real" and the "apparent" nucleation rate and the nuclei number concentration for atmospheric nucleation events, J. Aerosol Sci., 33(4), 609-622, doi:10.1016/S0021-8502(01)00194-X.

Kerminen, V. M., A. Virkkula, R. Hillamo, A. S. Wexler, and M. Kulmala (2000), Secondary organics and atmospheric cloud condensation nuclei production, J. Geophys. Res., 105(D7), 9255-9264, doi:10.1029/ 1999JD901203.

Kerminen, V. M., T. Anttila, K. E. J. Lehtinen, and M. Kulmala (2004), Parameterization for atmospheric new-particle formation: Application to a system involving sulfuric acid and condensable water-soluble organic vapors, Aerosol Sci. Technol., 38(10), 1001-1008, doi:10.1080/ 027868290519085

Kettle, A. J., and M. O. Andreae (2000), Flux of dimethylsulfide from the oceans: A comparison of updated data seas and flux models, J. Geophys. Res., 105(D22), 26,793-26,808, doi:10.1029/2000JD900252.

Kettle, A. J., et al. (1999), A global database of sea surface dimethylsulfide (DMS) measurements and a procedure to predict sea surface DMS as a function of latitude, longitude, and month, Global Biogeochem. Cycles, 13(2), 399-444, doi:10.1029/1999GB900004.

Koponen, I. K., A. Virkkula, R. Hillamo, V. M. Kerminen, and M. Kulmala (2003), Number size distributions and concentrations of the continental summer aerosols in Queen Maud Land, Antarctica, J. Geophys. Res., 108(D18), 4587, doi:10.1029/2003JD003614.

Korhonen, P., M. Kulmala, A. Laaksonen, Y. Viisanen, R. McGraw, and J. H. Seinfeld (1999), Ternary nucleation of $\mathrm{H}_{2} \mathrm{SO}_{4}, \mathrm{NH}_{3}$, and $\mathrm{H}_{2} \mathrm{O}$ in the atmosphere, J. Geophys. Res., 104(D21), 26,349-26,353, doi:10.1029/ 1999JD900784. 
Kulmala, M., H. Vehkamäki, T. Petaja, M. Dal Maso, A. Lauri, V. M. Kerminen, W. Birmili, and P. H. McMurry (2004), Formation and growth rates of ultrafine atmospheric particles: A review of observations, J. Aerosol Sci., 35(2), 143-176, doi:10.1016/j.jaerosci.2003.10.003.

Kulmala, M., K. E. J. Lehtinen, and A. Laaksonen (2006), Cluster activation theory as an explanation of the linear dependence between formation rate of $3 \mathrm{~nm}$ particles and sulphuric acid concentration, Atmos. Chem. Phys., 6, 787-793.

Laaksonen, A., A. Hamed, J. Joutsensaari, L. Hiltunen, F. Cavalli, W. Junkermann, A. Asmi, S. Fuzzi, and M. C. Facchini (2005), Cloud condensation nucleus production from nucleation events at a highly polluted region, Geophys. Res. Lett., 32, L06812, doi:10.1029/2004GL022092.

Lauer, A., J. Hendricks, I. Ackermann, B. Schell, H. Hass, and S. Metzger (2005), Simulating aerosol microphysics with the ECHAM/MADE GCM - Part I: Model description and comparison with observations, Atmos. Chem. Phys., 5, 3251-3276.

Lin, S. J., and R. B. Rood (1996), Multidimensional flux-form semiLagrangian transport schemes, Mon. Weather Rev., 124(9), 2046-2070, doi:10.1175/1520-0493(1996)124<2046:MFFSLT>2.0.CO;2.

Liss, P. S., and L. Merlivat (1986), Air-sea gas exchange rates: Introduction and synthesis, edited by P. B. Menard, in The Role of Air-Sea Gas Exchange in Geochemical Cycling, pp. 113-127, Springer, New York.

Liu, H., D. J. Jacob, I. Bey, and R. M. Yantosca (2001), Constraints from ${ }^{210} \mathrm{~Pb}$ and ${ }^{7} \mathrm{Be}$ on wet deposition and transport in a global threedimensional chemical tracer model driven by assimilated meteorological fields, J. Geophys. Res., 106(D11), 12,109-12,128, doi:10.1029/ 2000JD900839.

Liu, X. H., and J. E. Penner (2002), Effect of Mount Pinatubo $\mathrm{H}_{2} \mathrm{SO}_{4} / \mathrm{H}_{2} \mathrm{O}$ aerosol on ice nucleation in the upper troposphere using a global chemistry and transport model, J. Geophys. Res., 107(D12), 4141, doi:10.1029/2001JD000455.

Liu, X. H., J. E. Penner, and M. Herzog (2005), Global modeling of aerosol dynamics: Model description, evaluation, and interactions between sulfate and nonsulfate aerosols, J. Geophys. Res., 110, D18206, doi:10.1029/ 2004JD005674.

Liu, X., J. Penner, S. Ghan, and M. Wang (2007), Inclusion of ice microphysics in the NCAR Community Atmospheric Model Verision 3 (CAM3), J. Clim., 20, 4526-4547.

Lohmann, U., P. Stier, C. Hoose, S. Ferrachat, S. Kloster, E. Roeckner, and J. Zhang (2007), Cloud microphysics and aerosol indirect effects in the global climate model ECHAM5-HAM, Atmos. Chem. Phys., 7, 3425-3446.

Lucas, D. D., and H. Akimoto (2006), Evaluating aerosol nucleation parameterizations in a global atmospheric model, Geophys. Res. Lett., 33, L10808, doi:10.1029/2006GL025672.

Malm, W. C., M. L. Pitchford, M. Scuggs, J. F. Sisler, R. Ames, S. Copeland, K. A. Gebhart, and D. E. Day (2000), Spatial and seasonal patterns and temporal variability of haze and its constituents in the United States, Rep III, Coop. Inst. for Res., Colo. State Univ., Fort Collins.

Mari, C., D. J. Jacob, and P. Bechtold (2000), Transport and scavenging of soluble gases in a deep convective cloud, J. Geophys. Res., 105(D17), 22255-22,267, doi:10.1029/2000JD900211.

Martensson, E. M., E. D. Nilsson, G. de Leeuw, L. H. Cohen, and H. C. Hansson (2003), Laboratory simulations and parameterization of the primary marine aerosol production, J. Geophys. Res., 108(D9), 4297, doi:10.1029/2002JD002263.

McMurry, P. H., and S. K. Friedlander (1979), New particle formation in the presence of an aerosol, Atmos. Environ., 13(12), 1635-1651, doi:10.1016/0004-6981(79)90322-6.

Minikin, A., A. Petzold, J. Strom, R. Krejci, M. Seifert, P. van Velthoven, H. Schlager, and U. Schumann (2003), Aircraft observations of the upper tropospheric fine particle aerosol in the Northern and Southern hemispheres at midlatitudes, Geophys. Res. Lett., 30(10), 1503, doi:10.1029/ 2002GL016458.

Novakov, T., V. Ramanathan, J. E. Hansen, T. W. Kirchstetter, M. Sato, J. E. Sinton, and J. A. Sathaye (2003), Large historical changes of fossil-fuel black carbon aerosols, Geophys. Res. Lett., 30(6), 1324, doi:10.1029/ 2002GL016345

Nyeki, S., U. Baltensperger, I. Colbeck, D. T. Jost, E. Weingartner, and H. W. Gaggeler (1998), The Jungfraujoch high-Alpine research station (3454 m) as a background clean continental site for the measurement of aerosol parameters, J. Geophys. Res., 103(D6), 6097-6107, doi:10.1029/ 97JD03123.

O'Dowd, C., et al. (1999), On the photochemical production of new particles in the coastal boundary layer, Geophys. Res. Lett., 26(12), 1707-1710, doi:10.1029/1999GL900335.

O’Dowd, C. D., J. L. Jimenez, R. Bahreini, R. C. Flagan, J. H. Seinfeld, K. Hameri, L. Pirjola, M. Kulmala, S. G. Jennings, and T. Hoffmann (2002), Marine aerosol formation from biogenic iodine emissions, Nature, 417(6889), 632-636, doi:10.1038/nature00775.
Penner, J. E., D. J. Bergmann, J. J. Walton, D. Kinnison, M. J. Prather, D. Rotman, C. Price, K. E. Pickering, and S. L. Baughcum (1998), An evaluation of upper troposphere $\mathrm{NO}_{\mathrm{x}}$ with two models, J. Geophys. Res., 103(D17), 22097-22113, doi:10.1029/98JD01565.

Penner, J. E., et al. (2001), Aerosols, their direct and indirect effects, edited by J. T. Houghton et al., in Climate Change 2001: The Scientific Basis, Contribution of working group I to the Third Assessment Report of the Intergovernmental Panel on Climate Change, pp. 289-348, Cambridge Univ. Press, New York

Penner, J. E., et al. (2002), A comparison of model- and satellite-derived aerosol optical depth and reflectivity, J. Atmos. Sci., 59(3), 441-460, doi:10.1175/1520-0469(2002)059<0441:ACOMAS >2.0.CO;2.

Penner, J. E., S. Y. Zhang, and C. C. Chuang (2003), Soot and smoke aerosol may not warm climate, J. Geophys. Res., 108(D21), 4657, doi:10.1029/2003JD003409.

Pierce, J. R., and P. J. Adams (2006), Global evaluation of CCN formation by direct emission of sea salt and growth of ultrafine sea salt, J. Geophys. Res., 111, D06203, doi:10.1029/2005JD006186.

Pierce, J. R., K. Chen, and P. J. Adams (2007), Contribution of primary carbonaceous aerosol to cloud condensation nuclei: Processes and uncertainties evaluated with a global aerosol microphysics model, Atmos. Chem. Phys., 7, 5447-5466.

Prospero, J. M., M. Uematsu, and D. L. Savoie (1989), Mineral aerosol transport to the Pacific Ocean, edited by J. P. Ridley, R. Chester, and R. A Duce, in Chemical Oceanography, pp. 188-218, Elsevier, New York.

Putaud, J., et al. (2003), A European Aerosol Phenomenology, Report, 55 pp., Eur. Comm. Jt. Res. Cent., Ispra, Italy.

Quinn, P. K., and D. J. Coffman (1999), Comment on "Contribution of different aerosol species to the global aerosol extinction optical thickness: Estimates from model results" by Tegen et al., J. Geophys. Res., 104(D4), 4241 -4248, doi:10.1029/1998JD200066.

Raes, F., R. VanDingenen, E. Cuevas, P. F. J. VanVelthoven, and J. M. Prospero (1997), Observations of aerosols in the free troposphere and marine boundary layer of the subtropical northeast Atlantic: Discussion of processes determining their size distribution, J. Geophys. Res., 102(D17), 21,315-21,328, doi:10.1029/97JD01122.

Raes, F., R. Van Dingenen, E. Vignati, J. Wilson, J. P. Putaud, J. H. Seinfeld, and P. Adams (2000), Formation and cycling of aerosols in the global troposphere, Atmos. Environ., 34(25), 4215-4240, doi:10.1016/S13522310(00)00239-9.

Ramanathan, V., C. Chung, D. Kim, T. Bettge, L. Buja, J. T. Kiehl, W. M. Washington, Q. Fu, D. R. Sikka, and M. Wild (2005), Atmospheric brown clouds: Impacts on south Asian climate and hydrological cycle, Proc. Natl. Acad. Sci. U. S. A., 102(15), 5326-5333, doi:10.1073/ pnas.0500656102

Rasch, P. J., W. D. Collins, and B. E. Eaton (2001), Understanding the Indian Ocean Experiment (INDOEX) aerosol distributions with an aerosol assimilation, J. Geophys. Res., 106(D7), 7337-7355, doi:10.1029/ 2000JD900508.

Riipinen, I., et al. (2007), Connections between atmospheric sulphuric acid and new particle formation during QUEST III-IV campaigns in Heidelberg and Hyyti, Atmos. Chem. Phys., 7, 1899-1914.

Rotman, D. A., et al. (2004), IMPACT, the LLNL 3-D global atmospheric chemical transport model for the combined troposphere and stratosphere: Model description and analysis of ozone and other trace gases, J. Geophys. Res., 109, D04303, doi:10.1029/2002JD003155.

Rotstayn, L. D., et al. (2007), Have Australian rainfall and cloudiness increased due to the remote effects of Asian anthropogenic aerosols?, J. Geophys. Res., 112, D09202, doi:10.1029/2006JD007712.

Sato, M., J. Hansen, D. Koch, A. Lacis, R. Ruedy, O. Dubovik, B. Holben, M. Chin, and T. Novakov (2003), Global atmospheric black carbon inferred from AERONET, Proc. Natl. Acad. Sci. U. S. A., 100, 6319-6324, doi:10.1073/pnas.0731897100.

Savoie, D. L., J. M. Prospero, and E. S. Saltzman (1989), Nitrate, nonseasalt sulfate and methanesulfonate over the Pacific Ocean, edited by J. P.Ridley, R. Chester, and R. A. Duce, in Chemical Oceanography, pp. 219-250, Elsevier, New York

Savoie, D. I., J. M. Prospero, R. J. Larsen, F. Huang, M. A. Izaguirre, T. Huang, T. H. Snowdon, L. Custals, and C. G. Sanderson (1993), Nitrogen and sulfur species in Antarctic aerosols at Mawson, Palmer Station, and Marsh (King George Island), J. Atmos. Chem., 17(2), 95-122, doi:10.1007/BF00702821.

Savoie, D. L., R. Arimoto, W. C. Keene, J. M. Prospero, R. A. Duce, and J. N. Galloway (2002), Marine biogenic and anthropogenic contributions to non-sea-salt sulfate in the marine boundary layer over the North Atlantic Ocean, J. Geophys. Res., 107(D18), 4356, doi:10.1029/2001JD000970.

Schwarz, J. P., et al. (2006), Single-particle measurements of midlatitude black carbon and light-scattering aerosols from the boundary layer to the lower stratosphere, J. Geophys. Res., 111(D16), D16207, doi:10.1029/ 2006JD007076. 
Sherwood, S. (2002), A microphysical connection among biomass burning, cumulus clouds, and stratospheric moisture, Science, 295(5558), 1272-1275, doi: $10.1126 /$ science. 1065080 .

Sihto, S. L., et al. (2006), Atmospheric sulphuric acid and aerosol formation: Implications from atmospheric measurements for nucleation and early growth mechanisms, Atmos. Chem. Phys., 6, 4079-4091.

Smith, J. N., M. J. Dunn, T. M. VanReken, K. Iida, M. R. Stolzenburg, P. H. McMurry, and L. G. Huey (2008), Chemical composition of atmospheric nanoparticles formed from nucleation in Tecamac, Mexico: Evidence for an important role for organic species in nanoparticle growth, Geophys. Res. Lett., 35, L04808, doi:10.1029/2007GL032523.

Smith, S., R. Andres, L. Conception, and J. Lurz (2004), Historical sulfur dioxide emissions 1850-2000: Methods and results, JGCRI Res. Rep. PNNL 14537, 16 pp., Pac. Northwest Natl. Lab., Richland, Wash.

Smith, S. J., H. Pitcher, and T. M. L. Wigley (2001), Global and regional anthropogenic sulfur dioxide emissions, Global Planet. Change, 29(1-2), 99-119, doi:10.1016/S0921-8181(00)00057-6.

Spracklen, D. V., K. J. Pringle, K. S. Carslaw, M. P. Chipperfield, and G. W. Mann (2005a), A global off-line model of size-resolved aerosol microphysics: II. Identification of key uncertainties, Atmos. Chem. Phys., 5, $3233-3250$

Spracklen, D. V., K. J. Pringle, K. S. Carslaw, M. P. Chipperfield, and G. W. Mann (2005b), A global off-line model of size-resolved aerosol microphysics: I. Model development and prediction of aerosol properties, Atmos. Chem. Phys., 5, 2227-2252.

Spracklen, D. V., K. S. Carslaw, M. Kulmala, V. M. Kerminen, G. W. Mann, and S. L. Sihto (2006), The contribution of boundary layer nucleation events to total particle concentrations on regional and global scales, Atmos. Chem. Phys., 6, 5631-5648.

Spracklen, D. V., K. J. Pringle, K. S. Carslaw, G. W. Mann, P. Manktelow, and J. Heintzenberg (2007), Evaluation of a global aerosol microphysics model against size-resolved particle statistics in the marine atmosphere, Atmos. Chem. Phys., 7, 2073-2090.

Stier, P., et al. (2005), The aerosol-climate model ECHAM5-HAM, Atmos. Chem. Phys., 5, 1125-1156.

Stier, P., J. Feichter, S. Kloster, E. Vignati, and J. Wilson (2006), Emissioninduced nonlinearities in the global aerosol system: Results from the ECHAM5-HAM aerosol-climate model, J. Clim., 19(16), 3845-3862, doi:10.1175/JCLI3772.1.

Stolzenburg, M. R., P. H. McMurry, H. Sakurai, J. N. Smith, R. L. Mauldin, F. L. Eisele, and C. F. Clement (2005), Growth rates of freshly nucleated atmospheric particles in Atlanta, J. Geophys. Res., 110, D22S05, doi:10.1029/2005JD005935.

Taylor, K. E., and J. E. Penner (1994), Response of the climate system to atmospheric aerosols and greenhouse gases, Nature, 369(6483), 734-737, doi:10.1038/369734a0.

Textor, C., et al. (2006), Analysis and quantification of the diversities of aerosol life cycles within AeroCom, Atmos. Chem. Phys., 6, 1777-1813.

Twomey, S. (1977), Influence of pollution on shortwave albedo of clouds, J. Atmos. Sci., 34(7), 1149-1152, doi:10.1175/1520-0469(1977)034< 1149:TIOPOT $>2.0 . \mathrm{CO} ; 2$.

Vehkamäki, H., M. Kulmala, I. Napari, K. E. J. Lehtinen, C. Timmreck, M. Noppel, and A. Laaksonen (2002), An improved parameterization for sulfuric acid-water nucleation rates for tropospheric and stratospheric conditions, J. Geophys. Res., 107(D22), 4622, doi:10.1029/2002JD002184.

Vehkamäki, H., et al. (2004), Atmospheric particle formation events at Varrio measurement station in Finnish Lapland 1998-2002, Atmos. Chem. Phys., 4, 2015-2023.
Walton, J. J., M. C. MacCracken, and S. J. Ghan (1988), A global-scale Lagrangian trace species model of transport, transformation, and removal processes, J. Geophys. Res., 93(D7), 8339-8354, doi:10.1029/ JD093iD07p08339.

Wang, M., and J. Penner (2009), Aerosol indirect forcing in a global model with particle nucleation, Atmos. Chem. Phys., 9, 239-260.

Wang, Y. H., D. J. Jacob, and J. A. Logan (1998), Global simulation of tropospheric $\mathrm{O}_{3}-\mathrm{NO}_{\mathrm{x}}$-hydrocarbon chemistry: 1. Model formulation, J. Geophys. Res., 103(D9), 10,713-10,725, doi:10.1029/98JD00158.

Wanninkhof, R. (1992), Relationship between wind-speed and gas-exchange over the ocean, J. Geophys. Res., 97(C5), 7373-7382, doi:10.1029/ 92JC00188.

Weisenstein, D. K., J. E. Penner, M. Herzog, and X. Liu (2007), Global 2-D intercomparison of sectional and modal aerosol modules, Atmos. Chem. Phys., 7, 2339-2355.

Wesely, M. L., D. R. Cook, R. L. Hart, and R. E. Speer (1985), Measurements and parameterization of particulate sulfur dry deposition over grass, J. Geophys. Res., 90, 2131-2143, doi:10.1029/JD090iD01p02131.

Whitby, K. T. (1978), Physical characteristics of sulfur aerosols, Atmos. Environ., 12(1-3), 135-159, doi:10.1016/0004-6981(78)90196-8.

Williamson, D. L. (2002), Time-split versus process-split coupling of parameterizations and dynamical core, Mon. Weather Rev., 130(8), 2024-2041, doi:10.1175/1520-0493(2002)130<2024:TSVPSC > 2.0.CO;2.

Wolff, E. W., and H. Cachier (1998), Concentrations and seasonal cycle of black carbon in aerosol at a coastal Antarctic station, J. Geophys. Res., 103(D9), 11,033-11,041, doi:10.1029/97JD01363.

Yoon, Y. J., et al. (2007), Seasonal characteristics of the physicochemical properties of North Atlantic marine atmospheric aerosols, J. Geophys. Res., 112, D04206, doi:10.1029/2005JD007044.

Yu, F. Q., and R. P. Turco (2000), Ultrafine aerosol formation via ionmediated nucleation, Geophys. Res. Lett., 27(6), 883-886, doi:10.1029/1999GL011151.

Yu, F., and R. P. Turco (2008), Case studies of particle formation events observed in boreal forests: Implications for nucleation mechanisms, Atmos. Chem. Phys., 8, 6085-6102.

Zhang, K. M., and A. S. Wexler (2002), A hypothesis for growth of fresh atmospheric nuclei, J. Geophys. Res., 107(D21), 4577, doi:10.1029/ 2002JD002180.

Zhang, R. Y., I. Suh, J. Zhao, D. Zhang, E. C. Fortner, X. X. Tie, L. T. Molina, and M. J. Molina (2004), Atmospheric new particle formation enhanced by organic acids, Science, 304(5676), 1487-1490, doi:10.1126/science.1095139.

Zhang, R. Y., G. H. Li, J. W. Fan, D. L. Wu, and M. J. Molina (2007), Intensification of Pacific storm track linked to Asian pollution, Proc. Natl. Acad. Sci. U. S. A., 104(13), 5295-5299, doi:10.1073/pnas. 0700618104

Zhang, S., J. E. Penner, and O. Torres (2005), Inverse modeling of biomass burning emissions using Total Ozone Mapping Spectrometer aerosol index for 1997, J. Geophys. Res., 110, D21306, doi:10.1029/ 2004JD005738

X. Liu, Pacific Northwest National Laboratory, P.O. Box 999, MSIN K930, Richland, WA 99352-0000, USA.

J. E. Penner and M. Wang, Department of Atmospheric, Oceanic and Space Sciences, University of Michigan, 2455 Hayward Street, Ann Arbor, MI 48109-2143, USA. (minghuai@umich.edu) 